\title{
EVOLUÇÃO DO POTENCIAL PRODUTIVO DAS PRINCIPAIS VARIEDADES DE CANA-DE-AÇÚCAR CULTIVADAS NO ESTADO DE SÃO PAULO NOS ÚLTIMOS CINQÜENTA ANOS
}

\author{
HERMANN PAULO HOFFMANN \\ Engenheiro Agrônomo
}

Orientador: Prof. Dr. ANTONIO LUIZ FANCELLI

Tese apresentada à Escola Superior de Agricultura "Luiz de Queiroz", da Universidade de São Paulo, para obtenção do título de Doutor em Agronomia, Área de Concentração: Fitotecnia.

\author{
PIRACICABA \\ Estado de São Paulo - Brasil \\ Janeiro - 1997
}


Dados Internacionais de Catalogação na Publicação (CIP) DIVISÃo DE BIBLIOTECA E DOCUMENTAÇÃO - Campus "Luiz de Queiroz"/USP

\section{Hoffmann, Hermann Paulo}

Evolução do potencial produtivo das principais variedades de cana-de-açúcar cultivadas no Estado de São Paulo nos últimos cinqüenta anos / Hermann Paulo Hoffmann. - - Piracicaba, 1997.

97 p. : il.

Tese (doutorado) -- Escola Superior de Agricultura Luiz de Queiroz, 1997.

Bibliografia.

1. Cana-de-açúcar 2. Melhoramento 3. Produtividade 4. São Paulo (estado) 5. Variedade resistente I. Titulo 


\section{EVOLUÇĀO DO POTENCIAL PRODUTIVO DAS PRINCIPAIS VARIEDADES DE CANA-DE-AÇÚCAR CULTIVADAS NO ESTADO DE SÃO PAULO NOS ÚLTIMOS CINQÜENTA ANOS}

\section{HERMANN PAULO HOFFMANN}

Aprovado em: 09/04/1997

Comissão julgadora:

Prof. Dr. ANTONIO LUIZ FANCELLI ESALQ/USP

Prof. Dr. HASIME TOKESHI ESALQ/USP

Prof. Dr. SIZUO MATSUOKA CCA/UFSCar

Prof. Dr. AILTO ANTONIO CASAGRANDE FCAVIUNESP

Prof. Dr. MARCOS GUIMARÃES DE ANDRADE LANDELL IAC

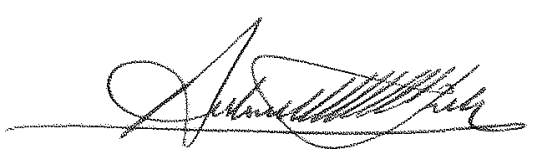

Prof. Dr. ANTONIO LUIZ FANCELLI

ORIENTADOR 
Aos meus pais Fernando e Mary, À minha esposa Celeste e Aos filhos Beatriz, Hermann e Isabel 


\section{AGRADECIMENTOS}

- Ao Prof. Dr. Antonio Luiz Fancelli, pela acolhida no ingresso ao Departamento de Agricultura, orientação, e transmissão de conhecimentos técnicos de grande valor.

- Ao Prof. Dr. Sizuo Matsuoka, que, com a sua capacidade de trabalho aliada a seus conhecimentos técnicos, influenciou na escolha do tema desta pesquisa além de ter prestado grande colaboração em todas as etapas.

- Ao Prof. Dr. Hasime Tokeshi, orientador no mestrado, que assegurou um melhor entendimento das questões relativas a resistência de plantas a doenças.

- Ao Prof. Dr. Antonio Carlos Arabicano Gheller pelo seu apoio no início do curso e facilidades proporcionadas no Centro de Ciências Agrárias.

- Ao Eng ${ }^{\circ} \mathrm{Agr}^{\circ}, \mathrm{M} . S c$. ., Antônio Augusto Franco Garcia pela realização das análises estatísticas.

- $\grave{A} \operatorname{Prof}^{a} \operatorname{Dr}^{a}$ Marineide Mendonça Aguillera pela versão do resumo para o inglês.

- Ao Engo Agro, M.Sc., Renê de Assis Sordi, da Copersucar, pela cessão de parte das mudas utilizadas nos ensaios.

- Ao Prof. Hideto Arizono pelas idéias e sugestões.

- À Universidade Federal de São Carlos, pela liberação para a realização do curso.

- Ao CNPq - Conselho Nacional de Desenvolvimento Científico e Tecnológico e à CAPES - Coordenadoria de Aprimoramento de Pessoal de Nivel Superior, pela concessão de bolsa de estudo em períodos distintos do curso.

- À Galo Bravo Açúcar e Álcool S.A. e à Usina Santa Bárbara S.A. por todo o apoio técnico, material e operacional na condução dos ensaios de campo. 
- Aos Eng ${ }^{\text {os }}$ Agr $^{\circ s}$ Marco Antonio Faria Fernandes, Eliel Gonçalves Papa e ao prático Antonio Carlos Poletine Ramos, da Galo Bravo S.A. Açúcar e Álcool pelo empenho e participação na condução dos ensaios de campo.

- Aos Eng ${ }^{\text {os }}$ Agr $^{\text {os }}$ João Américo Beltrame, Luiz Alberto Salviatti, Marco Aurélio Sancigolo, ex, e ao Técnico em Agropecuária Carlos Roberto de Jesus, da Usina Santa Bárbara S.A. Açúcar e Álcool pelo empenho e participação na condução do trabalhos.

- Aos Técnicos em Agropecuária Carlos José Loureiro, César Evair Ciola, Cláudio José Mendes, José Ciofi e Marilson da Silva Wermilinger pelos trabalhos de campo.

- À José Adalberto da Cruz da UFSCar/CCA, pela elaboração das figuras.

- À Luciana T. R. Vicente da UFSCar/CCA, pela orientação na elaboração e posterior correção das Referências Bibliográficas.

- À Luís Carlos de Sá da UFSCar/CCA, pela presteza e atenção nos serviços de digitação. 


\section{SUMÁRIO}

LISTA DE FIGURAS

Página

LISTA DE TABELAS

viii

RESUMO

$x$

SUMMARY

xii

1. INTRODUÇÃO

XV

2. REVISÃO DE LITERATURA 04

2.1. Seqüência histórica das variedades cultivadas no Brasil 04

2.2. Os programas de melhoramento $\quad 12$

2.2.1. Os programas de melhoramento no Brasil 13

2.2.1.1. Variedades "SP" 15

2.2.1.2. Variedades "IAC" 16

2.2.1.3. Variedades "RB" 17

2.2.1.4. Variedades "PO" 19

2.3. A evolução dos rendimentos 19

3. MATERIAL E MÉTODOS 23

3.1. Ensaios de competição varietal 23

3.1.1. Variedades 23

3.1.2. Locais 24

3.1.2.1. Fazenda Areia Branca (FAB), Santa Bárbara D'Oeste 25

3.1.2.2. Centro de Ciências Agrárias (CCA), Araras 26

3.1.2.3. Fazenda São João (FSJ), Jardinópolis 26

3.1.3. Delineamento estatístico 27

3.1.4. Tamanho da parcela $\quad 27$

3.1.5. Dados pluviométricos 28

3.2. Curva de maturação 28

3.3. Avaliação de resultados 29 


\section{Página}

3.3.1.Ensaios de competição

3.3.1.1. Avaliação de falhas de brotação nas parcelas

3.3.1.2. Capacidade de brotação de soca

29

3.3.1.3. Perfilhamento

30

3.3.1.4. Avaliação da ferrugem

30

3.3.1.5.Altura das plantas

31

3.3.1.6. Florescimento e chochamento

3.3.1.7. Dados de produção

3.3.2. Curva de Maturação

4. RESULTADOS E DISCUSSÃO 34

4.1.Ensaios de competição 34

4.1.1. Avaliação de falhas de brotação de cana-planta e soca 34

4.1.1.1.Capacidade de brotação de soca $\quad 41$

4.1.2.Perfilhamento 43

4.1.3.Avaliação de ferrugem 46

4.1.4. Altura dos colmos 51

4.1.5.Florescimento e chochamento 53

4.1.6. Dados de produção 55

4.1.6.1.Dados de toneladas de colmos por hectare (TCH)

4.1.6.2.Pol Cana 61

4.1.6.3. Toneladas de pol por hectare (TPH) 66

4.2.Curvas de maturação 66

4.3. Considerações Finais $\quad 82$

5.CONCLUSÕES $\quad 87$

6. REFERÊNCIAS BIBLIOGRÁFICAS 88

APÊNDICES 98 


\section{LISTA DE FIGURAS}

Página

1. Curva de emissão de perfilhos, dados médios dos três locais em cana-planta, para a média das 10 variedades.

2. Curvas de maturação das variedades Co290 e Co419

71

3. Curvas de maturação das variedades Co419 e CB41-76

71

4. Curvas de maturação das variedades CB41-76 e NA56-79

5. Curvas de maturação das variedades NA56-79, SP70-1143 e SP71-1406

6. Curvas de maturação das variedades SP70-1143, SP71-1406 e SP71-6163

7. Curvas de maturação das variedades SP70-1143, SP71-1406, SP71-6163 e RB72454.

8. Curvas de maturação das variedades SP70-1143, SP71-1406, SP71-6163 e RB835089

9. Curvas de maturação das variedades RB72454 e RB835089

10. Curvas de maturação das variedades NA56-79, RB72454 e CB41-76

11. Curvas de maturação das variedades NA56-79, RB72454 e Co290 75

12. Curvas de maturação das variedades NA56-79, RB72454 e Co419 76

13. Curvas de maturação das variedades NA56-79, RB72454 e IAC-48-65

14. Curvas de maturação das variedades NA56-79, RB72454 e RB835089

15. Curvas de maturação das variedades NA56-79, RB72454 e SP70-1143

16. Curvas de maturação das variedades NA56-79, RB72454 e SP71-1406 
Página

17. Curvas de maturação das variedades NA56-79, RB72454 e SP71-6163

18. Dendograma das variedades envolvidas no experimento para o conjunto das seguintes variáveis: falhas, perfilhamento, ferrugem, altura dos colmos, TCH, POL e TPH 


\section{LISTA DE TABELAS}

Página

1. Médias das falhas, em metros lineares na Fazenda Areia Branca, em cana-planta e cana-soca - dados transformados por $\sqrt{x+0,5}$

2. Médias das falhas, em metros lineares, no Centro de Ciências Agrárias, em cana-planta e cana-soca - dados transformados por $\sqrt{x+0,5}$

3. Médias das falhas, em metros lineares, na Fazenda São João, em cana-planta e cana-soca - dados transformados por $\sqrt{x+0,5}$

4. Médias das falhas em dois cortes (metros lineares), nos três locais - dados transformados por $\sqrt{x+0,5}$

5. Análise de variância conjunta entre os locais para Falhas, Peso, Pol e TPP.

6. Capacidade de brotação de cana-soca medida pela diferença de de falhas na soca e na cana-planta em metros nos três locais e a média dos locais; dados transformados por $\sqrt{x+0,5}$

7. Análise de variância conjunta entre locais, para perfilhamento em cana-planta

8. Médias do número de perfilhos, nas cinco leituras, nos três locais, em cana-planta.

9. Análise de variância conjunta entre os locais para ferrugem em cana-planta

10. Notas médias das três leituras de sintomas de ferrugem em cana-planta em cada local e média geral 
Página

11. Análise de variância entre os locais, para altura dos colmos em cana-planta.

12. Altura média dos colmos, em $\mathrm{cm}$, das duas leituras -300 dias e colheita - em cana-planta, nos três locais, individualmente, e média geral em cana-planta

13. Dados de toneladas de colmos por hectare $(\mathrm{TCH})$ na Fazenda Areia Branca

14. Dados de toneladas de colmos por hectare $(\mathrm{TCH})$ no Centro de Ciências Agrárias

15. Dados de toneladas de colmos por hectare ( $\mathrm{TCH})$ na Fazenda São João

16. Média dos dados de toneladas de colmos por hectare (TCH) nos três locais em cana-planta e cana-soca.

17. Médias de pol na Fazenda Areia Branca

18. Médias de pol no Centro de Ciências Agrárias

19. Dados de pol na Fazenda São João

20. Média dos dados de pol dos três locais em cana-planta e canasoca.

21. Dados de toneladas de pol por hectare (TPH) na Fazenda Areia Branca

22. Dados de toneladas de colmos por hectare (TPH) no Centro de Ciências Agrárias

23. Dados de toneladas de pol por hectare (TPH) na Fazenda São João

24. Média dos dados de toneladas de pol por hectare (TPH) nos três locais em cana-planta e cana-soca. 


\title{
EVOLUÇÃO DO POTENCIAL PRODUTIVO DAS PRINCIPAIS VARIEDADES DE CANA-DE-AÇÚCAR CULTIVADAS NO ESTADO DE SÃO PAULO NOS ÚLTIMOS CINQÜENTA ANOS
}

\author{
Autor: Hermann Paulo Hoffmann \\ Orientador: Prof. Dr. Antonio Luiz Fancelli
}

\section{RESUMO}

No presente trabalho procurou-se, através de ensaios de campo, mensurar o incremento em produtividade proporcionado pelas variedades melhoradas de cana-de-açúcar no Estado de São Paulo. Para compor os ensaios escolheram-se variedades de importância nesse Estado, da década de 40 até a primeira metade dos anos 90 , que, cronologicamente foram: Co290, Co419, CB41-76, IAC48-65, NA56-79, SP70-1143, SP71-1406 e SP71-6163, além da RB72454, que está adquirindo proeminência, e RB835089, em início de adoção. Os viveiros de mudas foram instalados a partir de setembro de 1992, submetendo-se os colmos inicialmente ao tratamento térmico por $52^{\circ} \mathrm{C}$ por 30 minutos para eliminar o efeito do raquitismo-dasoqueira (Clavibacter $x y l i$ subsp. $x y / l)$. Os ensaios foram instalados nos meses de março e abril de 1994, em três municípios de regiöes representativas da 
cultura: Santa Bárbara D'Oeste, Araras e Jardinópolis. Instalou-se ainda um experimento para determinação da curva de maturação das variedades, em Araras.

Além da obtenção dos dados diretamente ligados à produção agroindustrial conduziram-se os seguintes acompanhamentos complementares: medições de falhas em cana-planta e soca, perfilhamento, avaliação de sintomas de ferrugem, medição da altura dos colmos, avaliação da intensidade de florescimento e de chochamento.

As avaliações de falhas em cana-planta e cana-soca, forneceram dados que são coerentes com o perfil de brotação que as variedades contemporâneas, incluídas nos ensaios, apresentam em lavoura comercial. Partindo das melhores para as piores variedades para essa característica, a ordem foi a seguinte: SP70-1143, NA56-79, IAC48-65, CB4176, SP71-1406, Co290, RB835089, RB72454, SP71-6163, Co419.

Quanto às curvas de maturação, a variedade NA56-79 foi a mais precoce, enquanto as variedades SP70-1143 e RB72454 superaram as demais quanto aos teores de sacarose no final de safra, confirmando o perfil das mesmas.

Quanto aos rendimentos agrícolas a intensidade de ferrugem (Puccinia melanocephala $\mathrm{H}$. \& $\mathrm{P}$ Syd), doença de aparecimento recente no Brasil influenciou o posicionamento relativo entre as variedades, prejudicando 
variedades suscetíveis em Santa Bárbara D'Oeste, onde a intensidade de sintomas foi maior. A diferença a favor da variedade mais produtiva, RB835089 (altamente resistente à ferrugem ), e de liberação mais recente, em relação à mais antiga, Co290, foi de 23\% para toneladas de colmos para hectare (TCH) e $36 \%$ para toneladas de pol por hectare (TPH). Considerando-se as diferenças a favor, para os mesmos parâmetros, entre a variedade RB835089 e a menos produtiva, SP71-6163, obteve-se valores de $104 \%$ para $\mathrm{TCH}$ e $112 \%$ para TPH. Em ordem decrescente de produtividade as variedades se posicionaram para TCH na seguinte forma: RB835089, RB72454, SP70-1143, Co290, CB4176, Co419, NA56-79, IAC48-65, SP71-1406 e SP71-6163. Quanto à TPH, seguindo o mesmo critério, a ordem foi a seguinte: RB835089, RB72454, SP70-1143, Co419, Co290, NA56-79, IAC48-65, CB41-76, SP71-1406 e SP716163.

Conclui-se que o melhoramento genético têm logrado propiciar ganhos de produtividade com novas variedades, e que a alteração de ambiente, especialmente pela incidência de novas doenças, pode levar à degenerescência de variedades. 


\title{
EVOLUTION OF THE POTENTIAL PRODUCTIVITY OF THE MAIN SUGARCANE VARIETIES GROWN IN THE STATE OF SÃO PAULO IN THE LAST FIFTY YEARS
}

\author{
Author: Hermann Paulo Hoffmann \\ Adviser: Prof. Dr. Antonio Luiz Fancelli
}

\section{SUMMARY}

The aim of this research was to determine productivity increase achieved by growing genetically improved sugarcane (Saccharum spp.) varieties in the State of São Paulo in the last fifty years. Ten expressively grown varieties in this state from the fourties until the first half of the ninities were chosen to install three experiments. Cronologicaly the varieties were the following: Co290, Co419, CB41-76, IAC48-65, NA56-79, SP70-1143, SP711406 and SP71-6163, besides RB72454, which is becoming prominent, and RB835089, which is beguining to be adopted by the growers. The nurseries used for planting were first stablished in september of 1992, the initial stalks were submitted to hot-water treatment for $52^{\circ} \mathrm{C} / 30 \mathrm{~min}$. with the objective of eliminating the ratoon stunting disease effect (Clavibacter $x y / i$ subsp. $x y l i)$. The 
experiments were set in March and April,1994 in Santa Bárbara D'Oeste, Araras and Jardinópolis, Counties which present characteristics represent the main traditional sugarcane planting area. In Araras, another field experiment was set to determine the varieties maturation curve.

Besides those data which directly compose agroindustrial productivity, the following complementary evaluations were performed: failure in germination of plant cane and ratoon, tillering, rust (Puccinia melanocephala $\mathrm{H}$. \& P. Syd) incidence, stalk height, flowering and pithing.

Data on germination failure in both plant cane and ratoon were valuable parameters representing ratooning performance of those sugarcane varieties included in the experiments, when grown in commercial fields. Regarding to that parameter the following order, from the best variety to the worst one, was observed: SP70-1143, NA56-79, IAC48-65, CB41-76, SP711406, Co290, RB835089, RB72454, SP71-6163, Co419.

Based on the maturation curve it can be concluded that NA5679 was the best early-maturing variety; the varieties SP70-1143 and RB72454 presented the highest sugar content at the end of the harvesting season. These data conform to the known characteristics of those varieties.

Concerning cane yield, rust incidence degree played a major role in the relative ranking between the varieties, decreaseing the yield of those susceptible ones in Santa Bárbara D'Oeste, were the disease ocurred more 
intensively, as expected. The most productive variety, RB835089, which is highly resistant to rust produced $23 \%$ more tons of cane per hectare and $36 \%$ more tons of sugar per hectare than Co290, the most ancient variety of the studied period. Differences between RB835089 and the least productive variety, SP71-6163, were $104 \%$ and $112 \%$ in tons of cane and tons of sugar per hectare respectively. In decreasing order, concerning productivity in tons of cane per hectare, the following ranking was observed: RB835089, RB72454, SP70-1143, Co290, CB41-76, Co419, NA56-79, IAC48-65, SP71-1406 and SP71-6163. Concernig tons of sugar per hectare, and adopting the same criterion, the following order was observed: RB835089, RB72454, SP70-1143, Co419, Co290, NA56-79, IAC48-65, CB41-76, SP71-1406 and SP71-6163

Based on these data it can be concluded that the recently improved sugarcane varieties have presented better yields as compared to the formerly grown varieties, even after changes in the environment induced by the onset of rust. 


\section{INTRODUÇÃO}

A importância da variedade de cana-de-açúcar (híbridos de Saccharum spp) na agroindústria sucroalcooleira é indiscutivel e, no setor agrícola, é a introdução de novas variedades e seu correto manejo o principal recurso para se incrementar a produtividade. MATSUOKA (1991), cita que, no Brasil e em outros países do mundo, após os surtos epidêmicos de doenças. somente a substituição das variedades foi capaz de garantir a estabilidade da cultura. Nas condições brasileiras uma das principais variedades, em tempos recentes, foi a NA56-79, tendo sido a mais cultivada no Estado de São Paulo a partir de 1980 (RELATÓRIO, 1981); essa variedade elevou o patamar do rendimento de açúcar por área em torno de 9\%, conforme PINAZZA et al. (1984), baseados no trabalho de BASSINELLO (1976). Devido a problemas fitossanitários, ocasionados primeiramente pelo carvão (Ustilago scitaminea Syd.), e depois pela ferrugem (Puccinia melanocephala H. \& P. Syd.), essa variedade deixou de ser plantada e, graças as novas variedades disponiveis, principalmente SP70-1143, SP71-1406 e SP71-6163, liberadas pela 
COPERSUCAR, na década de 80 , aquele patamar de produtividade foi mantido.

Em 1986, ocorreu a primeira constatação da ferrugem nos canaviais brasileiros, em Capivari - SP (FERRUGEM, 1986; SORDl et al., 1986). A partir daí, nova mudança no grupo das variedades cultivadas vem ocorrendo pois, inicialmente, as variedades suscetíveis deixaram de ser plantadas e, mais recentemente, também as tidas como intermediárias, quando da introdução da doença, por estarem apresentando infecções elevadas, estão sendo substituídas por variedades mais resistentes. Especificamente quanto à variedade SP71-6163, que é suscetível à ferrugem, o motivo que tem levado à sua substituição é a síndrome do "amarelinho", cuja causa é controvérsa (MENEGHIN et al., 1994; VEGA, 1994).

Atualmente, no país há quatro programas de melhoramento, cujas instituições responsáveis são relacionados, a seguir, com as respectivas siglas utilizadas nas variedades: Instituto Agronômico de Campinas - IAC ; COPERSUCAR; - SP ; Universidades Federais (que assumiram o programa de melhoramento do extinto IAA/Planalsucar) - RB; Usina Da Barra -PO.

Quando se testam novas variedades, estas são comparadas com as mais produtivas comercialmente cultivadas na ocasião, ou seja, as contemporâneas. No entanto, uma comparação entre os rendimentos das variedades atualmente cultivadas e de suas antecessoras, poderá mensurar o 
ganho de produtividade a ser atribuído aos programas de melhoramento. Utilizar dados de literatura tem sido o caminho para se ter uma idéia da evolução das variedades, mas, como há alteração no sistema de produção e no equilíbrio biótico, e, consequentemente, no ambiente, somente ensaios específicos, conduzidos nas condições atuais, poderão estimar com mais precisão os ganhos de produção devido às variedades e, assim, mensurar a evolução do potencial produtivo das variedades melhoradas de cana-deaçúcar. 


\section{REVISÃO DE LITERATURA}

\subsection{A seqüência histórica das variedades cultivadas no Brasil}

A primeira variedade introduzida no país foi a "Creola" ou "Mirim" (MIOCQUE \& MACHADO, 1977), que foi cultivada até fins do século XIX. Segundo SEGALLA (1978) desde então, até 1920, se cultivava as canas ditas nobres, da espécie Saccharum officinarum, designadas por nomes como: Caiana, Imperial, Manteiga e outras. Aquelas variedades eram obtidas por seleção massal em população natural, pois se desconhecia a fertilidade das cariopses na inflorescência (MIOCQUE, 1993). A substituição daquele grupo de variedades iniciou-se a partir de 1922/23, em virtude do surgimento de uma doença, até então desconhecida, o mosaico da cana-de-açúcar, cujo agente causal foi posteriormente identificado como vírus por Brandes ${ }^{1}$, conforme KOIKE \& GILLASPIE (1989). As canas nobres eram suscetíveis e houve uma grande queda de produção. Por exemplo, no Estado de São Paulo, a produção baixou de 534.600 sacas de açúcar em 1923 para 220.000 sacas em 1925 (ARRUDA, 1941). Os danos causados pelo mosaico foram atenuados pela substituição gradativa por variedades resistentes; introduziu-se as primeiras

\footnotetext{
BRANDES, E. W. The mosaic disease of sugarcane and other grasses. U.S. Dep. Agric. Tech. Bull., 829, 26 p., 1919.
} 
variedades híbridas, originárias de Java, que foram as seguintes: POJ36, POJ213, POJ2727, POJ2878 (SEGALLA, 1978; MATTOS, 1942). SANGUINO (1978), cita que, no passado quando se priorizava a produtividade e não se considerava a reação às doenças, se propiciava surtos epidêmicos periódicos.

De acordo com AGUIRRE (1936), entre aquele grupo de variedades chamadas javanesas, a que teve maior aceitação foi a POJ213, conhecida como "Javinha", chegando a ocupar $80 \%$ da área cultivada do Estado de São Paulo. Esta variedade tinha como características favoráveis seu alto teor de sacarose e resistência ao mosaico; seus defeitos eram os colmos, finos e curvos.

As variedades $\mathrm{POJ}$ predominaram nos canaviais paulistas até 1939-40, quando então vieram a ser substituídas pela Co290, uma variedade indiana. O estudo desta variedade foi a primeira contribuição da Seção de Cana-de-Açúcar do Instituto Agronômico de Campinas, criada em 1935. Tal substituição ocorreu devido à maior produtividade da Co290 (SEGALLA, 1978).

A Co290 foi cultivada até 1953-54 quando, devido a uma queda acentuada de produção, sem uma causa definida na época, foi necessário a sua pronta substituição; segundo MATSUOKA (1991), evidências históricas indicam que a duas doenças poderia ser atribuída tal queda de produção: ao mosaico e à podridão vermelha (Glomerella tucumanensis Speg.). O Instituto 
Agronômico de Campinas, a partir da introdução e avaliação de novas variedades, tornou possível que a substituição ocorresse sem que se colocasse em risco a produção; iniciou-se o cultivo principalmente da variedade nacional CB41-76 e da indiana Co419 (SEGALLA, 1978).

No Brasil, até a fase da Co290, se obtinham novas variedades apenas por importação; a CB41-76 foi a primeira variedade brasileira cultivada em larga escala em São Paulo, obtida por hibridações realizadas na Estação Experimental do Ministério da Agricultura, Campos, RJ. Mas, outras variedades também passaram a ser cultivadas: as introduzidas Co331, Co413, Co419 e Co421 e várias nacionais: CB36-24, CB40-13, CB40-69, CB45-3 e CB49-260. Foram liberadas. também as primeiras "IAC": IAC47-31, IAC48-65, IAC49-131 e IAC50-134 (SEGALLA, 1978). Dessas, a IAC48-65 foi a mais cultivada (RUAS et al., 1983; RELATÓRIO, 1986), que veio posteriormente a ser utilizada como genitora nos programas de melhoramento gerando a variedade SP70-1143. Entre a CB41-76 e a Co419, esta última foi a mais plantada, chegando a ocupar de 60 a $70 \%$ dos canaviais paulistas (SEGALLA, 1978); tinha como principais características, a alta produtividade em solos férteis, despalha fácil, e bom teor de sacarose para a época (AZZI, 1971).

A partir de 1964 começaram a aparecer surtos de carvão (Ustilago scitaminea Syd.) no Estado de São Paulo afetando a Co419, acarretando a proibição do cultivo desta variedade pela Comissão Técnica 
Permanente de Cana-de-Açúcar do Estado de São Paulo (BRIEGER, 1968; BRIEGER \& ZUNCKELLER, 1965). Com a proibição da Co419, passou-se a cultivar a CB41-76; esta variedade tinha como vantagem a elevada resistência ao carvão, mas notou-se neste período, de 1967 a 1969, uma tendência de queda de rendimentos, pois experimentalmente se constatara que seu potencial produtivo era ligeiramente inferior ao da Co419 (SEGALLA et al., 1967). Além disso os canaviais comerciais dela se mostravam infetados pelo raquitismo-da-soqueira (MATSUOKA, 1976), cujo agente causal foi mais tarde determinado como sendo a batéria clavibacter xyli subsp. xyli DAVIS et al. 1984.

Com o cultivo da CB41-76 seguiu-se um período de relativa tranqüilidade com relação às doenças. De acordo com BASSINELLO et al. (1976), esta variedade, que era resistente às principais doenças da época, mosaico e carvão, e intermediária às demais, tinha como principais características a exigência em água e fertilidade, boa produtividade agrícola e fácil tombamento; sendo seu principal defeito o teor apenas médio de sacarose. Sua área cultivada chegou a 50\% do Estado de São Paulo em 1970 (AZZI, 1971).

A partir da metade da década de 70 dois fatores concorreram para a substituição da CB41-76: a busca de variedades com maior teor de 
sacarose, visando a melhoria dos rendimentos industriais, e a expansão da cultura, notadamente para solos fracos, motivada pelo PROÁLCOOL.

De 1972 a 1982 a área de cana no país passou de 1,54 para 3,36 milhões de hectares, uma evolução de 1,82 milhões de hectares. Este período marcou a expansão de uma das variedades mais importantes no país, que foi a NA56-79 (RUAS et al., 1983). Esta variedade tinha como principal característica o alto teor de sacarose para o padrão da época, que era a CB4176, além de ser menos exigente que esta última quanto à fertilidade dos solos (BASSINELLO et al., 1976). A NA56-79 foi desenvolvida por Roberto F. Ullivarri na Chacra Santa Rosa, em Salta, norte da Argentina; introduzida em São Paulo por Gilberto Miller Azzi em 1966, durante três anos permaneceu plantada nos jardins do antigo Escritório do Setor Técnico Agronômico Regional do Instituto do Açúcar e do Álcool, em Piracicaba-SP (FERNANDES, 1982). Segundo PINAZZA et al. (1984), a multiplicação desta variedade foi iniciada pelo Eng ${ }^{\circ}$ Agr ${ }^{\circ}$ Sérgio Bicudo Paranhos na Estação Experimental "José Vizioli", do Instituto Agronômico em Piracicaba-SP e, em seguida, iniciou-se a multiplicação na Estação Experimental do INSTITUTO do AÇÚCAR e do ÁLCOOL (IAA), em Araras-SP. Seu uso como padrão nos ensaios do Programa de Melhoramento do IAA/Planalsucar e a divulgação dos resultados obtidos por BASSINELLO (1976) e BASSINELLO et al. (1976) despertou o interesse do 
meio produtor de tal forma que, já em 1980, a NA56-79 tornou-se a variedade mais cultivada no Estado de São Paulo (RELATÓRIO, 1981).

O crescimento da área com a NA56-79 ocorreu na medida que havia a diminuição da área com a CB41-76; tal substituição não pôde ser integral uma vez que a primeira era uma variedade para a fase inicial da safra e, portanto, não cobria o período final da safra (PINAZZA et al., 1984).

A NA56-79 constitui-se em uma evolução para o setor sucroalcooleiro na região Centro-Sul, graças à antecipação do período de safra de junho para final de abril e aos aumentos dos rendimentos agrícola e industrial. PINAZZA et al. (1984), desenvolveram um estudo no qual, comparando as despesas de pesquisa realizadas pela Estação Experimental Centro-Sul do IAA/Planalsucar contra os benefícios gerados pela variedade, demostraram que a taxa interna de retorno da introdução desta variedade no Estado de São Paulo foi de 35,14\% e, a relação benefício/custo, de 1,65.

Após um período de intenso cultivo, a substituição da NA56-79 tornou-se necessária devido a problemas fitossanitários. Sua reação era intermediária a quase todas as doenças de importância na cultura da cana (BASSINELLO, 1976), e com o aumento da área cultivada e o plantio em solos mais fracos, os problemas fitossanitários se agravaram; inicialmente o carvão e posteriormente a ferrugem reduziram os rendimentos desta variedade, inviabilizando o seu cultivo (MATSUOKA, 1993). 
Após o periodo da NA56-79 houve, novamente, a participação de uma variedade rústica, SP70-1143 que passou a ter expansão mais expressiva em 1982, figurando como uma das dez mais plantadas no Estado de São Paulo (RUAS et al., 1983). Posteriormente outras variedades desenvolvidas pela Copersucar passaram a ter participação expressiva, especialmente a SP71-1406 e a SP71-6163. No Censo Varietal Quantitativo 1991, publicado pela COPERSUCAR (1992), estimou-se que as variedades SP estariam ocupando $66 \%$ das áreas com cana-de-açúcar no Centro-Sul. Esta ocupação se deu, principalmente em áreas anteriormente ocupadas pela NA5679. O que se observou é que, nesta fase das variedades SP, ao contrário do que tinha ocorrido no passado com outras variedades, nenhuma delas, isoladamente, chegou a ocupar um porcentual igual ou superior a $50 \%$ do total da área cultivada (COPERSUCAR, 1992). Em parte, isto se deveu ao fato de que com a evolução técnica do setor sucroalcooleiro, passou-se a explorar melhor o potencial das variedades quanto à exigência em solos e maturação; aquelas três variedades $\mathrm{SP}$ têm características bem distintas quanto às exigências mencionadas, o que tornou possível a alocação de cada variedade nas condições mais indicadas .

Ultimamente iniciou-se a fase da variedade RB72454, que a princípio foi liberada em Pernambuco pela Coordenadoria Regional Norte do IAA/PLANALSUCAR em 1982 (IAA/PLANALSUCAR, 1982b). Devido aos 
resultados favoráveis obtidos em ampla rede experimental, nas principais regiões produtoras foi liberada, posteriomente, também, a nivel nacional (IAA/PLANALSUCAR, 1987). Na sua liberação no Estado de São Paulo, esta variedade teve restrições no meio produtor devido à posição da Comissão de Controle do Carvão da Cana-de-Açúcar no Estado de São Paulo, que a condenou como variedade suscetível ao carvão, proibindo o seu cultivo. Sua liberação, a nível nacional, incluindo o Estado de São Paulo, ocorreu como resultado do empenho da Equipe de Melhoramento da Coordenadoria Regional Sul do IAA-PLANALSUCAR, em Araras-SP, que lutou muito pela liberação desta variedade, questionando, inclusive, os métodos adotados pela referida Comissão nos testes para carvão (MATSUOKA, 1993).

De acordo com o censo varietal quantitativo 1993, publicado pela COPERSUCAR (1994), as variedades mais plantadas, com seus respectivos porcentuais em 1993, no Estado de São Paulo foram: SP71-6163, 29,8\%; SP70-1143, 20,2\%; RB72454, 20,1\%. Deste grupo de variedades, a primeira não tem sido mais plantada devido à "Síndrome do Amarelinho" (COPERSUCAR, 1995; GHELLER, 1996) e a SP70-1143, devido à ferrugem, tende a ter sua área de cultivo estabilizada ou mesmo decrescida, à medida que surjam outras opções.

O levantamento mais atualizado demonstrou que a RB72454 foi a variedade mais plantada no ano de 1995 e tende ser a mais cultivada no 
Estado de São Paulo a partir de 1996, com 30,7\% dos novos canaviais (GHELLER, 1996). Contudo, espera-se que a sua participação não seja excessiva, pois estrategicamente isto não é recomendável, e também outras variedades promissoras passaram a ser plantadas, uma vez que estão em atividade, a nível de Estado de São Paulo, os programas de melhoramento já mencionados. Dentre as variedades de plantio crescentes, RB785148, RB806043, RB835089, RB835486, RB825336 e SP80-1842, a RB835089 apresentara em 1995 a maior área cultivada (GHELLER, 1996). Essa variedade, além de bastante produtiva é resistente a ferrugem (MATSUOKA et al., 1992).

\subsection{Os programas de melhoramento}

A primeira menção de que a cana-de-açúcar se multiplicava por sementes foi de LIMA (1842), numa tese apresentada na Faculdade de Medicina do Rio de Janeiro. Porém, na literatura mundial é referida que a primeira constatação de que a cana-de-açúcar podia se reproduzir por via sexuada ocorreu em Barbados (DANIELS \& TEW, 1987).

A grande pressão sobre os programas de melhoramento tem sido a busca de variedade resistentes às doenças de importância econômica; a variedade resistente é a medida de controle as doenças mais utilizada na 
cultura. Há vários exemplos de países que, devido a surtos epidêmicos, a cultura da cana-de-açúcar esteve próximo de um colapso; na maioria das vezes foi a obtenção de uma variedade com níveis de resistência que proporcionou a recuperação da produção (WALKER, 1987).

O primeiro exemplo de doença que tenha motivado a busca de resistência pelo melhoramento genético foi a epidemia de "Sereh" em Java, hoje Indonésia. Assim os holandeses, que eram os colonizadores, foram os pioneiros na criação de um melhoramento para a cultura. Seguindo o trabalho pioneiro em Java, a partir do ano de 1890 iniciaram-se programas de melhoramento em Barbados, Guiana Inglesa, Reunion, Austrália e Mauricios e depois, em todas as principais regiões canavieiras do mundo (HEINZ, 1987).

\subsubsection{Os programas de melhoramento no Brasil}

Segundo Andrade, citado por MACHADO et al. (1987), foi em 1892 que se produziu a primeira variedade de cana-de-açúcar no Brasil, a partir de panículas coletadas por Manoel Cavalcanti de Albuquerque, proprietário do Engenho Cachoeirinha em Escada-PE. Após esta primeira tentativa, somente a partir de 1910 se tentou iniciar um programa de melhoramento na Estação Experimental de Escada-PE. Seguiram-se posteriormente outras iniciativas e trabalhos no sentido de se tentar obter 
variedades nos seguintes locais: Estação Geral de Experimentação de Barreiras, Escola Superior de Agricultura de São Bento, em Tapera, e Estação Experimental de Curado, todos em Pernambuco, e Quissamã no Estado do Rio de Janeiro. Desses foi em Curado que se logrou maior sucesso com a obtenção de variedades, inicialmente com a sigla "PB" e posteriormente com a sigla IANE, (Instituto Agronômico do Nordeste). Deste programa a IANE 53-33 foi bem cultivada no nordeste.

O primeiro programa de melhoramento com duração que deixou uma contribuição expressiva foi o das variedades "CB" em Campos-RJ, que se iniciou em 1930. Na liderança desse programa esteve por maior parte do tempo Frederico Menezes Veiga, que logrou obter variedades que tiveram grande importância; as mais importantes foram CB41-76, que chegou a ser a variedade com a maior área no Estado de São Paulo, e a CB45-3, embora não cultivada nesse estado, foi a de maior participação no Brasil, devido ao expressivo cultivo em outros estados, notadamente do nordeste, Minas Gerais e Rio de Janeiro (RELATÓRIO, 1985).

Conforme ALVAREZ ${ }^{2}$, a partir de 1935, no Estado de São Paulo, criou-se a Seção de Cana-de-Açúcar no Instituto Agronômico de Campinas, embora José Manuel de Aguirre Júnior já tivesse iniciado hibridações para a obtenção de novas variedades no ano anterior (AGUIRRE

\footnotetext{
${ }^{2}$ ALVAREZ, R. ( IAC. Seção de Cana-de-Açúcar, IAC, Campinas) Comunicação pessoal, 1990.
} 
JR., 1936). Esses trabalhos foram interrompidos, sendo reativados em 1947, pelo pesquisador anteriormente citado e por Cyro Corte Brilho, quando passaram a ser conduzidos com regularidade.

Mais tarde, criaram-se os programas da Copersucar, em 1968, e o do IAA-Planalsucar, em 1970 (BRIEGER, 1978). O mais novo dos programas de melhoramento é o da Usina da Barra, criado em 1975 (NAGUMO, 1993).

O momento atual tem-se caracterizado, acima de tudo, por cortes nos orçamentos governamentais, tanto a nivel estadual como federal. Acrescentando-se a isso os problemas ocorridos - ferrugem e, mais recentemente, a síndrome do amarelecimento - e, finalmente, considerando a crescente importância da cultura, os Programas têm conseguido uma colaboração expressiva das unidades produtoras, tanto em contribuições financeiras como em colaboração nos próprios trabalhos de campo. Para justificar a importância da cultura, basta citar que a área cultivada com canade-açúcar no país em 1993 era de 5 milhões de hectares COPERSUCAR (1994).

\subsubsection{Variedades "SP"}

Foram 31 as variedades liberadas pela Copersucar até o momento (NOVAS, 1983; SEGUNDA, 1989; TERCEIRA, 1991; QUARTA, 1993; 
QUINTA, 1995). A partir dos dados compilados por GHELLER (1996), tem-se o seguinte: dentre as "SP", 13 constaram entre as mais cultivadas; a primeira a constar foi a SP70-1284; quanto à área ocupada, as de maior participação foram SP70-1143, SP71-1406 e SP71-6163. A SP70-1143 foi a mais cultivada, com $29,9 \%$ da área do Estado de São Paulo em 1989. Conjuntamente, as variedades "SP" chegaram a ocupar mais de $50 \%$ da área com cana-de-açúcar do estado, a partir do final dos anos oitenta (COPERSUCAR, 1992). Atualmente, duas delas estão com o plantio crescente: SP79-1011 e SP801842 (GHELLER, 1996; BRAGA JUNIOR \& SORDI, 1996), sendo que para primeira não se espera um crescimento expressivo devido à sua suscetibilidade à ferrugem.

\subsubsection{Variedades "IAC"}

As variedades "IAC" chegaram a ocupar no Estado de São Paulo um porcentual próximo de $20 \%$ no ano de 1981 . Naquele ano, a IAC52150, a mais cultivada das IAC's, chegou a $10 \%$ da área do estado, seguida pela IAC48-65, com 4,9\% e IAC51-205 com 3,4\% (RUAS et al, 1983). A IAC4865, das variedades liberadas por essa instituição, foi a que por mais tempo permaneceu entre as mais cultivadas (GHELLER, 1996). Dentre as variedades comercialmente cultivadas, esta tinha características altamente favoráveis 
como precocidade e baixa exigência quanto à fertilidade (CANA-DE-AÇÚCAR, 1980). Posteriormente, essa variedade veio a ser substituída pela SP70-1143 que foi obtida de um cruzamento da própria IAC48-65 (NOVAS, 1983). Quanto às demais variedades IAC, após este período de maior participação, somente as variedades IAC58-480 e IAC64-257, no final dos anos 80, apresentaram tendência de crescimento de suas áreas, mas os porcentuais não ultrapassaram a $0,8 \%$ para a primeira e $1,3 \%$ para a segunda (GHELLER, 1996). Embora tenham tido uma importante participação, não há, no momento, variedades "IAC" entre as mais cultivadas; mas novas variedades promissoras e clones estão sendo multiplicados em unidades produtoras. Esse Programa, da mesma forma que os demais, também tem procurado junto às unidades produtoras, através de convênios de parceria, captar recursos para o desenvolvimento de suas pesquisas.

\subsubsection{Variedades "RB"}

Este programa é o único de abrangência nacional, uma vez que a partir de 1991, conta com uma rede de sete Universidades Federais que assumiram as funções do ex-IAA/Planalsucar, ou sejam: Universidades Federais Rurais de Pernambuco e Rio de Janeiro e as Universidades Federais 
de Alagoas, Paraná, São Carlos, Sergipe e Viçosa. Foram liberadas por ele novas variedades para todos os estados produtores.

Enquanto pertencendo ao Instituto do Açúcar e do Álcool-IAA, a partir da Estação Experimental de Araras, SP, sede da Coordenadoria Regional Centro-Sul, foram liberadas 7 variedades; com a primeira liberação ocorrendo em 19/03/82 e seguindo-se outra em 1988 (IAA/Planalsucar, 1982a; 1987; 1988). Já com o programa sob a responsabilidade da Universidade Federal de São Carlos houve duas liberações: a primeira em 17/09/92, com a liberação

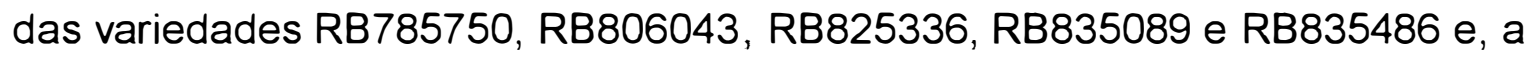
segunda, em 23/03/95, liberando as variedades superprecoces - RB835019, RB855156, RB855453 e RB855563 (MATSUOKA et al., 1995). Das variedades RB, a RB72454, liberada a nível nacional em 1987 (IAA/Planalsucar, 1988), foi a mais cultivada no Estado de São Paulo em 1995; naquele ano, as "RB" representaram $56 \%$ da área de formação dos novos canaviais e $31 \%$ da área de cultivo, de acordo com dados levantados por GHELLER (1996). Dos programas públicos, o da CCA/UFSCar foi o primeiro na região Centro-Sul em estabelecer parceria com o setor privado, hoje contando com mais de 68 parcerias naquela região entre produtores independentes e associações/sindicatos (Universidade Federal de São Carlos, 1996). 


\subsubsection{Variedades "PO"}

O programa da Usina da Barra, criado em 1975 (NAGUMO, 1993) para atender as exigências da própria empresa, mantém convênios com outras unidades produtoras. Até o momento, mesmo a nível local, somente a variedade P084-96 tem sido cultivada em área expressiva (GHELLER, 1996). Esse programa, como não possui um local para hibridação, tem utilizado sementes da Estação de Floração de Cruzamento de Serra do Ouro, Murici AL, vinculada à Universidade Federal de Alagoas, e mantida pela rede das Universidades Federais que atuam no melhoramento da cana-de-açúcar.

\subsection{A evolução dos rendimentos}

Os dados de produtividade na cultura da cana-de-açúcar atestam que houve uma evolução bastante significativa nos rendimentos agrícolas. Em grande parte, esses aumentos de produtividade estiveram ligados ao sucesso de uma variedade eficiente, assim como as quedas estiveram ligadas à falta de variedades suficientemente produtivas para manter a tendência de evolução dos rendimentos. Segundo LOOMIS \& WILLIAMS (1963), a máxima produção teórica calculada para a cana-de-açúcar é de 
0,7t/hectare/dia de matéria seca, o que representa dez vezes os rendimentos médios obtidos; isto significa que há mais ganhos a serem alcançados.

De acordo com BAVER (1963), o melhoramento da cana-deaçúcar no Havaí foi responsável por $75 \%$ dos ganhos de produtividade, considerando o período de 1950 a 1983, no referido estado norte-americano.

Em Queensland, Austrália, o setor industrial aumentou os seus rendimentos a uma taxa de $1,9 \%$ ao ano, de 1948 a 1975; de acordo com Hogarth $^{3}$, citado por HEINZ (1987), metade deste ganho se deve aos programas de melhoramento.

MARIOTTI (1982), considerando apenas as melhorias nas qualidades tecnológicas proporcionadas pelas variedades melhoradas na Argentina, concluiu que entre os anos de 1953 e 1982 necessitou-se $34 \%$ menos matéria prima para a produção de uma mesma quantidade de açúcar. Não se considerou o aumento do rendimento agrícola, proporcionado pelo maior potencial de produção das novas variedades como também a maior produção devido a resistência às doenças. Por outro lado, deve-se considerar que o aumento obtido também foi influenciado por melhorias no processamento industrial, na qualidade da matéria prima, e outros fatores.

Um dos trabalhos mais completos sobre a produtividade agrícola na cultura da cana-de-açúcar no Brasil é o de PELIN (1985). Segundo

\footnotetext{
${ }^{3}$ HOGARTH, D.M. New varieties lift sugar production. Producers Review, 66(10): 21-22
} 
levantamento bibliográfico realizado por este autor, entre a década de 30 e o ano de 1983 , no Estado de São Paulo, a produtividade evoluiu de 33,8 para 75,50 t/ha. Ainda sobre estes dados, embora tenha havido uma clara tendência de acréscimos, notou-se que a evolução mais acentuada dos rendimentos ocorreu a partir de meados da década de 70 . Se considerados valores médios da ordem de 30 t/ha para os primeiros anos da série e o valor final de 75,50 t/ha, conclui-se que o ultimo valor é 2,5 vezes o primeiro; em porcentagem 0 aumento foi de $150 \%$. Dados mais recentes referenciam rendimento médio de 77,20 t/ha a 77,3t/ha no Estado de São Paulo (CARVALHO et al. 1993). Há unidades produtoras com rendimento médio por volta de 90 t/ha.

$$
\text { BULLIO \& CAMPOS (1988), realizaram uma avaliação }
$$
econômica dos resultados obtidos pelas variedades SP, comparando-as com outras variedades cultivadas na safra 1986/87; concluíram que as variedades "SP", considerando-se a área cultivada pelas usinas cooperadas, proporcionaram uma margem de contribuição adicional de US\$16 milhões somente naquele ano. Comparando-se as progênies de 1991 a 1994 do programa de melhoramento da COPERSUCAR (MELHORAMENTO, 1996), constatou-se um aumento de 5,05\% de toneladas de cana e 2,55\% de sólidos solúveis por hectare ao ano no período.

MATSUOKA (1991), revisando a contribuição das variedades de cana-de-açúcar ao setor sucroalcooleiro indicou as variedades mais 
importantes nos últimos quarenta anos e as razões que levaram-nas a serem substituídas, também estimando os acréscimos proporcionados pela NA56-79, em comparação com a CB41-76. O autor, utilizando 79 dados experimentais de colheitas, constatou que a NA56-79 se igualou à CB41-76 em produção de cana por área; porém, quanto ao teor de sacarose, superou a segunda em $24 \%$, para cana planta, e $17 \%$ para cana soca. Estes valores são superiores ao valor anteriormente considerado por PINAZZA et al. (1984), que foi de $9 \%$.

Evidentemente, o trabalho com variedades é a base da pesquisa na cultura, mas os aumentos de produtividade também foram resultados da evolução de todas as atividades que formam o sistema de produção da cultura, juntando tecnologia e eficiência administrativa, embora seja uma realidade o fato de que não existe tecnologia que dê resposta se não houver variedade responsiva. É correto, portanto, atribuir grande parte do aumento de produtividade à variedade; a obtenção das variedades é a prioridade das pesquisas em cana-de-açúcar (PELIN, 1985). 


\section{MATERIAL E MÉTODOS}

\subsection{Ensaios de competição varietal}

\subsubsection{Variedades}

No ano de 1992 obteve-se colmos das variedades Co290, Co419 e IAC 48-65 junto a Copersucar e das variedades CB41-76, NA56-79, RB72454, RB835089, SP70-1143, SP71-1406 e SP71-6163 no próprio CCA. Inicialmente cortou-se os colmos em toletes de três gemas para o tratamento térmico com água quente a $52^{\circ} \mathrm{C}$ por 30 minutos (BINÔMIO, 1989), para o controle de possiveis efeitos do raquitismo-da-soqueira causado pela bactéria Clavibacter xyli subsp. xyli. Após esse tratamento, banhou-se os toletes com uma solução $150 \mathrm{~g}$ benomyl $(500 \mathrm{~g} / \mathrm{kg})$ em 100 litros de água, visando o controle de doenças do solo como a podridão abacaxi, causada pelo fungo Ceratocystis paradoxa. Uma vez que o número de colmos inicialmente disponivel era insuficiente, fez-se a multiplicação do viveiro em 1993 no Centro de Ciências Agrárias para acumular muda suficiente à necessidade dos ensaios. Nessa multiplicação tomou-se toda a precaução de arrancar os 
colmos manualmente sem o uso de facão para se impedir a recontaminação pela bactéria do raquitismo-da-soqueira.

As variedades e seus genitores (MACHADO JÚNIOR, 1994) estão relacionadas a seguir:
1. CB41-76
(POJ2878 $x$ ?)
2. $\operatorname{Co} 290$
(Co221 x D74 ou Kansar)
3. $\operatorname{Co4} 19$
(POJ2878 x Co290)
4. $\operatorname{AC} 48-65$
(CP27-108 $\times$ ?)
5. NA56-79
(Co419, autopolinização)
6. RB72454
(CP53-76 x ?)
7. RB835089
(RB72454 x NA56-79)
8. SP70-1143
(IAC48-65 x ?)
9. SP71-1406
(NA56-79 $\times$ ?)
10. SP71-6163
(NA56-79 $\times$ ?)

\subsubsection{Locais}

Os ensaios, em número de três, foram instalados em regiões representativas da cultura da cana-de-açúcar no Estado de São Paulo: Santa Bárbara D'Oeste, Fazenda Areia Branca (FAB) - Usina Santa Bárbara S.A.; Araras, Centro de Ciências Agrárias (CCA) da Universidade Federal de São 
Carlos e Jardinópolis, Fazenda São João (FSJ) - Galo Bravo Açúcar e Álcool S.A., empresa que a sede localiza-se em Ribeirão Preto.

\subsubsection{Fazenda Areia Branca (FAB), Santa Bárbara D’Oeste}

Data do plantio: 08/03/94.

Tipo de solo: latossolo vermelho amarelo distrófico (as análises físicas e químicas de amostras de solo retiradas no ensaio encontram-se no Apêndice 1).

Espaçamento entre linhas: 1,35 m.

Adubação de plantio: $500 \mathrm{~kg}$ por hectare da fórmula 05-25-25.

Controle de ervas daninhas: aplicação de 2,0 litros por hectare de tebuthiuron, $500 \mathrm{~g} / \mathrm{l}$.

Data da colheita da cana planta: 21/07/95.

Adubação de soqueira: 78 kg por hectare de N (via orgânica) e $120 \mathrm{~kg}$ por de $\mathrm{K}_{2} \mathrm{O}$ por hectare (via mineral).

Controle de ervas daninhas na soqueira: 3,0 litros por hectare de ametryne $800 \mathrm{~g} / \mathrm{kg}$ e 3,0 litros por hectare de diuron $800 \mathrm{~g} / \mathrm{kg}$. Data da colheita da cana soca: 16/09/96. 


\subsubsection{Centro de Ciências Agrárias (CCA), Araras}

Data do plantio: 18/03/94

Tipo de solo: vermelho escuro distrófico (as análises físicas e quimicas de amostras de solo retiradas no ensaio encontramse no Apêndice 2).

Espaçamento entre linhas: $1,35 \mathrm{~m}$.

Adubação de plantio: $400 \mathrm{~kg}$ por hectare da fórmula 05-25-25.

Controle de ervas daninhas: aplicação de 2,4 litros por hectare de tebuthiuron, 500g/l.

Data da colheita da cana planta: 19/07/95 .

Adubação de soqueira: 400 kg por hectare da fórmula 14-06-28.

Controle de ervas daninhas na soqueira: o controle do mato foi inicialmente por cultivo mecânico e, no fechamento, por capina manual.

Data da colheita da cana soca: 07/08/96.

\subsubsection{Fazenda São João (FSJ), Jardinópolis}

Data de plantio: 05/04/94. 
Tipo de solo: latossolo roxo distrófico (as análises físicas e químicas de amostras de solo retiradas no ensaio encontramse no Apêndice 3).

Espaçamento entre linhas: 1,35 m .

Adubação de plantio: $516 \mathrm{~kg}$ por hectare da fórmula 00-25-25.

Controle de ervas daninhas: aplicação de 2,4 litros por hectare de tebuthiuron, $500 \mathrm{~g} / 1$.

Data da colheita da cana-planta: 17/08/95.

Adubação de soqueira: 484 kg por hectare da fórmula 18-00-36.

Controle de ervas daninhas na soqueira: fenoxan $500 \mathrm{~g} / \mathrm{l}, 1,5$ I por hectare; hexazinone $142 \mathrm{~g} / \mathrm{kg}$ + diuron $488 \mathrm{~g} / \mathrm{kg}, 1,5 \mathrm{~kg}$ por hectare.

Data da colheita da cana soca: 13/06/96.

3.1.3. Delineamento estatístico - Blocos ao acaso, com três repetições, com arranjo em parcela subdividida para cortes.

3.1.4. Tamanho da parcela: 5 sulcos de $8 \mathrm{~m}$ de comprimento; área útil de $54 \mathrm{~m}^{2}$. 


\subsubsection{Dados pluviométricos}

Os dados pluviométricos (Apêndices 8 e 9) foram obtidos tomando por base os pluviômetros instalados o mais próximo possivel dos ensaios. No CCA, devido ao extravio dos dados do período, utilizou-se informações da Usina Santa Lúcia, distante em linha reta $3 \mathrm{~km}$ do local do ensaio; quanto às duas unidades produtoras, obteve-se a precipitação a partir dos pluviômetros instalados nas próprias fazendas onde se localizavam os ensaios.

\subsection{Curva de maturação}

LOCAL - Centro de Ciências Agrárias.

Data do plantio: $18 / 03 / 94$

Tipo de solo: Latossolo roxo (as análises físicas e químicas de amostras de solo retiradas no ensaio encontram-se no Apêndice 2).

Espaçamento entre linhas: 1,35 m.

Adubação de plantio: 400 kg por hectare da fórmula 05-25-25.

Controle de ervas daninhas: aplicação de 2,4 litros por hectare de tebuthiuron, $500 \mathrm{~g} / 1$.

Adubação de soqueira: 400 kg por hectare da fórmula 14-06-28. 
Variedades (tratamentos) - As dez variedades já citadas anteriormente.

Delineamento - Blocos ao acaso, com três repetições por época.

Tamanho da parcela - Três sulcos de $5 \mathrm{~m}$ de comprimento; área útil de $21 \mathrm{~m}^{2}$.

\subsection{Avaliação de resultados}

\subsubsection{Ensaios de competição}

\subsubsection{Avaliação de falhas de brotação nas parcelas}

Visando caracterizar as variedades, comparando-as inclusive quanto às brotações em cana planta e soca, adotou-se os procedimentos de STOLF et al. (1991). Tais procedimentos constituíram-se na medição com uma trena de $20 \mathrm{~m}$ das falhas maiores que $0,5 \mathrm{~m}$, totalizando-se o número das mesmas. Avaliou-se todas as cinco linhas de plantio de cada parcela.

\subsubsection{Capacidade de brotação de soca}

A partir dos dados de falhas de planta e soca estimou-se o que se chamou de "capacidade de brotação de soca", que é a diferença entre as falhas medidas na planta e as medidas em soca. 


\subsubsection{Perfilhamento}

Visando conhecer o comportamento varietal quanto à capacidade de emissão de perfilhos, foram realizadas contagens do número de perfilhos na linha central de cada parcela, aos 90, 150, 180, 240 e 300 dias após o plantio; a periodicidade dessas leituras foi estipulada baseando-se nos dados obtidos por MACHADO et al. (1982) .

\subsubsection{Avaliação da ferrugem}

Para se caracterizar as variedades quanto à reação à ferrugem foram feitas três leituras em cana-planta. Avaliou-se a folha +3 , seguindo o método de numeração de folhas da cana-de-açúcar estabelecido por Kuijper (Apêndice 4), de cinco perfilhos contíguos na linha central de cada parcela, atribuindo-se notas de 1 a 9 , de acordo com uma escala diagramática (Apêndice 5) desenvolvida por AMORIM (1987).

Datas das leituras:

Fazenda Areia Branca: 08/09/94, 12/12/94, 22/02/95.

Centro de Ciências Agrárias: 05/09/94, 07/12/94, 20/02/95.

Fazenda São João: 18/10/94, 14/12/94, 23/02/95. 


\subsubsection{Altura das plantas}

Para se determinar a altura das plantas mediu-se em canaplanta os colmos com uma régua de $4,0 \mathrm{~m}$, tomando por base a distância do solo até o primeiro "dewlap" visível, ou o colar das plantas ( LONGO \& MATSUOKA, 1984), conforme figura de numeração de falhas de Kuijper no Apêndice 4. De cada parcela utilizou-se dez colmos contíguos das ruas centrais.

\subsubsection{Florescimento e chochamento}

Para a avaliação do florescimento e do chochamento utilizou-se a metodologia desenvolvida pelo Programa de Melhoramento da UFSCar, que atribui notas tanto para o florescimento como para chochamento (PADRONIZAÇÃO, 1994). As figuras explicando o critério de avaliação encontram-se no Apêndices 6 e 7.

\subsubsection{Dados de produção}

Para a obtenção do peso das parcelas, em cana planta e soca pesaram-se os colmos com o uso de uma garra e um dinamômetro, como é rotina nos ensaios de competição de variedades. Para a estimativa do teor de 
sacarose - pol \% cana - foram retiradas dez canas de cada parcela, que representavam as amostras enviadas aos respectivos laboratórios de cada local. As análises laboratoriais nos três locais seguiram o mesmo padrão.

\subsubsection{Curva de Maturação}

Foram colhidas amostras mensais de dez colmos, de abril a novembro, para a avaliação da maturação das variedades. Para cada amostra foi feita medição da pol, já citada, e estes dados foram usados para se obter a curva de maturação característica de cada variedade.

\subsection{Análise estatística}

Para cada uma das variáveis medidas nos ensaios, foram feitas as análises de variância individuais e conjuntas, de acordo com o modelo matemático apresentado por STEEL \& TORRIE (1980) para medidas repetidas no tempo. Estudou-se a adequação dos dados às pressuposições exigidas para realização das análises, adotando-se transformações de dados nos casos pertinentes.

Com objetivo de facilitar a visualização do comportamento das variedades quanto ao conjunto das suas características, efetuou-se uma 
análise de agrupamentos pelo método UPGMA, que é um método não ponderado de agrupamento aos pares usando médias aritméticas (BUSSAB et al., 1990). Tal análise permitiu a confecção de um dendograma com as variedades em estudo, para ilustrar o agrupamento entre elas.

No caso de variáveis medidas apenas em cana-planta, em diferentes épocas, como o perfilhamento, a ferrugem e a altura de planta, o delineamento foi de blocos ao acaso com arranjo fatorial, usado para elaboração das análises (STEEL \& TORRIE, 1980). 


\title{
4. RESULTADOS E DISCUSSÃO
}

\subsection{Ensaios de competição}

\subsubsection{Avaliação de falhas de brotação de cana-planta e soca}

\begin{abstract}
A avaliação das falhas, nos três locais, individualmente, e em conjunto (Tabelas $1,2,3,4$ ) traduziu o perfil dessas variedades quanto à brotação em planta e soca. Os resultados obtidos são coerentes com que se depara a nivel de campo, tomando-se por base, principalmente, o comportamento apresentado pelas variedades mais contemporâneas, ainda cultivadas a nivel comercial, como a RB72454 e a SP70-1143.

Deve-se esclarecer que face às deficiências de brotação observadas em cana-planta, seria possivel corrigir os resultados de produção baseando-se no trabalho de STOLF et al. (1991). Não se procedeu a tal correção por considerar-se que a deficiência na brotação em planta e soca, embora influenciada pelo ambiente - condições do solo, umidade e temperatura - é uma característica própria de cada variedade. A brotação de soca é uma das características de maior importância a ser analisada na seleção de variedades. Segundo os valores encontrados pelos autores anteriormente
\end{abstract}


TABELA 1 - Médias das falhas em metros lineares na Fazenda Areia Branca, em cana-planta e cana-soca - dados transformados por $\sqrt{x+0,5}$.

\begin{tabular}{lll}
\hline Variedade & Cana-planta & Cana-soca \\
\hline SP71-6163 & $0,66 \mathrm{a}, \mathrm{b}$ & $3,39 \mathrm{a}$ \\
Co419 & $0,53 \mathrm{a}, \mathrm{b}$ & $2,34 \mathrm{~b}$ \\
Co290 & $0,27 \mathrm{a}, \mathrm{b}$ & $2,31 \mathrm{~b}$ \\
SP71-1406 & $0,00 \mathrm{~b}$ & $2,08 \mathrm{~b}, \mathrm{c}$ \\
RB72454 & $0,35 \mathrm{a}, \mathrm{b}$ & $1,87 \mathrm{~b}, \mathrm{c}$ \\
NA56-79 & $0,53 \mathrm{a}, \mathrm{b}$ & $1,54 \mathrm{~b}, \mathrm{c}$ \\
CB41-76 & $0,79 \mathrm{a}, \mathrm{b}$ & $1,43 \mathrm{c}, \mathrm{d}$ \\
IAC48-65 & $0,67 \mathrm{a}, \mathrm{b}$ & $1,43 \mathrm{c}, \mathrm{d}$ \\
RB835089 & $0,98 \mathrm{a}$ & $1,38 \mathrm{c}, \mathrm{d}$ \\
SP70-1143 & $0,42 \mathrm{a}, \mathrm{b}$ & $0,62 \mathrm{~d}$ \\
\hline Médias & 0,52 & 1,84 \\
\hline
\end{tabular}

Médias seguidas pela mesma letra não diferem estatisticamente pelo teste de Duncan ao nível de $5 \%$. 
TABELA 2 - Médias das falhas, em metros lineares, no Centro de Ciências Agrárias, em cana-planta e cana-soca - dados transformados por $\sqrt{x+0,5}$.

\begin{tabular}{lll}
\hline Variedade & Cana-planta & Cana-soca \\
\hline SP71-6163 & $1,80 \mathrm{c}, \mathrm{d}$ & $3,67 \mathrm{a}$ \\
Co419 & $2,80 \mathrm{a}$ & $3,56 \mathrm{a}$ \\
Co290 & $2,26 \mathrm{a}, \mathrm{b}$ & $2,45 \mathrm{~b}$ \\
SP71-1406 & $1,16 \mathrm{a}$ & $2,37 \mathrm{~b}$ \\
RB72454 & $2,40 \mathrm{a}, \mathrm{b}$ & $2,31 \mathrm{~b}$ \\
RB835089 & $1,89 \mathrm{~b}, \mathrm{a}$ & $2,16 \mathrm{~b}$ \\
CB41-76 & $1,89 \mathrm{~b}, \mathrm{c}$ & $2,08 \mathrm{~b}$ \\
NA56-79 & $1,44 \mathrm{c}, \mathrm{d}, \mathrm{e}$ & $1,76 \mathrm{~b}$ \\
IAC48-65 & $0,98 \mathrm{e}$ & $1,65 \mathrm{~b}$ \\
SP70-1143 & $0,99 \mathrm{e}$ & $0,74 \mathrm{c}$ \\
\hline Médias & 1,76 & 2,27 \\
\hline
\end{tabular}

Médias seguidas pela mesma letra não diferem estatisticamente pelo teste de Duncan ao nível de 5\%. 
TABELA 3 - Médias das falhas, em metros lineares, na Fazenda São João, em cana-planta e cana-soca - dados transformados por $\sqrt{\mathrm{x}+0,5}$.

\begin{tabular}{lll}
\hline Variedade & Cana-planta & Cana-soca \\
\hline Co419 & $1,98 \mathrm{a}, \mathrm{b}$ & $3,55 \mathrm{a}$ \\
SP71-6163 & $2,04 \mathrm{a}, \mathrm{b}$ & $2,80 \mathrm{a}, \mathrm{b}$ \\
RB72454 & $1,50 \mathrm{a}, \mathrm{b}$ & $2,72 \mathrm{a}, \mathrm{b}$ \\
SP71-1406 & $1,71 \mathrm{a}, \mathrm{b}$ & $2,69 \mathrm{a}, \mathrm{b}$ \\
RB835089 & $1,99 \mathrm{a}, \mathrm{b}$ & $2,65 \mathrm{a}, \mathrm{b}$ \\
SP70-1143 & $2,64 \mathrm{a}$ & $2,38 \mathrm{~b}, \mathrm{c}$ \\
Co290 & $1,39 \mathrm{a}, \mathrm{b}$ & $2,22 \mathrm{~b}, \mathrm{c}$ \\
CB41-76 & $1,09 \mathrm{~b}$ & $2,14 \mathrm{~b}, \mathrm{c}$ \\
IAC48-65 & $1,54 \mathrm{a}, \mathrm{b}$ & $1,69 \mathrm{~b}, \mathrm{c}$ \\
NA56-79 & $1,32 \mathrm{a}, \mathrm{b}$ & $1,35 \mathrm{c}$ \\
\hline Médias & 1,72 & $2,42 \mathrm{C}$ \\
\hline
\end{tabular}

Médias seguidas pela mesma letra não diferem estatisticamente pelo teste de Duncan ao nivel de 5\%. 
TABELA 4- Médias das falhas em dois cortes (metros lineares), nos três locais, dados transformados por $\sqrt{x+0,5}$.

\begin{tabular}{|c|c|c|c|c|c|c|c|}
\hline Variedade & FAB & & CCA & & FSJ & & Média/Variedade \\
\hline Co419 & 1,29 & $a, b$ & 3,18 & $a$ & 2,77 & $a$ & $2,46 a$ \\
\hline SP71-6163 & 2,02 & a & 2,73 & $a, b$ & 2,42 & $a, b, c$ & $2,39 a$ \\
\hline RB72454 & 1,11 & $b, c$ & 2,36 & $b, c$ & 2,11 & $a, b, c$ & $1,86 b$ \\
\hline RB835089 & 1,18 & $b, c$ & 2,02 & c. $d$ & 2,32 & $a, b, c$ & $1,84 b$ \\
\hline Co290 & 1,29 & $b$ & 1,81 & $b, c$ & 1,81 & $a, b, c$ & $1,82 b$ \\
\hline SP71-1406 & 1,04 & $b, c$ & 1,76 & $c, d, e$ & 2,20 & $a, b, c$ & $1,67 b, c$ \\
\hline CB41-76 & 1,11 & $b, c$ & 1,98 & $c, d$ & 1,62 & $b, c$ & $1,57 b, c$ \\
\hline IAC48-65 & 1,05 & $b, c$ & 1,32 & $e, f$ & 1,62 & $b, c$ & $1,33 \mathrm{c}$ \\
\hline NA56-79 & 1,04 & $b, c$ & 1,60 & $d, e$ & 1,34 & a & $1,32 \mathrm{c}$ \\
\hline SP70-1143 & 0,52 & c & 0,87 & $f$ & 2,51 & a & $1,30 \mathrm{c}$ \\
\hline $\begin{array}{l}\text { Médias/ } \\
\text { Locais }\end{array}$ & 1,17 & B & 2,02 & A & 2,07 & A & 1,76 \\
\hline
\end{tabular}

Médias seguidas pela mesma letra para variedades na vertical e para locais na horizontal, não diferem estatisticamente pelo teste de Duncan ao nível de $5 \%$. 
citados, atribui-se para falhas de $20 \%$ perdas de $6,4 \mathrm{t}$ por hectare, em canaviais de rendimento de 100 t/hectare.

Constatou-se diferenças significativas entre os locais, variedades, cortes e as interações entre locais e variedades, para o número de falhas (Tabela 5). Quanto aos locais, na FAB as falhas foram menos intensas (Apêndice 10), diferindo estatisticamente dos outros dois locais; onde as falhas ocorreram com maior intensidade, e não diferiram entre si (Tabela 4 e Apêndices 11 e 12).

Quanto à cana-planta, a melhor condição para a brotação na Fazenda Areia Branca deveu-se, provavelmente, à precipitação pluviométrica mais favorável após o plantio, comparada com os outros dois locais (Apêndice 8). As características físicas do solo na FAB, conforme Apêndice 3, também pareceram ser mais favoráveis à brotação inicial das gemas no plantio, pois a maior participação de areia e menor quantidade de argila nas camadas superficiais tornam menos favoráveis as condições para a formação de torrões. Os torrões prejudicam a brotação inicial das gemas, pois provocam a formação de bolsões de ar; ocorrem em solos mais argilosos como os do CCA (Apêndice 1) e prejudicam a germinação.

Quanto às variedades, na Tabela 4, estão as médias gerais das falhas em planta e soca, e por variedade e local. As que apresentaram piores 
Tabela 5 - Análise de variância conjunta entre os locais para Falhas, Peso, Pol e TPP.

\begin{tabular}{|c|c|c|c|c|c|}
\hline \multirow[b]{2}{*}{ F.V. } & \multirow[b]{2}{*}{ G.L } & \multicolumn{4}{|c|}{ Q. M. } \\
\hline & & Falhas & Peso & Pol & TPP \\
\hline Locais & 2 & $14,9926^{\star \star}$ & $87.271,0389^{\star \star}$ & $56,4154^{\star \star}$ & $5.642,7665^{\star \star}$ \\
\hline Locais x Rep & 6 & 0,5222 & $11.492,7611$ & 0,3667 & 282,4781 \\
\hline Var. & 9 & $3,0823^{\star \star}$ & $215.704,7562^{\star \star}$ & $7,3885^{\star \star}$ & $5.437,1580^{\star \star}$ \\
\hline Locais $\times$ Var. & 18 & $0,9017^{\star \star}$ & $17.365,1006^{\star \star}$ & $1,9250^{\star \star}$ & $646,0772^{\star \star}$ \\
\hline $\begin{array}{l}\text { Locais } x \text { Var } x \\
\text { Rep.(Residuo A) }\end{array}$ & 54 & 0,3757 & $5.398,5265$ & 0,4407 & 125,8877 \\
\hline Corte & 1 & $32,0929^{\star \star}$ & $811.373,4722^{\star *}$ & $36,0372^{\star \star}$ & $26.036,7183^{\star \star}$ \\
\hline Locais $\times$ corte & 2 & 2,6906 & $71.604,5389$ & 71,2895 & $3.662,6354$ \\
\hline $\begin{array}{l}\text { Locais } \times \text { Rep } \\
\times \text { Corte } \\
\text { Var. } \times \text { Corte }\end{array}$ & $\begin{array}{l}6 \\
9\end{array}$ & $\begin{array}{l}0,2641 \\
1,4590\end{array}$ & $2.436,2833$ & 0,4481 & 92,2971 \\
\hline $\begin{array}{l}\text { Locais x Var. } \\
\text { x Corte } \\
\text { Resíduo B }\end{array}$ & $\begin{array}{l}18 \\
54\end{array}$ & 0,3498 & $10.865,0080$ & 0,6921 & 299,5642 \\
\hline Média & & 1,76 & 569,31 & 14,63 & 84,05 \\
\hline C.V. \% & & 22,96 & 8,81 & 3,76 & 8,96 \\
\hline
\end{tabular}

** significativo ao nível de $1 \%$, pelo teste $\mathrm{F}$.

Falhas $=$ dados transformados por $\sqrt{\mathrm{x}+0,5}$.

TPP $=$ peso de pol por parcela 
resultados foram Co419 e SP71-6163, e as que melhor brotaram foram SP701143, NA56-79 e IAC48-65. As demais, com resultados intermediários, apresentaram pequenas diferenças entre si.

A variedade SP71-6163, nos três locais, teve desenvolvimento lento, principalmente nas socas, retardando o fechamento o que favoreceu a infestação de plantas daninhas nas parcelas prejudicando por competição a brotação das socas.

Quanto à interferência de precipitações na brotação de soca (Apêndice 9) os efeitos foram semelhantes no CCA e na FAB face as chuvas que antecederam o corte. Na FSJ, por outro lado, a precipitação que antecedeu ao corte e a do próprio período de junho-setembro/95, foram inferiores às dos outros dois locais.

\subsubsection{Capacidade de brotação de soca}

Na capacidade de brotação de soca analisou-se o aumento das falhas de cana-planta para cana-soca, isolando os efeitos da brotação em cana-planta. Conforme os dados apresentados na Tabela 6, destacou-se como melhor variedade a SP70-1143, que se sobressaiu perante as demais; a nivel de lavoura comercial, quando em condições drásticas para brotação de soca, nota-se semelhante diferenciação. 
Tabela 6 - Capacidade de brotação de cana-soca medida pela diferença de falhas na soca e na cana-planta em metros nos três locais e a média dos locais; das transformadas por $\sqrt{x+0,5}$.

\begin{tabular}{lcccc}
\hline & \multicolumn{3}{c}{ Locais } & \\
\cline { 2 - 3 } Variedades & FAB & CCA & FSJ & MÉDIA \\
\hline SP70-1143 & 0,20 & $-0,25$ & $-0,26$ & $-0,10$ \\
RB835089 & 0,40 & 0,27 & 0,66 & 0,44 \\
NA56-79 & 1,01 & 0,32 & 0,03 & 0,45 \\
IAC48-65 & 0,76 & 0,67 & 0,15 & 0,53 \\
CB41-76 & 0,64 & 0,19 & 1,05 & 0,63 \\
RB72454 & 1,52 & $-0,11$ & 1,22 & 0,88 \\
Co290 & 2,04 & 0,19 & 0,83 & 1,02 \\
SP71-1406 & 2,08 & 1,21 & 0,98 & 1,42 \\
Co419 & 1,81 & 0,76 & 1,57 & 1,38 \\
SP71-6163 & 2,73 & 1,87 & 0,76 & 1,79 \\
\hline Médias/Locais & 1,32 & 0,51 & 0,70 & 0,84 \\
\hline
\end{tabular}

Médias seguidas pela mesma letra não diferem estatisticamente pelo teste de Duncan. 
No grupo das piores variedades nesta análise estão: SP711406, Co419 e SP71-6163. Com o passar dos cortes acredita-se que essas variedades venham a se distanciar ainda mais negativamente em relação às demais.

\subsubsection{Perfilhamento}

O comportamento das variedades de cana-de-açúcar quanto a intensidade de emissão de perfilhos é bem conhecido; os dados obtidos são semelhantes aos obtidos por MACHADO et al. (1982) e ROCHA (1984); o acompanhamento do perfilhamento no presente trabalho teve por finalidade conhecer especificamente as variedades estudadas para esse caráter, uma vez que não se dispõem desses dados para as variedades mais antigas, como a Co290 e a Co419.

A análise de variância para perfilhamento entre os locais, Tabela 7, evidencia as diferenças entre locais, variedades, datas de leituras e interações entre locais e variedades, locais e dados de leituras e interação entre variedades e datas de leitura. Os três locais diferiram entre si, tendo o perfilhamento médio sido em $8,0 \mathrm{~m}$ de sulcos 142,83 na FAB, 115,85 na FSJ e 109,17 no CCA.

Na Figura 1 visualiza-se o crescimento intenso na emissão dos perfilhos a partir dos noventa dias do plantio, atingindo um pico aos 180 dias; 
TABELA 7 - Análise de variância conjunta entre locais, para perfilhamento em cana-planta.

\begin{tabular}{lcc}
\hline F.V. & G.L. & Q.M. \\
\hline Locais & 2 & $47.618,25^{\star \star}$ \\
Locais x Rep. & 6 & $1.740,69$ \\
Var. & 9 & $6.328,02^{\star \star}$ \\
Locais x Var. & 18 & $2.022,43^{\star \star}$ \\
Dias & 4 & $30.342,08^{\star \star}$ \\
Locais x Dias & 8 & $3.408,07$ \\
Var. x Dias & 36 & $651,56^{\star \star}$ \\
Locais x Var. x Dias & 72 & 235,51 \\
Residuo & 294 & 265,02 \\
\hline Total & 449 & 122,62 \\
Média & & 13,28 \\
C.V. & & \\
\hline
\end{tabular}

** = significativo ao nível de $1 \%$ pelo teste $\mathrm{F}$.

Dias $=$ datas das leituras. 


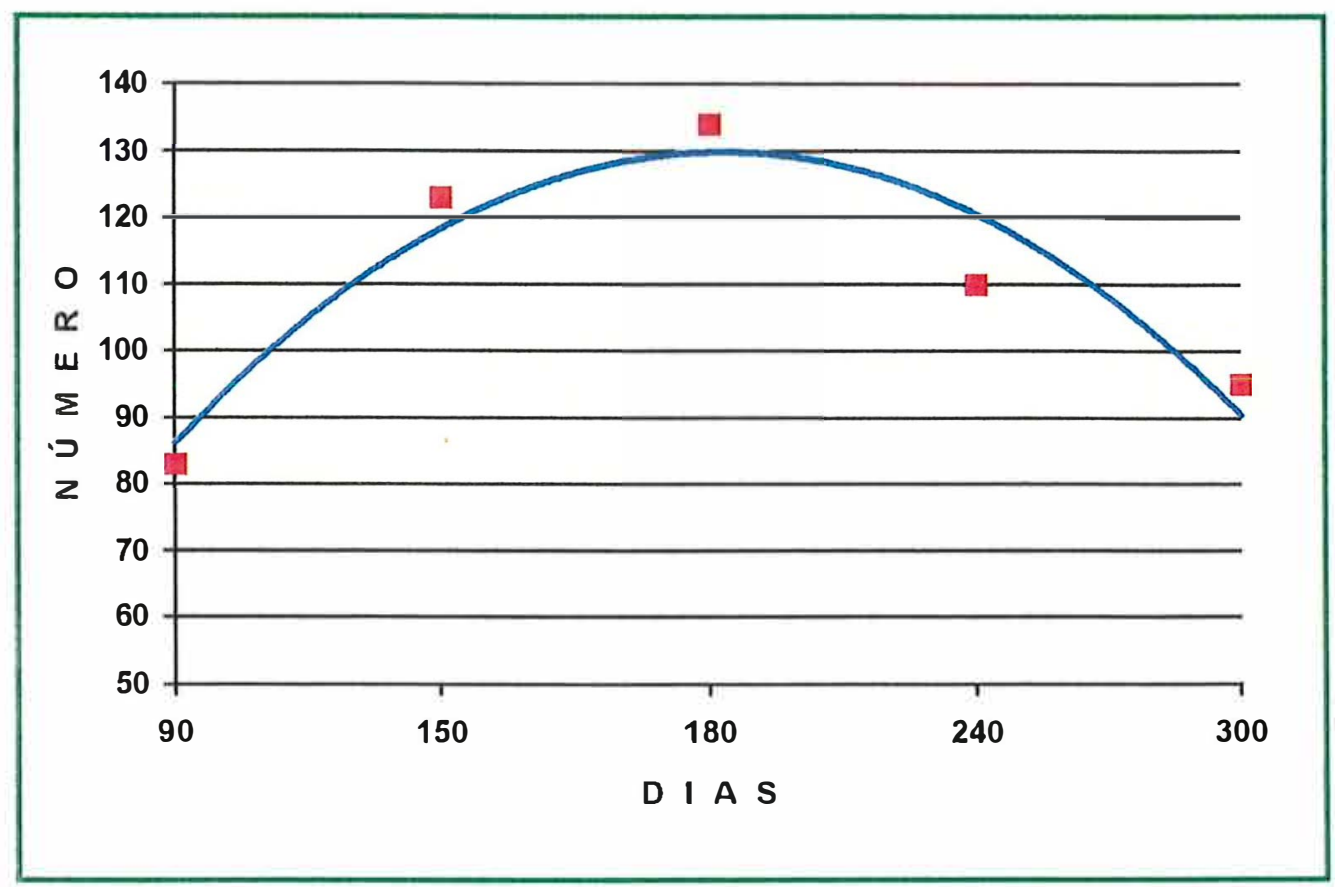

FIG. 1 - Curva de emissão de perfilhos, dados médios dos três locais em cana-planta, para a média das dez variedades. 
após esse periodo observou-se uma queda acentuada até os 240 dias. O número de perfilhos permaneceu decrescendo até 300 dias. Os dados originais dos três locais encontram-se nos Apêndices 13,14 e 15. Comparando-se o pico de perfilhamento obtido no trabalho com outros dados de literatura, verifica-se que o mesmo foi retardado em função do plantio mais tardio, março/abril, e da ocorrência subsequente de seca prolongada após o plantio (Apêndice 8).

Nota-se, pelos dados médios na Tabela 8 que as variedades se diferenciaram para perfilhamento: SP70-1143 foi a de maior perfilhamento.

\subsubsection{Avaliação de ferrugem}

A avaliação da intensidade de ferrugem teve por finalidade principal caracterizar a reação das variedades à doença. Conforme MATSUOKA et al. (1994), os resultados das leituras permitem uma melhor interpretação dos resultados de produção.

A análise de variância para ferrugem (Tabela 9), demonstra diferenças para locais, variedades e datas de leitura, além das interações entre locais e variedades, locais e datas de leituras, variedades e datas de leituras, e entre locais, variedades e datas de leituras. Deste modo, esta variável é específica para cada condição. 
TABELA 8-Médias do número de perfilhos, nas cinco leituras, nos três locais, em cana-planta.

\begin{tabular}{lc}
\hline Variedade & Número de Perfilhos \\
\hline SP70-1143 & $137,80 \mathrm{a}$ \\
RB835089 & $119,53 \mathrm{~b}$ \\
RB72454 & $113,67 \mathrm{~b}, \mathrm{c}$ \\
NA56-79 & $111,93 \mathrm{~b}, \mathrm{c}$ \\
SP71-6163 & $109,33 \mathrm{~b}, \mathrm{c}$ \\
CB41-76 & $107,87 \mathrm{c}$ \\
Co290 & $106,53 \mathrm{c}$ \\
IAC48-65 & $103,27 \mathrm{c}, \mathrm{d}$ \\
Co419 & $93,20 \mathrm{~d}, \mathrm{e}$ \\
SP71-1406 & $88,60 \mathrm{e}$ \\
\hline Média & 109,17 \\
\hline
\end{tabular}

*Avaliação nos 8 metros das linhas centrais das parcelas.

Médias seguidas pela mesma letra não diferem estatisticamente pelo teste de Dunca ao nível de $5 \%$. 
TABELA 9 - Análise de variância conjunta entre os locais para ferrugem em cana-planta.

\begin{tabular}{lcc}
\hline F.V. & G.L. & Q.M. \\
\hline Locais & 2 & $46,8046^{\star \star}$ \\
Locais x Rep. & 6 & 0,1707 \\
Var. & 9 & $16,5992^{\star \star}$ \\
Locais x Var. & 18 & $1,9827^{\star \star}$ \\
Data & 2 & $17,1113^{\star \star}$ \\
Locais x Data & 4 & $11,1490^{\star \star}$ \\
Var. x Data & 18 & $1,2726^{\star \star}$ \\
Locais x Var. x Data & 36 & $1,03085^{\star \star}$ \\
Residuo & 174 & 0,0936 \\
\hline Média & & 2,03 \\
C.V. & & 15,05 \\
\hline
\end{tabular}

${ }^{\star *}=$ significativo ao nível de $1 \%$ pelo teste $\mathrm{F}$. 
TABELA 10 - Notas médias das três leituras de sintomas de ferrugem em canaplanta em cada local e média geral.

\begin{tabular}{|c|c|c|c|c|c|c|c|c|}
\hline \multirow{3}{*}{$\begin{array}{l}\text { Variedade } \\
\text { NA56-79 }\end{array}$} & \multicolumn{6}{|c|}{ Média nos locais } & \multirow{2}{*}{\multicolumn{2}{|c|}{ Média Geral }} \\
\hline & \multicolumn{2}{|l|}{ FAB } & \multicolumn{2}{|c|}{ CCA } & \multicolumn{2}{|l|}{ FSJ } & & \\
\hline & 4,44 & a & 2,60 & $a$ & 2,18 & $a$ & 3,07 & $a$ \\
\hline SP70-1143 & 4,31 & a & 2,51 & a & 1,89 & $b$ & 2,90 & $b$ \\
\hline SP71-1406 & 4,31 & a & 2,18 & b & 1,89 & b & 2,79 & b \\
\hline SP71-6163 & 3,64 & $b$ & 2,36 & $a, b$ & 1,78 & $b$ & 2,59 & c \\
\hline IAC48-65 & 3,00 & c & 1,71 & c & 1,73 & b & 2,15 & d \\
\hline Co290 & 2,42 & $d$ & 1,69 & c & 1,33 & c & 1,81 & e \\
\hline CB41-76 & 2,56 & d & 1,27 & $d$ & 1,31 & c & 1,71 & e \\
\hline Co419 & 1,40 & e & 1,00 & $d$ & 1,00 & $d$ & 1,13 & $f$ \\
\hline RB835089 & 1,33 & e & 1,00 & $d$ & 1,00 & $d$ & 1,11 & $f$ \\
\hline RB72454 & 1,13 & e & 1,00 & $d$ & 1,00 & $d$ & 1,04 & $f$ \\
\hline Médias & 2,85 & C & 1,73 & $A$ & 1,51 & $B$ & 2,03 & \\
\hline
\end{tabular}

Médias seguidas pela mesma letra, para variedades na vertical e para locais na horizontal, não diferem estatisticamente pelo teste de Duncan ao nível de 5\%. 
Quanto aos três locais (Tabela 10), constatou-se diferenças significativas na incidência de ferrugem: ela foi maior na $F A B$ seguida pelo CCA e, finalmente, pela FSJ. Essas diferenças quanto aos locais, traz a comprovação do que se observa nas graduações para a ferrugem nos ensaios de campo: a incidência de ferrugem é maior em regiões de clima mais ameno e úmido, como a de Piracicaba, e menores em climas mais quentes, como a de Ribeirão Preto. Observou-se, também, uma flutuação na severidade de sintomas ao longo das leituras (Apêndices 16,17 e 18). No CCA os sintomas foram mais intensos na primeira leitura de 05/09/94, regredindo em 07/12/94, e novamente se acentuando, embora de forma mais branda, na leitura de 20/02/95. Na FAB, onde as notas dos sintomas foram mais elevadas, observouse também a mesma flutuação de sintomas. Quanto à FSJ não se constatou sintomas na primeira leitura feita em 18/10/94; apareceram alguns sintomas na leitura de 14/12/94, e somente na última, em 23/02/95, os sintomas se intensificaram. Os dados de leitura de sintomas obtidos evidenciam que há uma interação entre o agente causal e as condições climáticas, sendo condições favoráveis as temperaturas amenas e elevada umidade no ar (MATSUOKA et al., 1994).

Quanto às variedades, na Tabela 10 encontra-se a média geral das notas nos três locais. As variedades Co419, RB72454, RB835089 se mostraram como altamente resistentes, tendo apresentado sintomas leves 
somente na USB, onde as condições para a manifestação da doença foram mais favoráveis. Os sintomas mais intensos, ocorreram em ordem decrescente, nas seguintes variedades: NA56-79, SP70-1143, SP71-1406 e SP71-6163. As variedades restantes CB41-76, C0290, IAC48-65, se comportaram de forma intermediária (Tabela 10). Como as variedades RB72454 e RB835089 são as de liberação mais recente, percebe-se que tal resistência deve ser importante nas variedades modernas.

\subsubsection{Altura dos colmos}

Como parte das variedades estudadas já não é cultivada comercialmente, optou-se por mensurar a altura dos colmos para caracterizar o material e proporcionar aos leitores uma idéia do porte das variedades. Os dados originais referentes a esse parâmetro encontram-se nos Apêndices 19, 20 e 21. De posse destes dados foi possível também comparar as variedades entre si. A análise de variância para altura dos colmos encontra-se na Tabela 11; houve diferenças para locais, datas de leitura e as interações entre locais e variedades e entre locais e datas de leitura. Porém, como a interação entre locais, variedades e dias não foi significativa, apenas uma leitura, aos 300 dias ou na colheita para esta variável, é suficiente para comparar as variedades.

Os colmos foram mais altos, em ordem crescente, respectivamente no CCA, FSJ e FAB; as diferenças foram significativas entre 
TABELA 11 - Análise de variância entre os locais, para altura dos colmos em cana-planta.

\begin{tabular}{lcc}
\hline F.V. & G.L. & Q.M. \\
\hline Locais & 2 & $44.902,64^{\star \star}$ \\
Locais $\times$ Rep. & 6 & 232,37 \\
Var. & 9 & $9.204,34^{\star \star}$ \\
Locais x Var. & 18 & $266,25^{\star}$ \\
Dias & 1 & $252.885,06^{\star \star}$ \\
Locais x Dias & 2 & $1.334,11^{\star \star}$ \\
Var. $\times$ Dias & 9 & 241,40 \\
Locais x Var. x Dias & 18 & 126,37 \\
Resíduo & 114 & 156,39 \\
\hline Média & & 259,26 \\
C.V. & & 4,82 \\
\hline
\end{tabular}

${ }^{*},{ }^{\star \star}=$ significado a $5 \%$ e $1 \%$, respectivamente. 
os locais (Tabela 12).

Quanto às variedades, o posicionamento relativo foi muito próximo na FAB no CCA. Na FSJ, por outro lado, as variedades NA56-79 e SP71-1406 estiveram melhor posicionadas em comparação às demais; acredita-se que isso tenha ocorrido face à menor incidência de ferrugem nessa usina (Tabela 10), o que não deprimiu a produtividade das duas variedades citadas.

\subsubsection{Florescimento e chochamento}

A avaliação da intensidade de florescimento e chochamento teve por finalidade caracterizar as variedades estudadas para essas características depreciativas.

A partir dos dados dos Apêndices 22, 23 e 24 constatou-se que em cana-planta a única variedade que floresceu foi a IAC48-65; essa variedade é bastante florifera, sendo esse o seu principal defeito, juntamente com 0 chochamento intenso. Quanto ao chochamento, isoladamente, além da IAC4865, mostrou essa característica a variedade SP70-1143 nos três locais. As variedades NA56-79 e RB835089 apresentaram chochamento, em apenas um local, respectivamente na FAB e FSJ.

Em cana soca ocorreu florescimento e chochamento mais 
TABELA 12 - Altura média dos colmos, em cm, das duas leituras - 300 dias e colheita - em cana-planta, nos três locais, individualmente, e média geral em cana-planta.

\begin{tabular}{|c|c|c|c|c|c|c|c|c|}
\hline \multirow{3}{*}{$\begin{array}{l}\text { Variedade } \\
\text { RB835089 }\end{array}$} & \multicolumn{6}{|c|}{ Média nos locais } & \multirow{2}{*}{\multicolumn{2}{|c|}{ Média Geral }} \\
\hline & \multicolumn{2}{|l|}{ FAB } & \multicolumn{2}{|l|}{ CCA } & \multicolumn{2}{|l|}{ FSJ } & & \\
\hline & 272,62 & $a$ & 327,90 & $a$ & 269,42 & $a$ & 289,98 & $\bar{a}$ \\
\hline RB72454 & 254,95 & $b$ & 311,30 & $a$ & 258,28 & $a, b, c$ & 274,84 & $b$ \\
\hline NA56-79 & 249,18 & $b, c$ & 310,68 & $a$ & 264,27 & $a, b, c$ & 274,71 & $b$ \\
\hline IAC48-65 & 247,78 & $b, c$ & 312,62 & a & 250,18 & $b, c, d$ & 270,19 & $b, c$ \\
\hline SP71-1406 & 240,13 & $c, d$ & 290,83 & $b$ & 262,88 & $a, b$ & 264,62 & $c, d$ \\
\hline CB41-76 & 247,07 & $b, c$ & 292,53 & $b$ & 251,43 & $b, c, d$ & 263,68 & $c, d$ \\
\hline SP70-1143 & 241,32 & $c, d$ & 285,47 & $b$ & 243,52 & $c, d$ & 256,77 & $d, e$ \\
\hline Co290 & 234,47 & $d$ & 279,35 & $b, c$ & 242,02 & $d$ & 251,94 & e \\
\hline Co419 & 218,67 & $e$ & 262,45 & c & 224,85 & e & 235,32 & $f$ \\
\hline SP71-6163 & 199,05 & $f$ & 233,37 & $d$ & 119,12 & $f$ & 210,51 & $g$ \\
\hline Médias & 240,52 & $C$ & 290,65 & $\bar{A}$ & 246,60 & B & 259,26 & \\
\hline
\end{tabular}

Médias seguidas pela mesma letra, para variedades na vertical e para locais na horizontal, não diferem estatisticamente pelo tese de Duncan ao nível de 5\%. 
intensamente; apresentaram essas características além da IAC48-65, as variedades Co290, NA56-79, RB835089 e SP70-1143. A variedade RB72454 apresentou apenas uma diferenciação flora, e ainda somente no CCA.

As variedades SP71-1406 e SP71-6163 não floresceram e não apresentaram chochamento.

\subsubsection{Dados de produção}

A análise de variância conjunta para dados de produção encontra-se na Tabela 5. Os dados ligados diretamente à produção são: peso, pol, e a resultante das duas variáveis, o peso de pol por parcela. Ocorreram diferenças estatísticas para todos esses componentes de produção; entre os locais, variedades e cortes, e ainda nas interações entre locais e variedades, e variedades e cortes, exceto para pol. A seguir serão discutidas cada uma das variáveis; os valores de peso por parcela foram transformados para toneladas de colmos por hectare (TCH), e os de peso de pol por parcela (TPP) para toneladas de pol por hectare (TPH). Os dados originais de produção, peso, pol e peso de pol por parcela dos três locais, encontram-se nos Apêndices 26, 27 e 28. 


\subsubsection{Dados de toneladas de colmos por hectare (TCH).}

A maior produção de colmos, de 111,32 (TCH) como média de cana-planta e soca (Tabelas $13,14,15$ ) ocorreu na FAB, enquanto no CCA e FSJ foram de 107,36 (TCH) e 97,60 (TCH), respectivamente. Tal produção na FAB pode ter sido favorecida pelas precipitações mais regulares (Apêndice 9) e pelo bom controle de plantas daninhas durante todo o ciclo. O perfilhamento das plantas na FAB (Tabela 8) também foi mais intenso, tendo proporcionado uma população de colmos mais elevada; sabe-se que na cultura da cana-deaçúcar o componente "número de colmos" influencia diretamente a produção (SKINNER et al., 1987). Considerando-se ainda que na FAB a incidência de ferrugem foi maior que nos outros locais (Tabela 10), poder-se-ia esperar, provavelmente, caso a incidência da doença fosse a mesma nos três locais, um diferencial favorável ainda maior para esse local.

Quanto às variedades, o posicionamento relativo entre elas foi semelhante nos três locais. As duas mais produtivas, RB835089 e RB72454, tiveram o mesmo comportamento nos três locais, enquanto que a menos produtiva foi a SP71-6163 (Tabelas 13, 14, 15 e 16). A variedade SP70-1143, apesar de ter sido a segunda mais suscetível à ferrugem (Tabela 10) foi, na média dos locais a terceira mais produtiva (Tabela 16), apresentando certa regularidade de produção. Quanto às demais, foi possível constatar que a 
Tabela 13 - Dados de toneladas de colmos por hectare (TCH) na Fazenda Areia Branca.

\begin{tabular}{llll}
\hline & Colheita cana- & Colheita cana- & \\
Variedade & planta: 21/07/95 & soca: 16/09/96 & Média \\
\hline RB835089 & $148,15 \mathrm{a}$ & $162,03 \mathrm{a}$ & $155,09 \mathrm{a}$ \\
RB72454 & $154,69 \mathrm{a}$ & $135,49 \mathrm{~b}$ & $145,09 \mathrm{a}$ \\
Co419 & $130,00 \mathrm{~b}$ & $113,15 \mathrm{~b}, \mathrm{c}, \mathrm{d}$ & $121,57 \mathrm{~b}$ \\
C0290 & $120,31 \mathrm{~b}, \mathrm{c}$ & $121,60 \mathrm{~b}, \mathrm{c}$ & $120,96 \mathrm{~b}$ \\
SP70-1143 & $115,68 \mathrm{c}, \mathrm{d}$ & $121,30 \mathrm{~b}, \mathrm{c}$ & $118,49 \mathrm{~b}, \mathrm{c}$ \\
CB41-76 & $107,53 \mathrm{c}, \mathrm{d}, \mathrm{e}$ & $101,85 \mathrm{c}, \mathrm{d}$ & $104,69 \mathrm{c}, \mathrm{d}$ \\
IAC48-65 & $106,98 \mathrm{~d}, \mathrm{e}$ & $93,21 \mathrm{~d}, \mathrm{e}$ & $100,09 \mathrm{~d}$ \\
NA56-79 & $94,75 \mathrm{e}, \mathrm{f}$ & $89,81 \mathrm{~d}, \mathrm{e}$ & $92,28 \mathrm{~d}$ \\
SP71-1406 & $100,06 \mathrm{e}, \mathrm{f}$ & $76,23 \mathrm{e}$ & $88,15 \mathrm{~d}$ \\
SP71-6163 & $90,37 \mathrm{~b}$ & $43,21 \mathrm{~b}$ & $66,79 \mathrm{e}$ \\
\hline Médias & 116,85 & 105,79 & 111,32 \\
\hline
\end{tabular}

Médias seguidas pela mesma letra não diferem estatisticamente pelo teste de Duncan ao nível de $5 \%$. 
Tabela 14 - Dados de toneladas de colmos por hectare (TCH) no Centro de Ciências Agrárias.

\begin{tabular}{llll}
\hline & Colheita cana- & Colheita cana- & \\
Variedade & planta: 19/07/95 & soca: 07/08/96 & Média \\
\hline RB835089 & $143,58 \mathrm{a}, \mathrm{b}$ & $141,98 \mathrm{a}$ & $142,78 \mathrm{a}$ \\
RB72454 & $154,51 \mathrm{a}$ & $125,31 \mathrm{~b}$ & $139,91 \mathrm{a}$ \\
SP70-1143 & $123,02 \mathrm{~b}, \mathrm{c}, \mathrm{d}$ & $120,37 \mathrm{~b}$ & $121,70 \mathrm{~b}$ \\
C0290 & $121,48 \mathrm{~b}, \mathrm{c}, \mathrm{d}$ & $110,80 \mathrm{~b}$ & $116,14 \mathrm{~b}, \mathrm{c}$ \\
CB41-76 & $126,98 \mathrm{~b}, \mathrm{c}$ & $83,95 \mathrm{c}$ & $105,46 \mathrm{~b}, \mathrm{c}, \mathrm{d}$ \\
NA56-79 & $116,24 \mathrm{~b}, \mathrm{c}, \mathrm{d}$ & $85,19 \mathrm{c}$ & $100,71 \mathrm{c}, \mathrm{d}$ \\
SP71-1406 & $137,22 \mathrm{a}, \mathrm{b}, \mathrm{c}$ & $54,94 \mathrm{~d}$ & $96,08 \mathrm{~d}$ \\
IAC48-65 & $110,25 \mathrm{c}, \mathrm{d}$ & $79,32 \mathrm{c}$ & $94,78 \mathrm{~d}$ \\
C0419 & $123,84 \mathrm{~b}, \mathrm{c}, \mathrm{d}$ & $62,96 \mathrm{~d}$ & $93,43 \mathrm{~d}$ \\
SP71-6163 & $98,09 \mathrm{~d}$ & $27,16 \mathrm{e}$ & $62,62 \mathrm{e}$ \\
\hline Médias & 125,52 & 89,20 & 107,36 \\
\hline
\end{tabular}

Médias seguidas pela mesma letra não diferem estatisticamente pelo teste de Duncan ao nivel de $5 \%$. 
Tabela 15 - Dados de toneladas de colmos por hectare (TCH) na Fazenda São João.

\begin{tabular}{llll}
\hline Variedade & $\begin{array}{c}\text { Colheita cana- } \\
\text { planta: 17/07/95 }\end{array}$ & $\begin{array}{c}\text { Colheita cana- } \\
\text { soca: 13/06/96 }\end{array}$ & Média \\
\hline RB835089 & $130,37 \mathrm{a}$ & $100,31 \mathrm{a}$ & $115,34 \mathrm{a}$ \\
RB72454 & $124,51 \mathrm{a}$ & $104,51 \mathrm{a}$ & $114,51 \mathrm{a}$ \\
CB41-76 & $119,57 \mathrm{a}, \mathrm{b}$ & $85,06 \mathrm{a}, \mathrm{b}$ & $102,31 \mathrm{a}, \mathrm{b}$ \\
NA56-79 & $123,46 \mathrm{a}$ & $79,44 \mathrm{a}, \mathrm{b}$ & $101,45 \mathrm{a}, \mathrm{b}$ \\
SP70-1143 & $105,19 \mathrm{c}$ & $90,80 \mathrm{a}, \mathrm{b}$ & $97,99 \mathrm{a}, \mathrm{b}$ \\
Co290 & $107,78 \mathrm{c}$ & $86,98 \mathrm{a}, \mathrm{b}$ & $97,38 \mathrm{a}, \mathrm{b}$ \\
IAC48-65 & $101,54 \mathrm{c}$ & $89,94 \mathrm{a}, \mathrm{b}$ & $95,74 \mathrm{~b}$ \\
Co419 & $110,49 \mathrm{~b}, \mathrm{c}$ & $68,09 \mathrm{~b}$ & $89,29 \mathrm{~b}, \mathrm{c}$ \\
SP71-1406 & $109,75 \mathrm{~b}, \mathrm{c}$ & $68,76 \mathrm{~b}$ & $89,26 \mathrm{~b}, \mathrm{c}$ \\
SP71-6163 & $79,38 \mathrm{~d}$ & $66,05 \mathrm{~b}$ & $72,72 \mathrm{c}$ \\
\hline Médias & 111,20 & 83,99 & 97,60 \\
\hline
\end{tabular}

Médias seguidas pela mesma letra não diferem estatisticamente pelo teste de Duncan ao nível de $5 \%$. 
Tabela 16 - Média dos dados de toneladas de colmos por hectare (TCH) nos três locais, em cana-planta e cana-soca.

\begin{tabular}{|c|c|c|}
\hline Variedade & $\mathrm{TCH}$ & \\
\hline RB835089 & 137,74 & $a$ \\
\hline RB72454 & 133,17 & $a$ \\
\hline SP70-1143 & 112,73 & $b$ \\
\hline Co290 & 111,49 & b \\
\hline CB41-76 & 104,16 & $b, c$ \\
\hline Co419 & 101,43 & C \\
\hline NA56-79 & 98,15 & $c, d$ \\
\hline IAC48-65 & 96,87 & $c, d$ \\
\hline SP71-1406 & 91,16 & $d$ \\
\hline SP71-6163 & 67,38 & e \\
\hline Média & 105,43 & \\
\hline
\end{tabular}

Médias seguidas pela mesma letra não diferem estatisticamente pelo teste de Duncan ao nivel de $5 \%$. 
Co419 esteve bem posicionada unicamente na FAB (Tabela 13), onde pode ter sido beneficiada pela alta incidência de ferrugem em outras variedades (Tabela 10). Como esperado, as variedades mais cultivadas atualmente foram as que se mostraram mais produtivas.

\subsubsection{Pol Cana}

Direcionou-se as colheitas para meio de safra, a fim de se avaliar a capacidade de acúmulo de sacarose em meses típicos de safra, evitando-se, assim, não favorecer as variedades precoces ou as tardias. Quanto aos locais (Tabelas 17,18 e 19) os valores mais altos para pol foram obtidos no CCA, seguidos pelos obtidos na FAB e FSJ, respectivamente. Por necessidade operacional, o corte da cana-soca na FSJ foi antecipado, o que visivelmente prejudicou os valores obtidos (Tabela 19). Os dados médios dos três locais encontram-se na Tabela 20. A variedade NA56-79 apresentou os valores mais altos para pol, seguida pelas variedades RB72454, RB835089 e Co419. As variedades Co290 e CB41-76 apresentaram os valores mais baixos. As demais, IAC48-65, SP71-1406, SP71-6163 e SP70-1143, estiveram bem próximas uma das outras, em torno da média, que foi de 14,63 . Novamente, as duas variedades mais recentes foram as mais bem posicionadas, à exceção da Co419 e da NA56-79. 
Tabela 17 - Médias de pol na Fazenda Areia Branca.

\begin{tabular}{lccc}
\hline Variedade & $\begin{array}{c}\text { Colheita cana- } \\
\text { planta: } 21 / 07 / 95\end{array}$ & $\begin{array}{c}\text { Colheita cana- } \\
\text { soca: } 16 / 09 / 96\end{array}$ & Média \\
\hline C0419 & $16,00 \mathrm{a}$ & $15,91 \mathrm{a}$ & $15,95 \mathrm{a}$ \\
RB72454 & $15,14 \mathrm{a}, \mathrm{b}$ & $15,70 \mathrm{a}, \mathrm{b}$ & $15,42 \mathrm{a}$ \\
RB835089 & $15,13 \mathrm{a}, \mathrm{b}$ & $15,42 \mathrm{a}, \mathrm{b}, \mathrm{c}$ & $15,28 \mathrm{a}, \mathrm{b}$ \\
NA56-79 & $15,30 \mathrm{a}, \mathrm{b}$ & $14,96 \mathrm{a}, \mathrm{b}, \mathrm{c}, \mathrm{d}$ & $15,13 \mathrm{a}, \mathrm{b}$ \\
SP70-1143 & $14,50 \mathrm{~b}, \mathrm{c}$ & $15,76 \mathrm{a}, \mathrm{b}$ & $15,13 \mathrm{a}, \mathrm{b}$ \\
IAC48-65 & $14,56 \mathrm{~b}, \mathrm{c}$ & $14,49 \mathrm{c}, \mathrm{d}, \mathrm{e}$ & $14,52 \mathrm{~b}, \mathrm{c}$ \\
SP71-1406 & $14,81 \mathrm{~b}$ & $14,08 \mathrm{~d}, \mathrm{e}$ & $14,44 \mathrm{~b}, \mathrm{c}$ \\
Co290 & $13,74 \mathrm{c}$ & $14,68 \mathrm{~b}, \mathrm{c}, \mathrm{d}$ & $14,21 \mathrm{c}$ \\
CB41-76 & $13,74 \mathrm{c}$ & $14,51 \mathrm{c}, \mathrm{d}, \mathrm{e}$ & $14,13 \mathrm{c}$ \\
SP71-6163 & $14,52 \mathrm{~b}, \mathrm{c}$ & $13,49 \mathrm{e}$ & $14,01 \mathrm{c}$ \\
\hline Médias & 14,74 & $14,90 \mathrm{l}$ & 14,82 \\
\hline
\end{tabular}

Médias seguidas pela mesma letra não diferem estatisticamente pelo teste de Duncan ao nivel de $5 \%$. 
Tabela 18 - Médias de pol no Centro de Ciências Agrárias.

\begin{tabular}{|c|c|c|c|c|c|c|}
\hline \multirow{2}{*}{$\frac{\text { Variedade }}{\text { NA56-79 }}$} & \multicolumn{2}{|c|}{$\begin{array}{c}\text { Colheita cana- } \\
\text { planta: } 19 / 07 / 95\end{array}$} & \multicolumn{2}{|c|}{$\begin{array}{l}\text { Colheita cana- } \\
\text { soca: } 07 / 08 / 96\end{array}$} & \multicolumn{2}{|c|}{ Média } \\
\hline & 15,72 & $a$ & 16,29 & $a$ & 16,00 & $a$ \\
\hline SP70-1143 & 15,487 & a & 16,35 & a & 15,92 & a \\
\hline RB835089 & 15,68 & a & 16,14 & a & 15,91 & a \\
\hline RB72454 & 15,40 & a & 16,31 & a & 15,86 & a \\
\hline Co419 & 15,46 & a & 16,25 & a & 15,85 & a \\
\hline IAC48-65 & 15,74 & a & 15,57 & $a, b$ & 15,66 & $a$ \\
\hline SP71-6163 & 15,18 & a & 16,07 & a & 15,62 & a \\
\hline SP71-1406 & 15,32 & $a$ & 15,88 & $a$ & 15,60 & a \\
\hline Co290 & 14,08 & $b$ & 14,88 & $b, c$ & 14,48 & $b$ \\
\hline CB41-76 & 14,10 & $b$ & 14,03 & c & 14,07 & $b$ \\
\hline Médias & 15,22 & & 15,78 & & 15,50 & \\
\hline
\end{tabular}

Médias seguidas pela mesma letra não diferem estatisticamente pelo teste de Duncan ao nivel de $5 \%$. 
Tabela 19 - Médias de pol na Fazenda São João.

\begin{tabular}{llll}
\hline Variedade & $\begin{array}{c}\text { Colheita cana- } \\
\text { planta: } 17 / 07 / 95\end{array}$ & $\begin{array}{c}\text { Colheita cana- } \\
\text { soca: 13/06/96 }\end{array}$ & Média \\
\hline NA56-79 & 16,16 a & $13,51 \mathrm{a}$ & $14,84 \mathrm{a}$ \\
SP72454 & $15,73 \mathrm{a}$ & $13,16 \mathrm{a}$ & $14,44 \mathrm{a}$ \\
SP71-6163 & $15,59 \mathrm{a}$ & $12,99 \mathrm{a}$ & $14,29 \mathrm{a}$ \\
IAC48-65 & 15,96 a & $12,44 \mathrm{a}$ & $14,20 \mathrm{a}$ \\
SP71-1406 & 15,94 a & $12,42 \mathrm{a}$ & $14,18 \mathrm{a}$ \\
RB835089 & 15,27 a, b, c & $12,48 \mathrm{a}$ & $13,87 \mathrm{a}, \mathrm{b}$ \\
C0419 & 15,36 a, b & $10,72 \mathrm{~b}$ & $13,04 \mathrm{~b}, \mathrm{c}$ \\
SP70-1143 & 14,85 a, b, c & $10,75 \mathrm{~b}$ & $12,80 \mathrm{c}, \mathrm{d}$ \\
Co290 & 14,14 b, c & $10,48 \mathrm{~b}$ & $12,31 \mathrm{c}, \mathrm{d}$ \\
CB41-76 & 13,85 c & $9,90 \mathrm{~b}$ & $11,88 \mathrm{~d}$ \\
\hline Médias & 15,28 & 11,88 & 13,58 \\
\hline
\end{tabular}

Médias seguidas pela mesma letra não diferem estatisticamente pelo teste de Duncan ao nivel de $5 \%$. 
Tabela 20 - Média dos dados de pol dos três locais, em cana-planta e canasoca.

\begin{tabular}{lc}
\hline Variedade & Pol \\
\hline NA56-79 & 15,32 a \\
RB72454 & $15,24 \mathrm{a}, \mathrm{b}$ \\
RB835089 & $15,02 \mathrm{a}, \mathrm{b}, \mathrm{c}$ \\
Co419 & $14,95 \mathrm{a}, \mathrm{b}, \mathrm{c}$ \\
IAC48-65 & $14,79 \mathrm{~b}, \mathrm{c}$ \\
SP71-1406 & $14,74 \mathrm{c}$ \\
SP71-6163 & $14,64 \mathrm{c}$ \\
SP70-1143 & $14,61 \mathrm{c}$ \\
Co290 & $13,67 \mathrm{~d}$ \\
CB41-76 & $13,36 \mathrm{~d}$ \\
\hline Médias & 14,63 \\
\hline
\end{tabular}

Médias seguidas pela mesma letra não diferem estatisticamente pelo teste de Duncan ao nivel de $5 \%$. 


\subsubsection{Toneladas de pol por hectare (TPH)}

As médias de produção de pol foram semelhantes na FAB e no CCA (Tabelas 21 e 22), respectivamente, com valores de 16,61 e 16,59, e maiores do que na FSJ (Tabela 23) cuja média, 13,49, foi prejudicada pela baixa produção de colmos por área $(\mathrm{TCH})$ e pela antecipação da colheita da cana soca, o que reduziu a pol, já discutido anteriormente.

Entre as variedades, na média dos três locais (Tabela 24) as mais produtivas foram RB835089 e RB72454; com 20,87 e 20,76, respectivamente, enquanto a terceira mais produtiva foi a SP70-1143, com 16,67. As menores produções foram as das variedades SP71-6163 (pelo amarelecimento) e SP71-1406. As demais, Co419, Co290, NA56-79, IAC48-65 e CB41-76 não diferiram estatisticamente entre si.

\subsection{Curvas de maturação}

Montaram-se as figuras das curvas de maturação em duas seqüências; na primeira, Figuras 2 a 9 , onde as variedades foram comparadas entre si pela ordem cronológica de adoção, a partir da primeira a ser cultivada, Co290, até a mais recente, RB835089. Na segunda seqüência, Figuras 10 a 17 todas a variedades foram comparadas individualmente com NA56-79, a mais 
Tabela 21 - Médias de toneladas de pol por hectare (TPH) na Fazenda Areia Branca.

\begin{tabular}{llll}
\hline Variedade & $\begin{array}{l}\text { Colheita cana- } \\
\text { planta: 21/07/95 }\end{array}$ & $\begin{array}{l}\text { Colheita cana- } \\
\text { soca: 16/09/96 }\end{array}$ & Média \\
\hline RB835089 & $22,40 \mathrm{a}, \mathrm{b}$ & $24,99 \mathrm{a}$ & $23,70 \mathrm{a}$ \\
RB72454 & $23,40 \mathrm{a}$ & $21,26 \mathrm{~b}$ & $22,33 \mathrm{a}$ \\
Co419 & $20,80 \mathrm{~b}$ & $18,00 \mathrm{~b}, \mathrm{c}$ & $19,40 \mathrm{~b}$ \\
SP70-1143 & $16,78 \mathrm{c}$ & $19,14 \mathrm{~b}$ & $17,96 \mathrm{~b}$ \\
Co290 & $16,55 \mathrm{c}, \mathrm{d}$ & $17,84 \mathrm{~b}, \mathrm{c}$ & $17,20 \mathrm{~b}, \mathrm{c}$ \\
CB41-76 & $14,79 \mathrm{c}, \mathrm{d}, \mathrm{e}$ & $14,77 \mathrm{c}, \mathrm{d}$ & $14,78 \mathrm{c}, \mathrm{d}$ \\
IAC48-656 & $15,57 \mathrm{c}, \mathrm{d}$ & $13,51 \mathrm{~d}, \mathrm{e}$ & $14,54 \mathrm{~d}$ \\
NA56-79 & $14,49 \mathrm{~d}, \mathrm{e}$ & $13,42 \mathrm{~d}, \mathrm{e}$ & $13,95 \mathrm{~d}$ \\
SP71-1406 & $14,82 \mathrm{c}, \mathrm{d}, \mathrm{e}$ & $10,76 \mathrm{e}$ & $12,79 \mathrm{~d}$ \\
SP71-6163 & $13,13 \mathrm{e}$ & $5,84 \mathrm{f}$ & $9,49 \mathrm{e}$ \\
\hline Médias & 17,27 & 15,95 & 16,61 \\
\hline
\end{tabular}

Médias seguidas pela mesma letra não diferem estatisticamente pelo teste de Duncan ao nivel de $5 \%$. 
Tabela 22- Dados de toneladas de pol por hectare (TPH) no Centro de Ciências Agrárias.

\begin{tabular}{llll}
\hline Variedade & $\begin{array}{c}\text { Colheita cana- } \\
\text { planta: } 19 / 07 / 95\end{array}$ & $\begin{array}{c}\text { Colheita cana- } \\
\text { soca: 07/08/96 }\end{array}$ & Média \\
\hline RB835089 & $22,51 \mathrm{a}, \mathrm{b}$ & $22,91 \mathrm{a}$ & $22,71 \mathrm{a}$ \\
RB72454 & $23,77 \mathrm{a}$ & $20,42 \mathrm{a}, \mathrm{b}$ & $22,10 \mathrm{a}$ \\
SP70-1143 & $19,07 \mathrm{~b}, \mathrm{c}$ & $19,67 \mathrm{~b}$ & $19,37 \mathrm{~b}$ \\
Co290 & $17,17 \mathrm{c}, \mathrm{d}$ & $16,49 \mathrm{c}$ & $16,83 \mathrm{~b}, \mathrm{c}$ \\
NA56-79 & $18,27 \mathrm{c}, \mathrm{d}$ & $13,88 \mathrm{c}, \mathrm{d}$ & $16,07 \mathrm{c}$ \\
SP71-1406 & $21,04 \mathrm{a}, \mathrm{b}, \mathrm{c}$ & $8,72 \mathrm{f}$ & $14,88 \mathrm{c}$ \\
CB41-76 & $17,96 \mathrm{c}, \mathrm{d}$ & $11,78 \mathrm{~d}, \mathrm{e}$ & $14,87 \mathrm{c}$ \\
IAC48-65 & $17,36 \mathrm{c}, \mathrm{d}$ & $12,34 \mathrm{~d}, \mathrm{e}$ & $14,85 \mathrm{c}$ \\
Co419 & $19,10 \mathrm{~b}, \mathrm{c}$ & $10,25 \mathrm{e}, \mathrm{f}$ & $14,67 \mathrm{c}$ \\
SP71-6163 & $14,77 \mathrm{~d}$ & $4,34 \mathrm{~g}$ & $9,56 \mathrm{~d}$ \\
\hline Médias & 19,10 & 14,08 & 16,59 \\
\hline
\end{tabular}

Médias seguidas pela mesma letra não diferem estatisticamente pelo teste de Duncan ao nivel de $5 \%$. 
Tabela 23 - Dados de toneladas de pol por hectare (TPH) na Fazenda São João.

\begin{tabular}{llll}
\hline Variedades & $\begin{array}{l}\text { Colheita cana- } \\
\text { planta: 17/07/95 }\end{array}$ & $\begin{array}{l}\text { Colheita cana- } \\
\text { soca: 13/06/96 }\end{array}$ & Média \\
\hline RB72454 & $19,62 \mathrm{a}, \mathrm{b}$ & $13,70 \mathrm{a}$ & $16,66 \mathrm{a}$ \\
RB835089 & $19,94 \mathrm{a}$ & $12,49 \mathrm{a}, \mathrm{b}$ & $16,22 \mathrm{a}, \mathrm{b}$ \\
NA56-79 & $19,96 \mathrm{a}$ & $10,72 \mathrm{a}, \mathrm{b}, \mathrm{c}$ & $15,34 \mathrm{a}, \mathrm{b}, \mathrm{c}$ \\
IAC48-65 & $16,21 \mathrm{c}$ & $11,16 \mathrm{a}, \mathrm{b}, \mathrm{c}$ & $13,68 \mathrm{~b}, \mathrm{c}, \mathrm{d}$ \\
SP71-1406 & $17,50 \mathrm{a}, \mathrm{b}, \mathrm{c}$ & $8,55 \mathrm{c}, \mathrm{d}$ & $13,02 \mathrm{c}, \mathrm{d}, \mathrm{e}$ \\
SP70-1143 & $15,63 \mathrm{c}$ & $9,77 \mathrm{~b}, \mathrm{c}, \mathrm{d}$ & $12,70 \mathrm{~d}, \mathrm{e}$ \\
CB41-76 & $16,55 \mathrm{c}$ & $8,43 \mathrm{c}, \mathrm{d}$ & $12,49 \mathrm{~d}, \mathrm{e}$ \\
Co290 & $15,23 \mathrm{c}$ & $9,11 \mathrm{~b}, \mathrm{c}, \mathrm{d}$ & $12,17 \mathrm{~d}, \mathrm{e}$ \\
Co419 & $17,01 \mathrm{~b}, \mathrm{c}$ & $7,29 \mathrm{~d}$ & $12,15 \mathrm{~d}, \mathrm{e}$ \\
SP71-6163 & $12,37 \mathrm{~d}$ & $8,58 \mathrm{c}, \mathrm{d}$ & $10,48 \mathrm{e}$ \\
\hline Médias & 17,00 & 9,98 & 13,49 \\
\hline
\end{tabular}

Médias seguidas pela mesma letra não diferem estatisticamente pelo teste de Duncan ao nivel de 5\%. 
Tabela 24 - Dados de toneladas de pol por hectare (TPH) dos três locais, em cana-planta e cana-soca.

\begin{tabular}{ll}
\hline Variedade & TPH \\
\hline RB835089 & $20,87 \mathrm{a}$ \\
RB72454 & $20,36 \mathrm{a}$ \\
SP70-1143 & $16,67 \mathrm{~b}$ \\
Co419 & $15,41 \mathrm{c}, \mathrm{b}$ \\
Co290 & $15,40 \mathrm{c}, \mathrm{b}$ \\
NA56-79 & $15,12 \mathrm{c}$ \\
IAC48-65 & $14,36 \mathrm{c}, \mathrm{d}$ \\
CB41-76 & $14,05 \mathrm{c}, \mathrm{d}$ \\
SP71-1406 & $13,56 \mathrm{~d}$ \\
SP71-6163 & $9,84 \mathrm{e}$ \\
\hline Média & 15,56 \\
\hline
\end{tabular}

Médias seguidas pela mesma letra não diferem estatisticamente pelo teste de Duncan ao nivel de $5 \%$. 


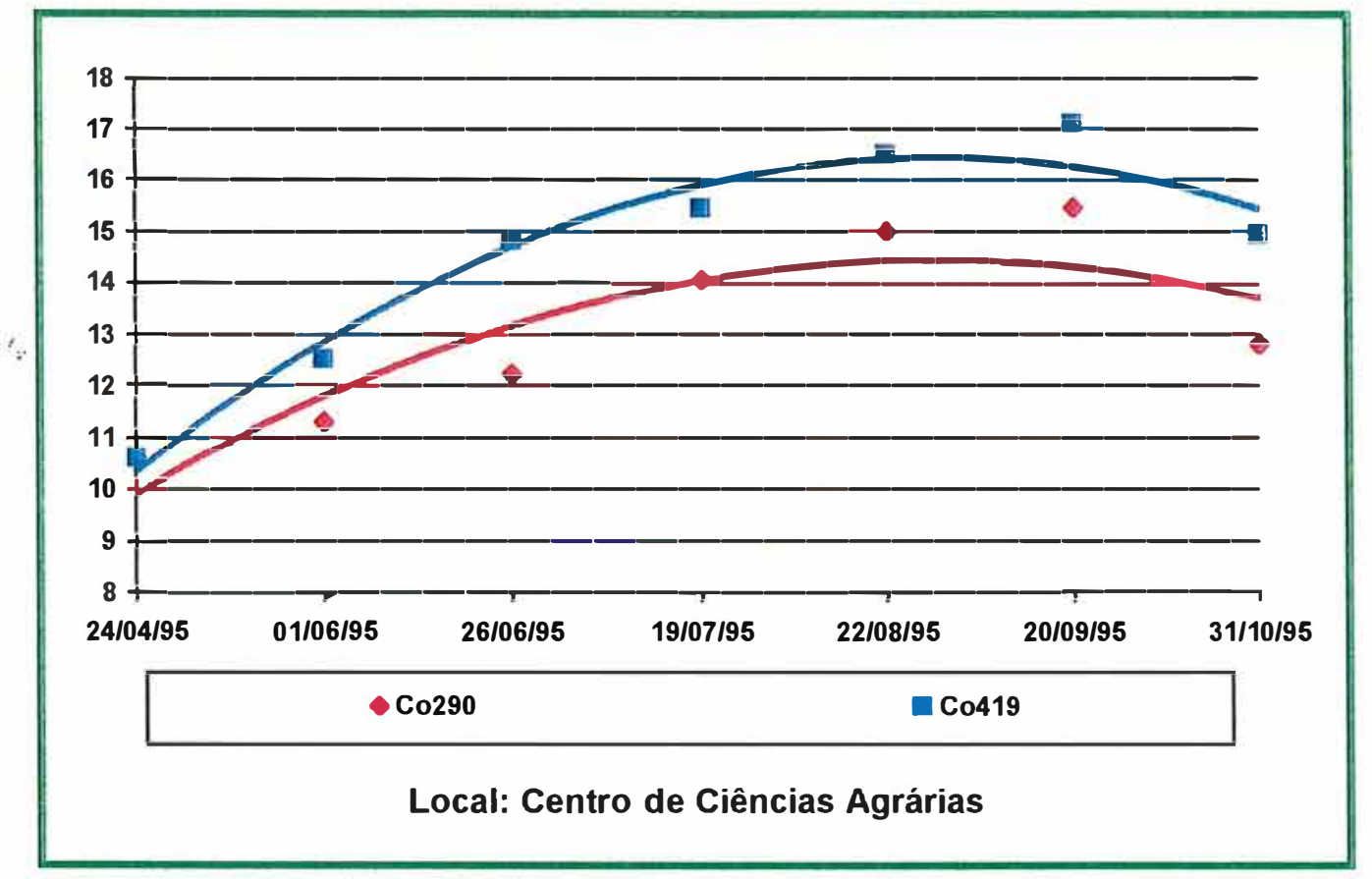

Fig. 2- Curvas de maturação das variedades Co290 e Co419.

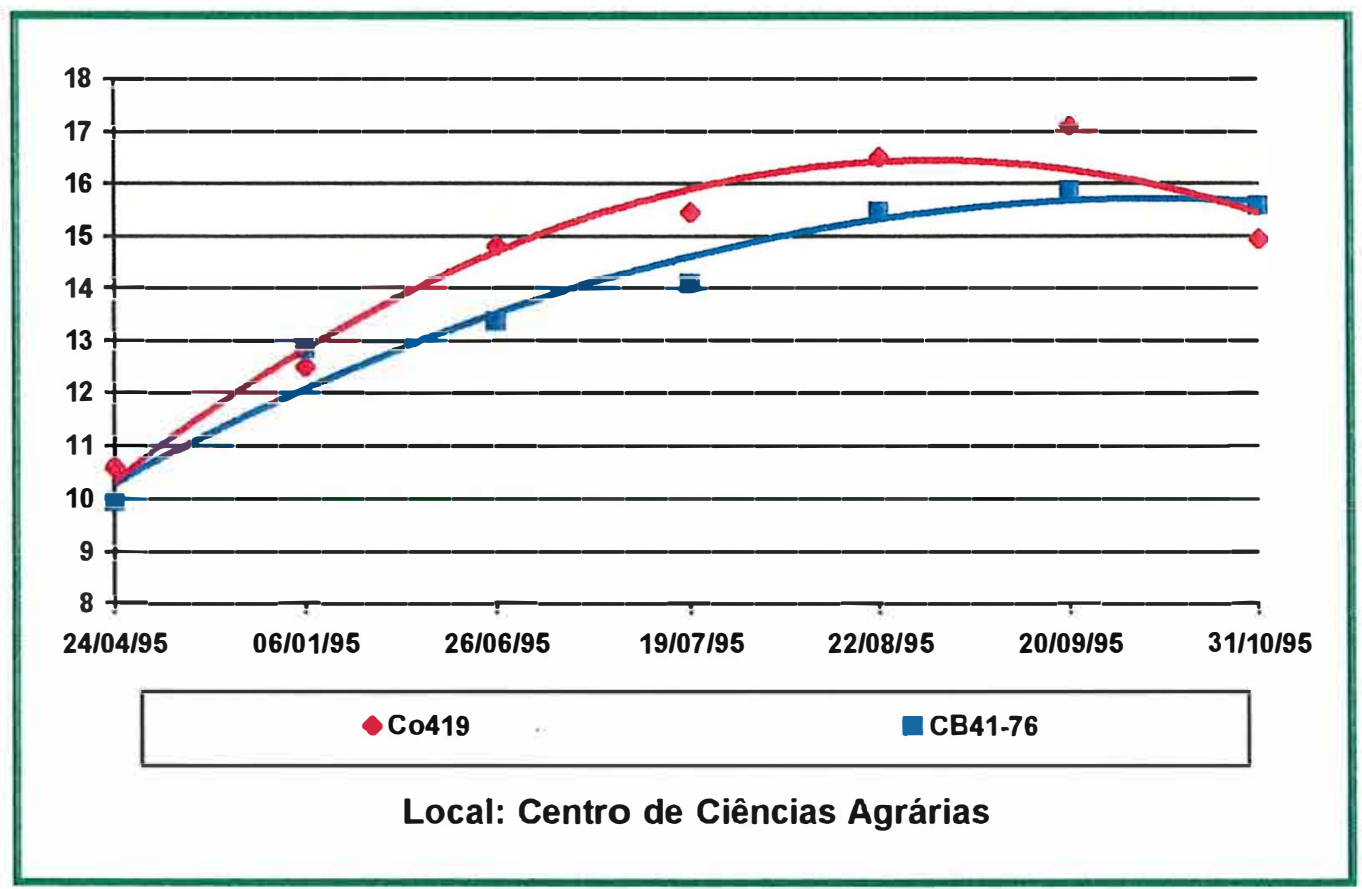

Fig. 3- Curvas de maturação das variedades Co419 e CB41-76. 


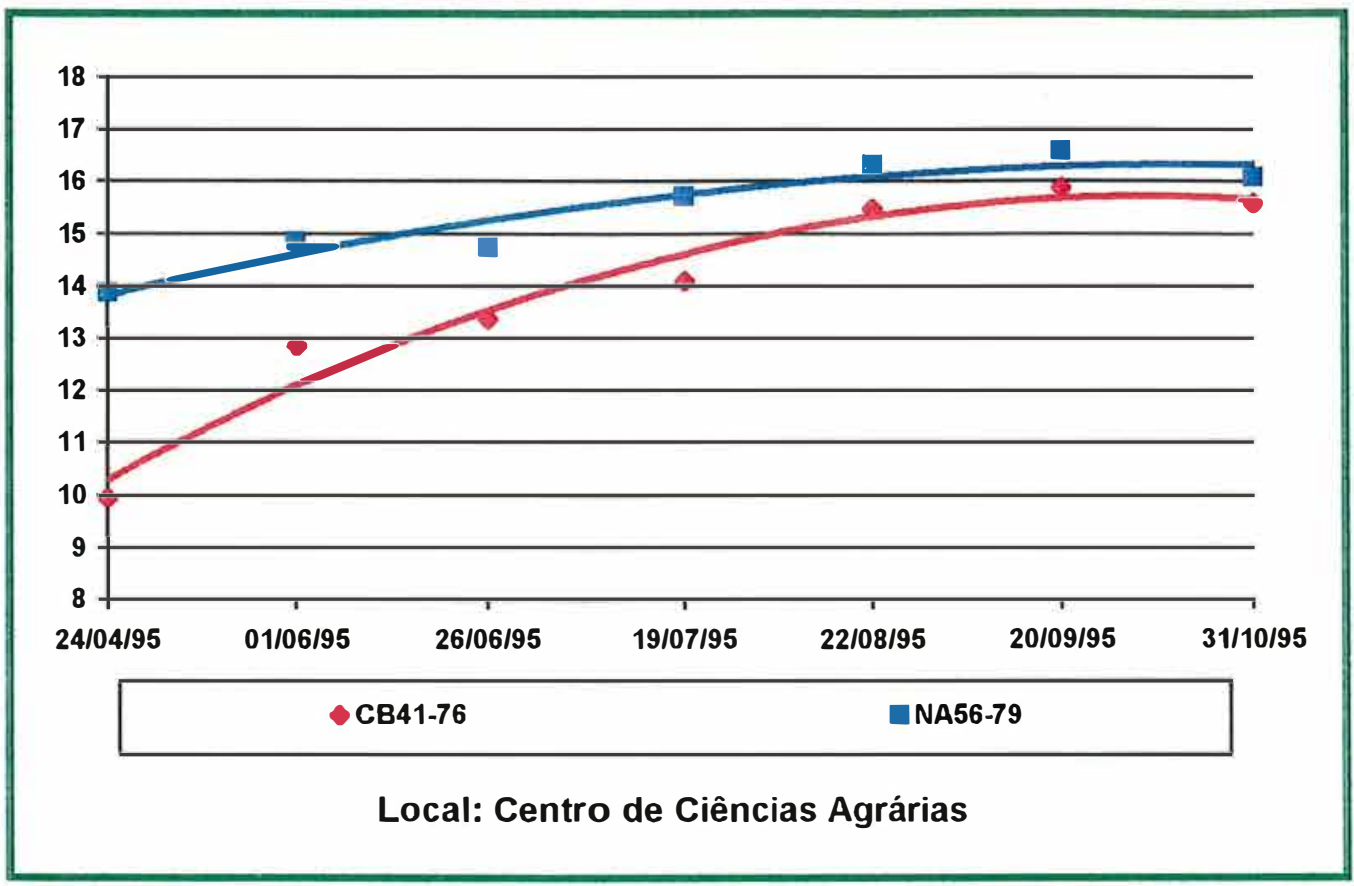

Fig. 4- Curvas de maturação das variedades CB41-76 e NA56-79.

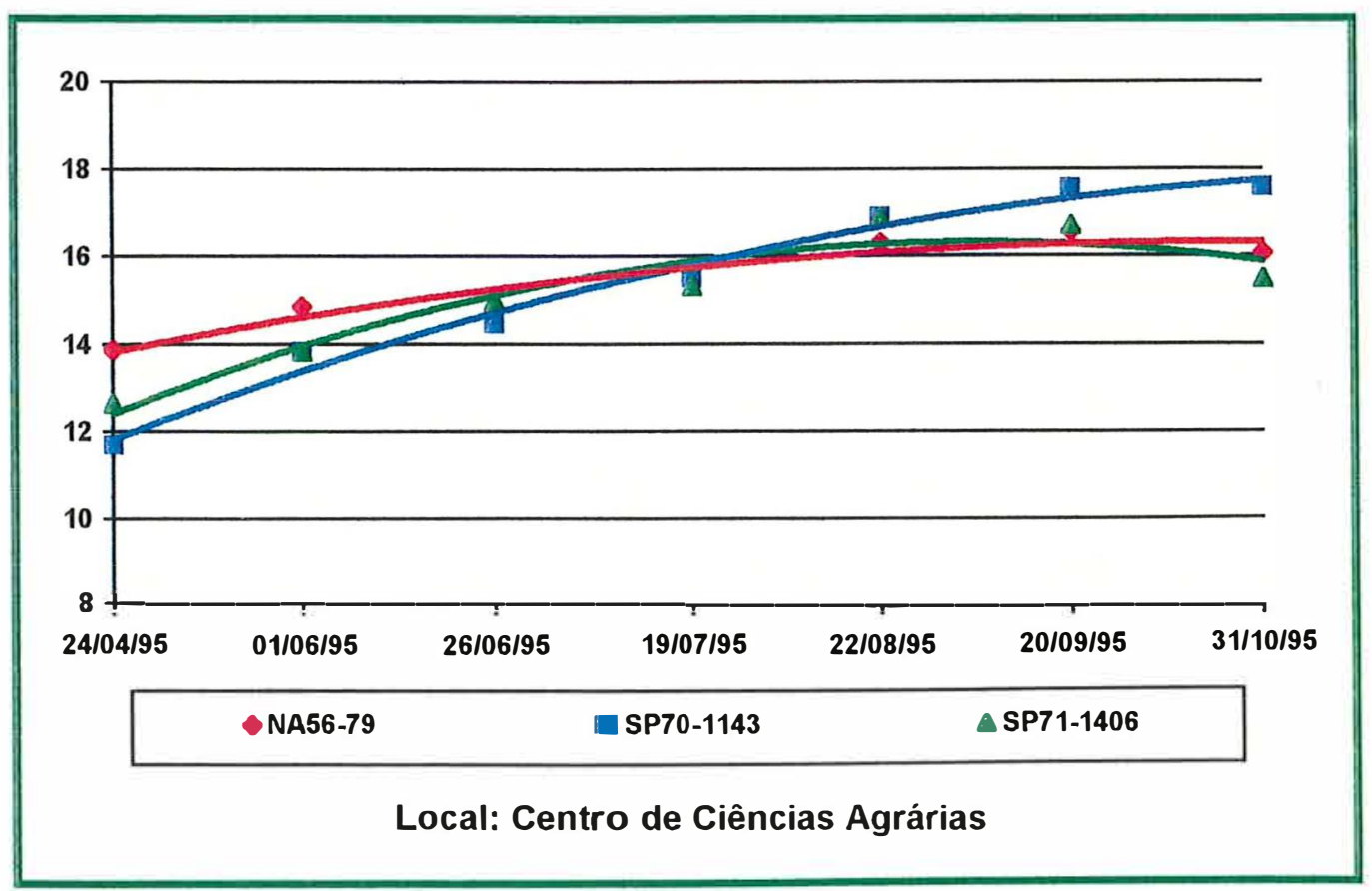

Fig. 5- Curvas de maturação das variedades NA56-79, SP70-1143 e SP71-1406. 


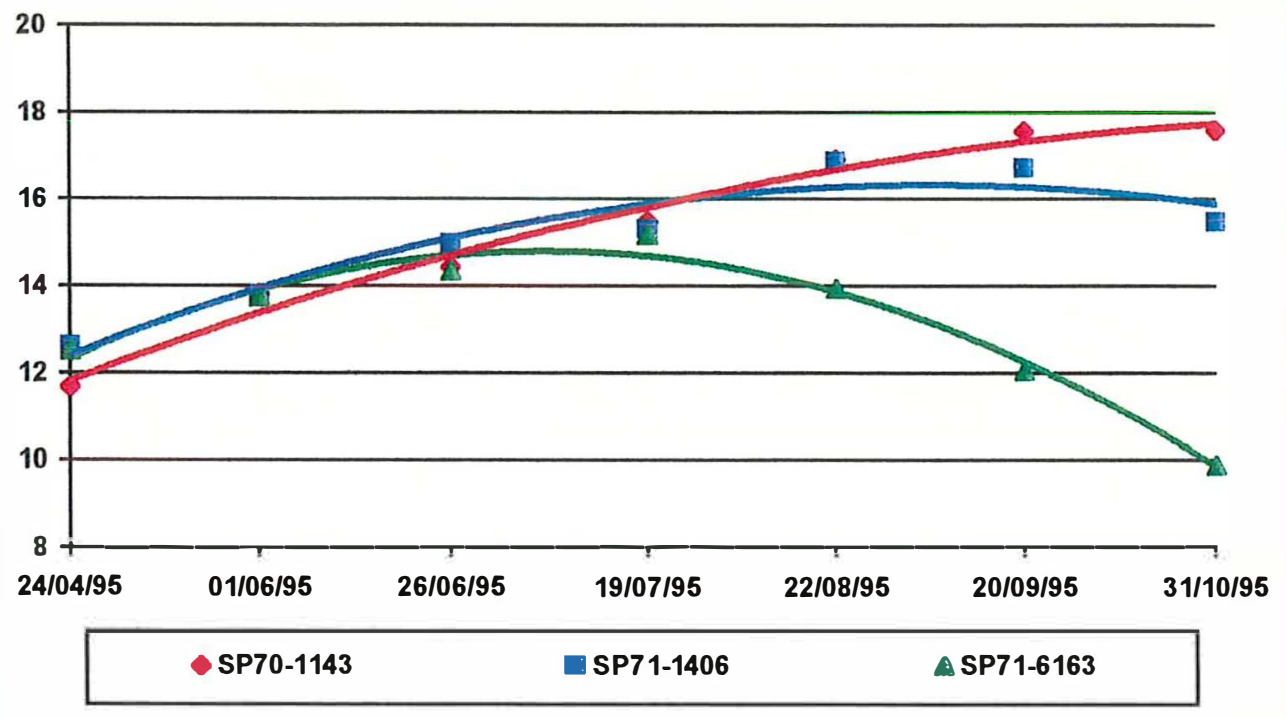

Local: Centro de Ciências Agrárias

Fig. 6- Curvas de maturação das variedades SP70-1143, SP71-1406 e SP71-6163.

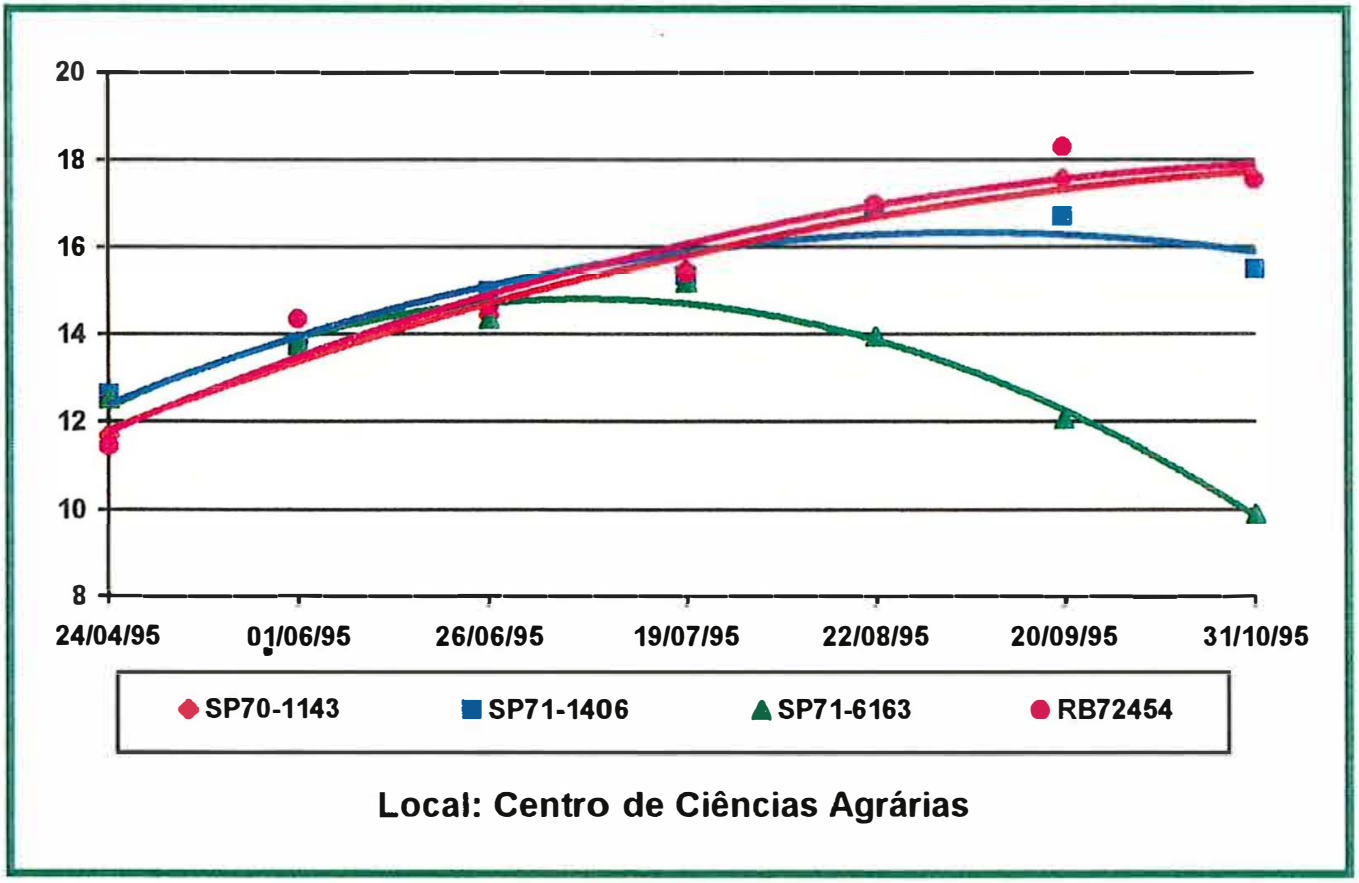

Fig. 7- Curvas de maturação das variedades SP70-1143, SP71-1406, SP71-6163 e RB72454. 


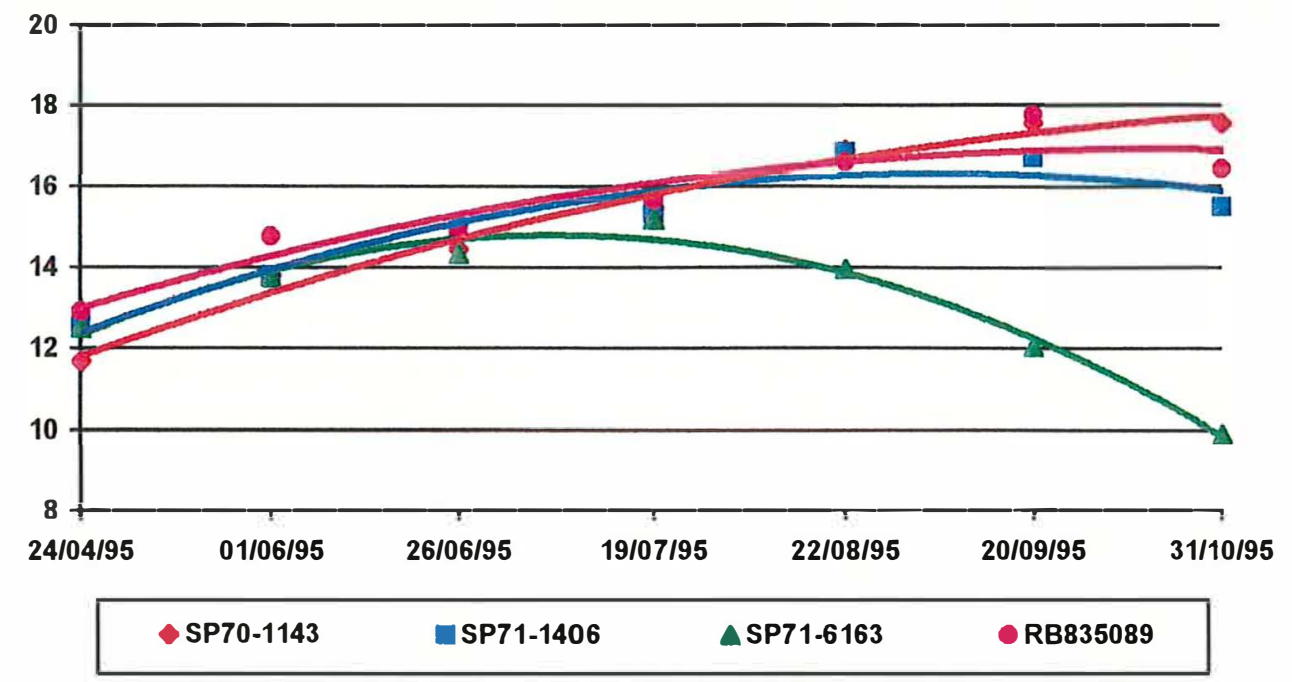

Local: Centro de Ciências Agrárias

Fig. 8- Curvas de maturação das variedades SP70-1143, SP71-1406, SP71-6163 e RB835089.

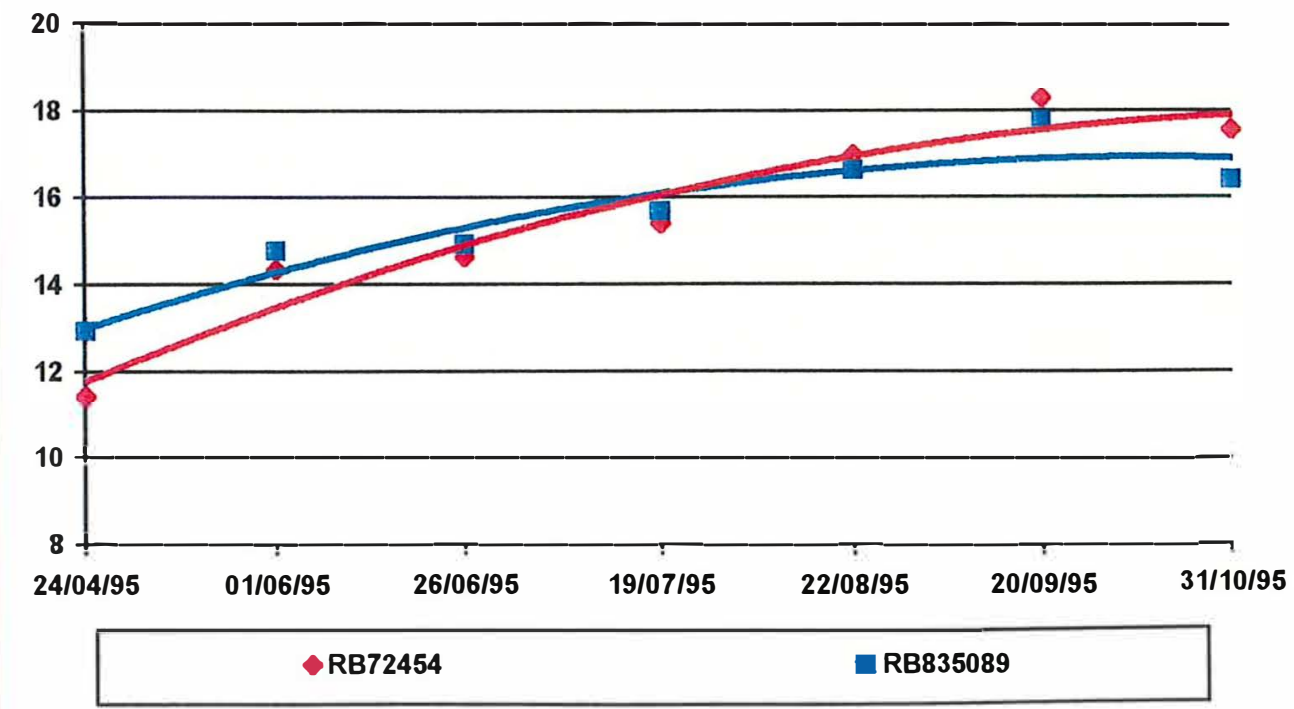

Local: Centro de Ciências Agrárias

Fig. 9- Curvas de maturação das variedades RB72454 e RB835089. 


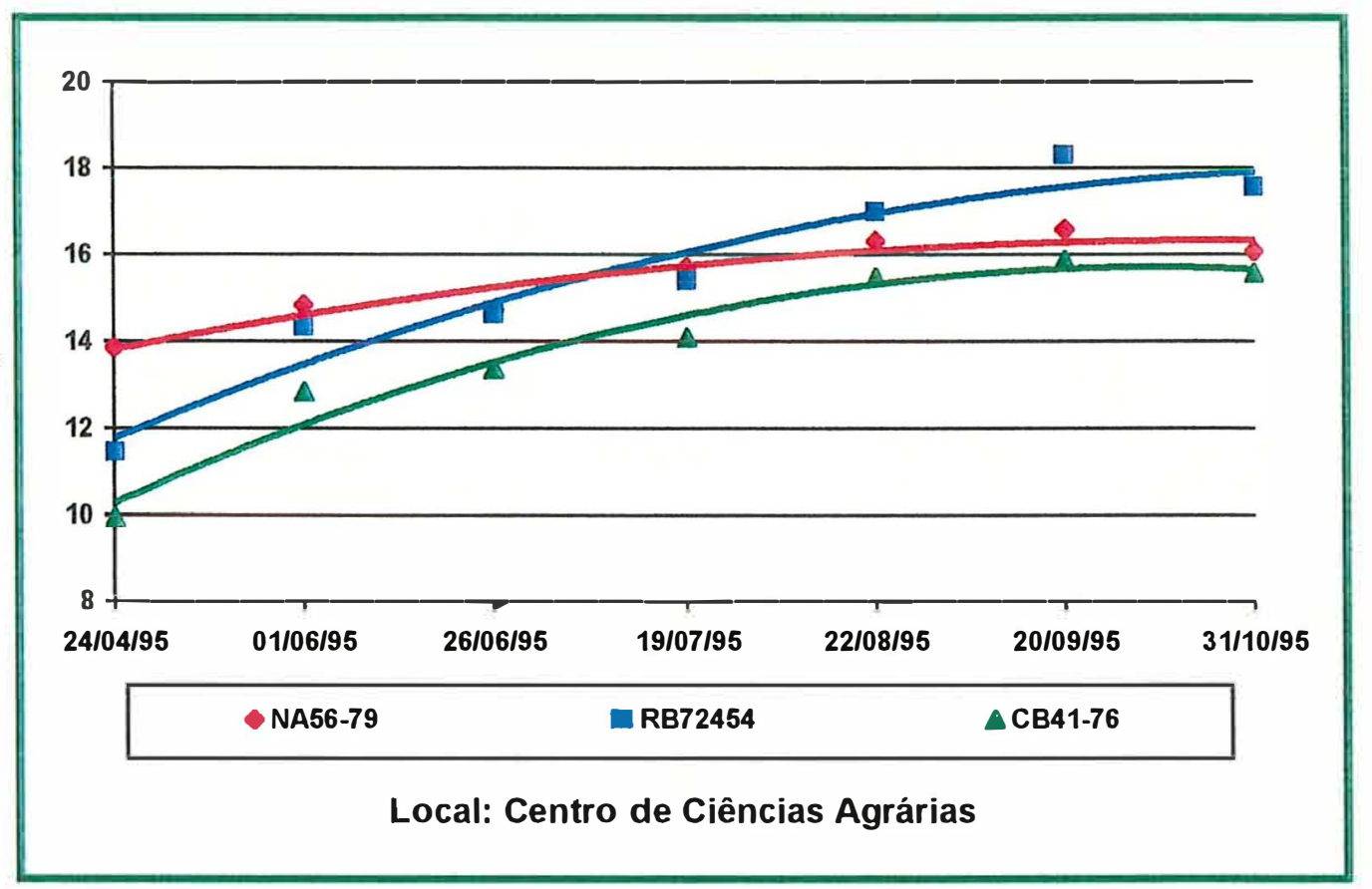

Fig. 10- Curvas de maturação das variedades NA56-79, RB72454 e CB41-76.

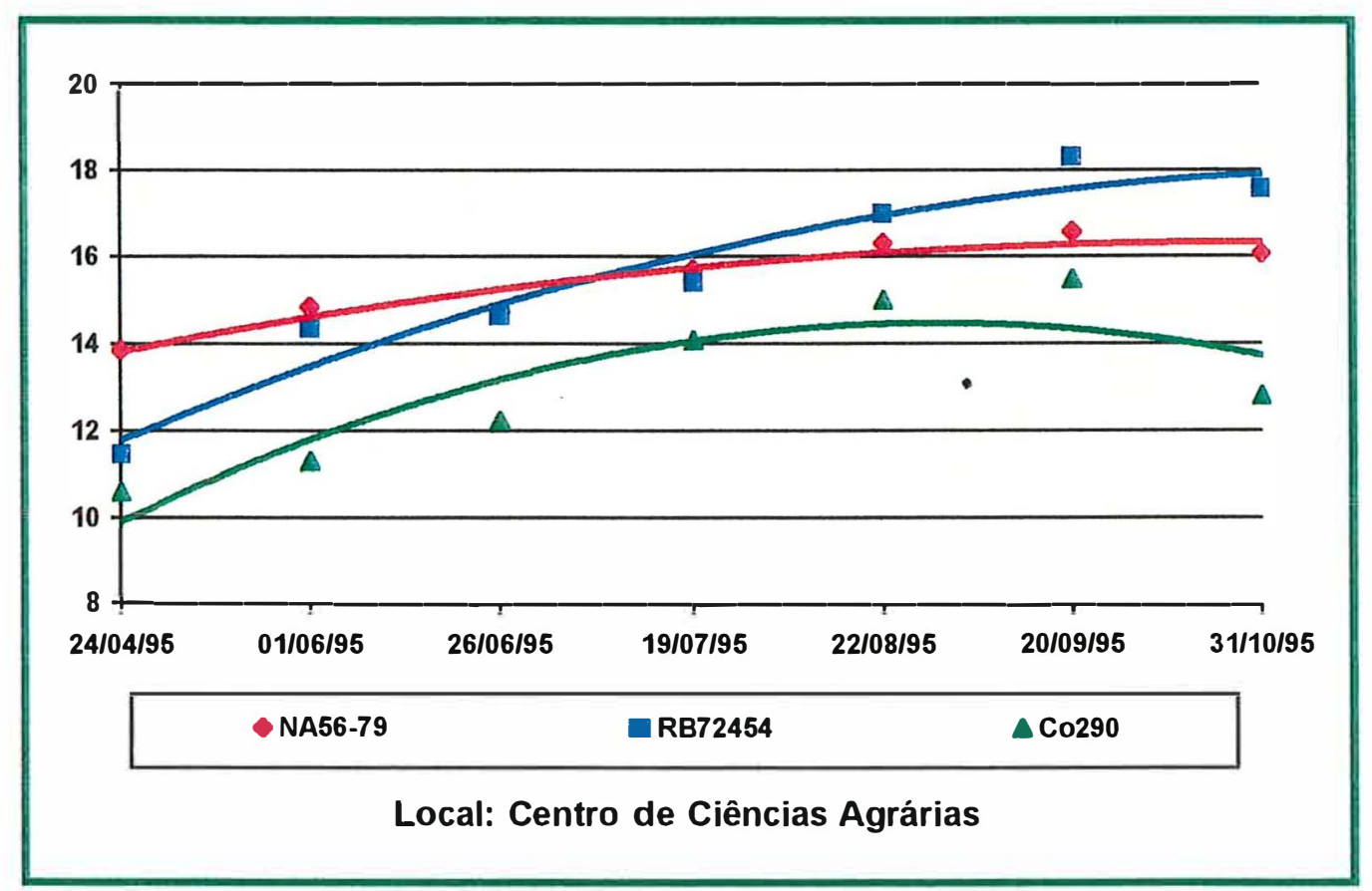

Fig. 11- Curvas de maturação das variedades NA56-79, RB72454 e Co290. 


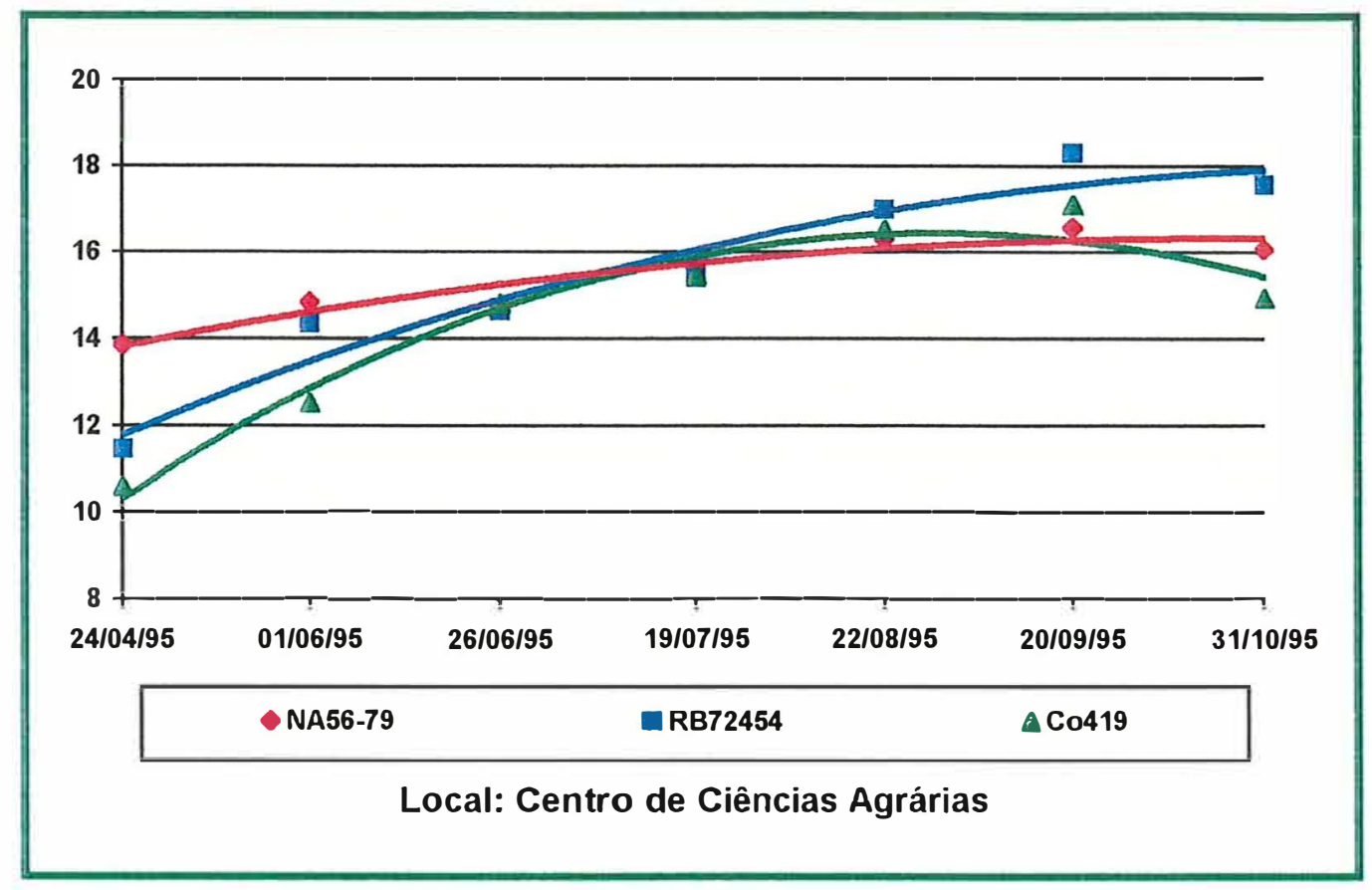

Fig. 12- Curvas de maturação das variedades NA56-79, RB72454 e Co419.

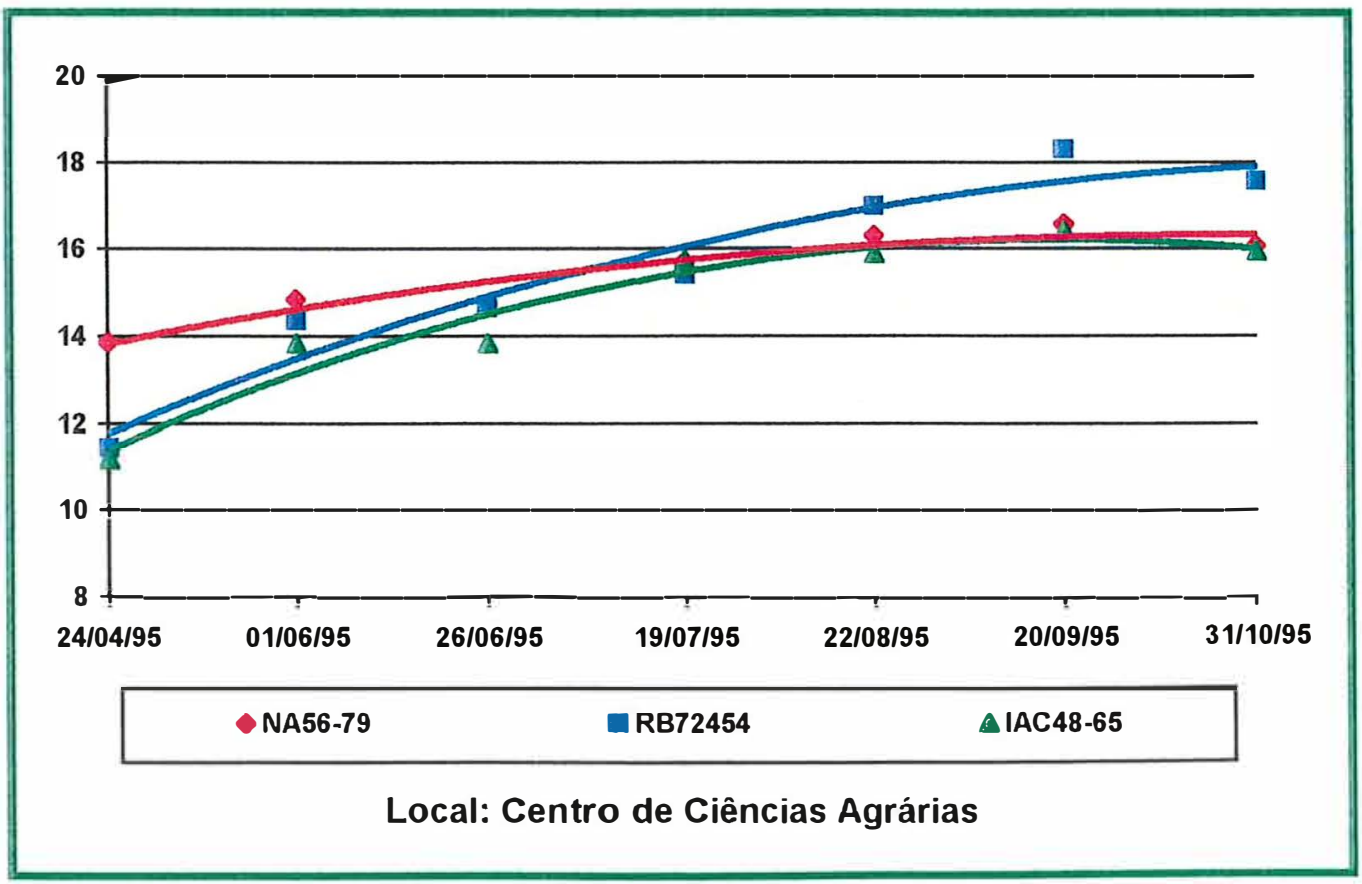

Fig. 13- Curvas de maturação das variedades NA56-79, RB72454 e IAC48-65. 


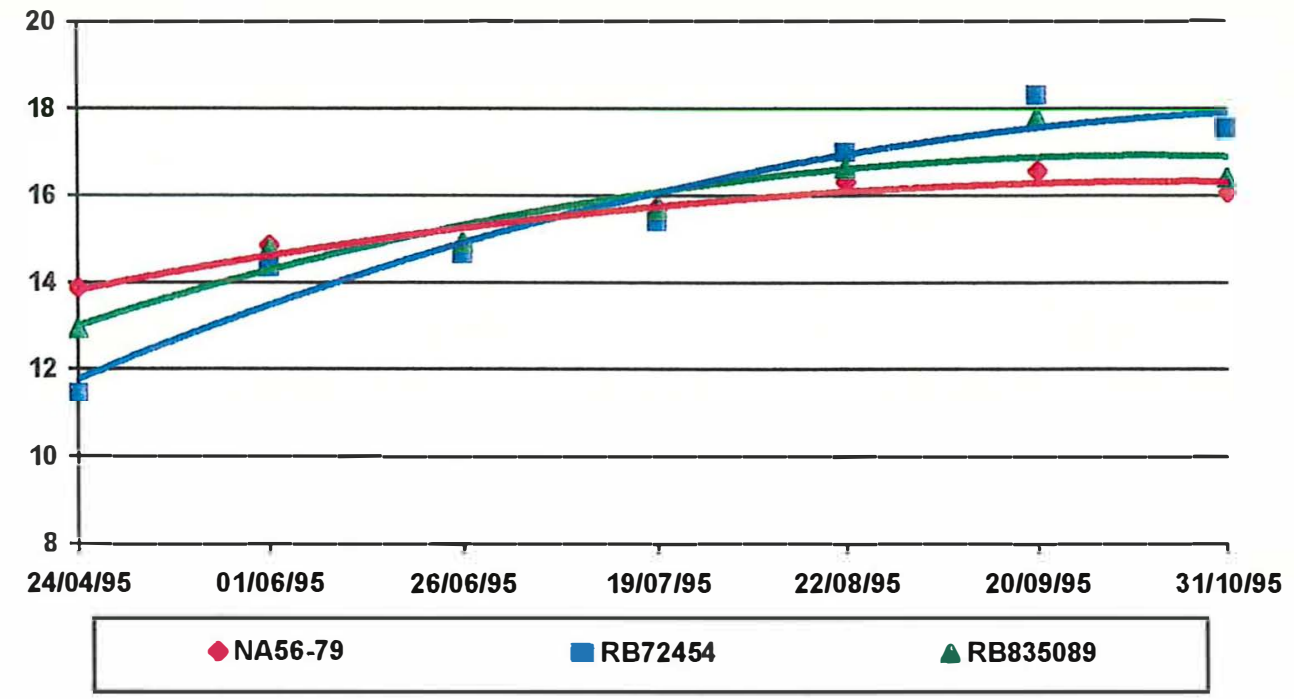

Local: Centro de Ciências Agrárias

Fig. 14- Curvas de maturação das variedades NA56-79, RB72454 e RB835089.

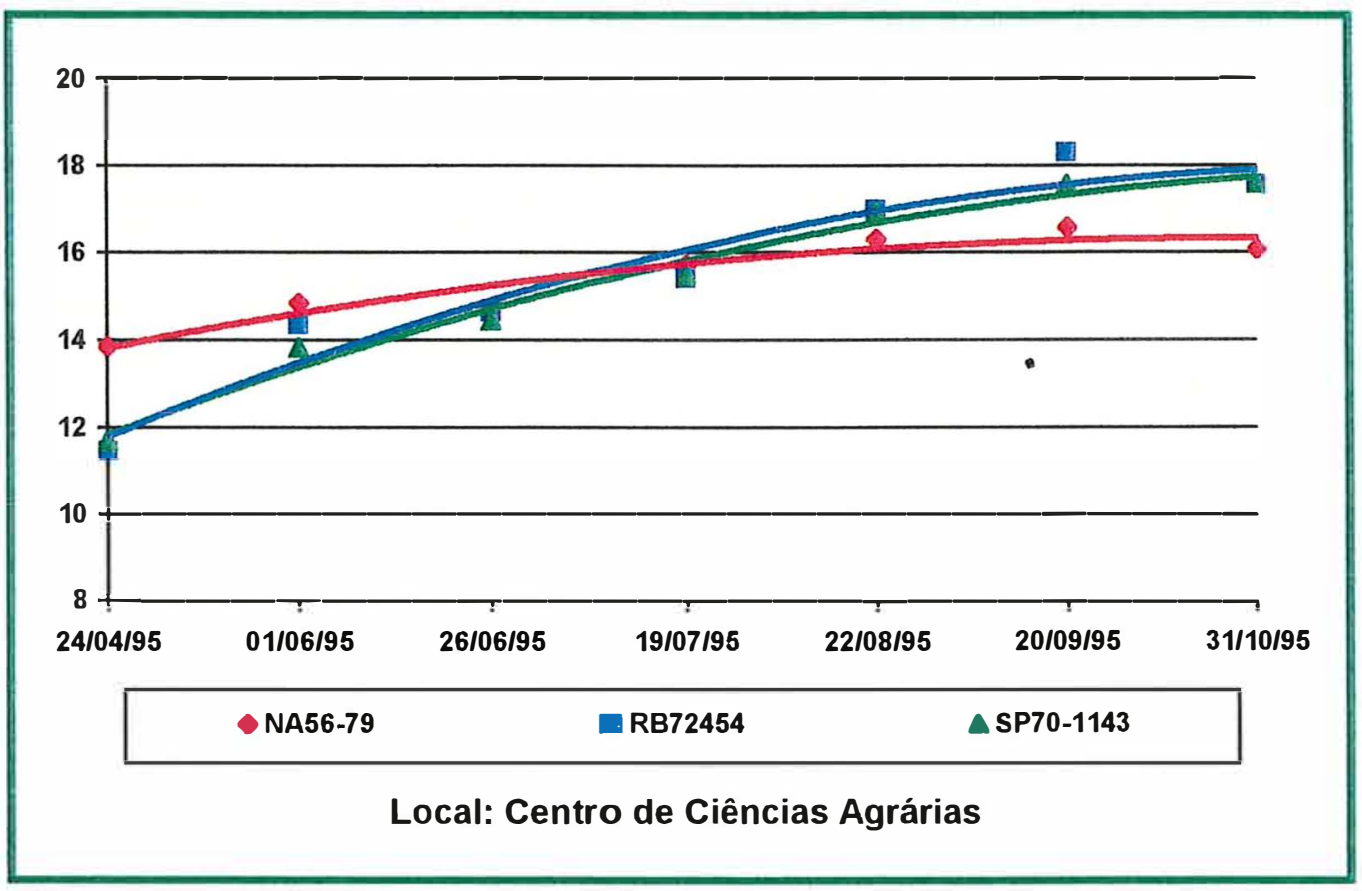

Fig. 15- Curvas de maturação das variedades NA56-79, RB72454 e SP70-1143. 


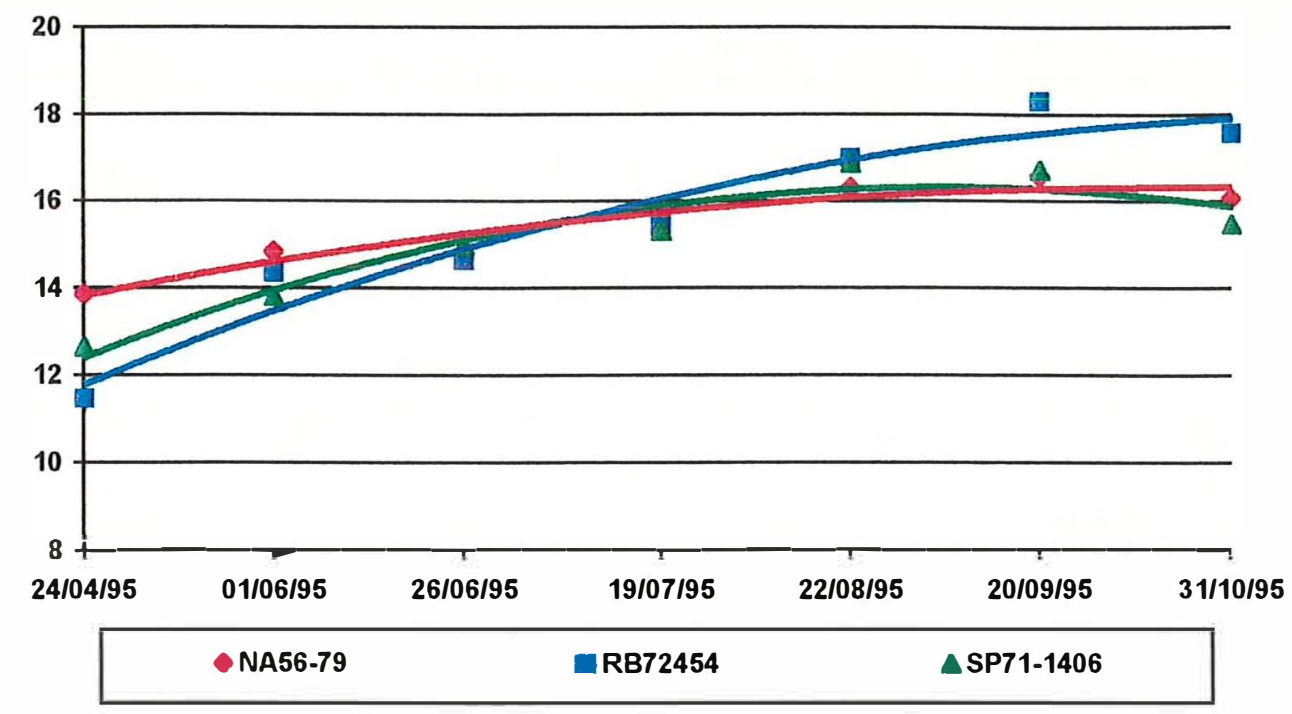

Local: Centro de Ciências Agrárias

Fig. 16- Curvas de maturação das variedades NA56-79, RB72454 e SP71-1406.

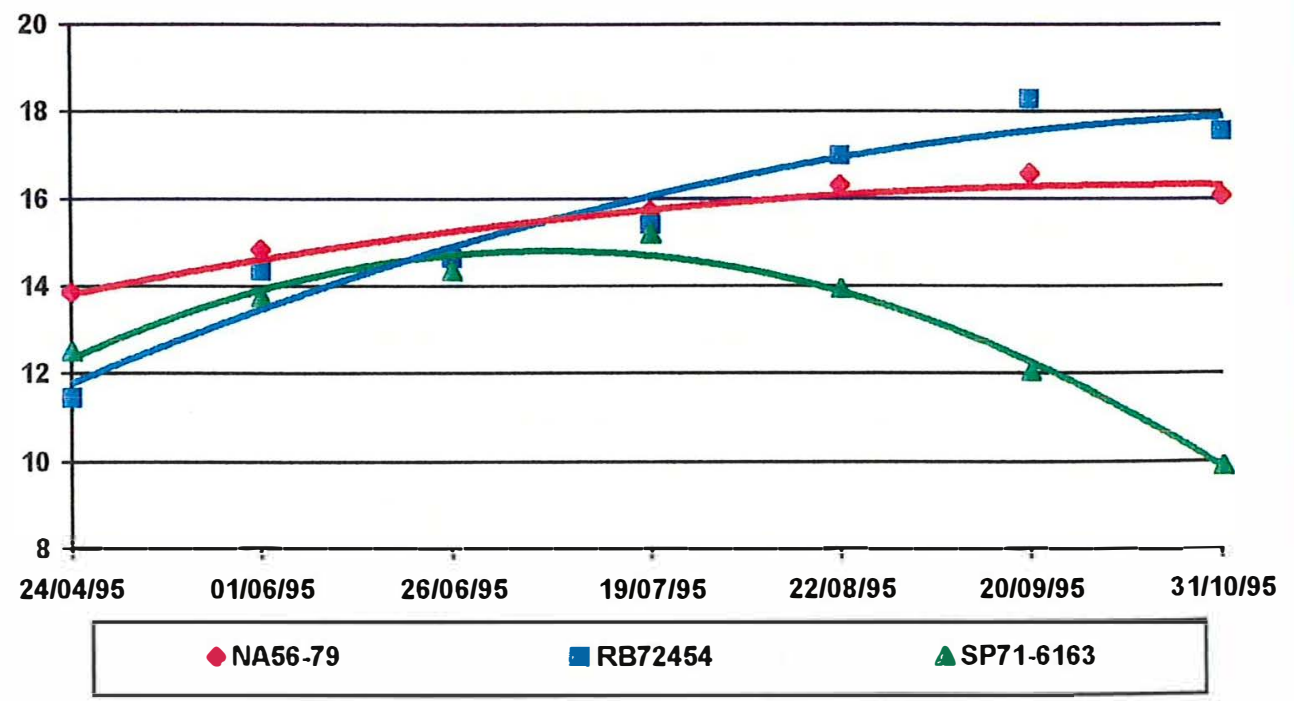

Local: Centro de Ciências Agrárias

Fig. 17- Curvas de maturação das variedades NA56-79, RB72454 e SP71-6163. 
precoce, e RB72454, hoje a variedade mais cultivada no Brasil. Dados originais encontram-se no Apêndice 25.

Iniciando a interpretação das curvas, na primeira seqüência, na Figura 2, são apresentadas as curvas da Co290 e Co419. A segunda variedade, que veio a substituir a primeira em importância na área de cultivo (MATSUOKA, 1991), mostrou-se mais rica durante todo o período da amostragem, principalmente a partir do final de junho. Nota-se, neste caso, o ganho proporcionado pela introdução de uma variedade com maior teor de sacarose.

Posteriormente, em termos de variedade de importância a variedade Co419 foi substituída pela CB41-76. Observa-se na Figura 3 que a CB41-76 apresentou teores mais baixos de sacarose, o que está em conformidade com dados do passado, como os apresentados por SEGALLA et al. (1967); essa variedade, apesar de ser mais pobre, e não ter vantagem produtivida, veio a substituir a primeira em razão da sua elevada resistência ao carvão (MATSUOKA, 1991).

A seguir, houve a substituição da CB41-76 pela NA56-79. Desta vez, não por problemas fitossanitários, e sim pelo melhor comportamento da primeira, que apresentava maiores teores de sacarose (BASSINELLO et al., 1976), o que se corroborou pelos dados do presente trabalho (Figura 4). 
No ciclo seguinte, ocorreu uma substituição por questões fitossanitárias: a NA56-79, devido ao aumento da incidência de carvão a nível de campo, teve sua área de cultivo diminuida e passaram a predominar as variedades SP70-1143 e SP71-1406. Aqui se repetiu uma perda, pois a NA5679 é mais rica que as duas "SP" no início de safra (Figura 5).

Posteriormente, o que ocorreu não foi propriamente uma substituição e sim um aumento no interesse pela variedade SP71-6163; esta variedade embora precoce têm um período útil de industrialização curto; notase esta tendência por exemplo, em algumas curvas de maturação apresentadas pela COPERSUCAR (QUARTA, 1993). A curva obtida, Figura 6, mostrou a queda do teor de sacarose no final de safra da SP71-6163; o tombamento pelo vento pode ter prejudicado a variedade (MIOCQUE, 1996), fazendo com que os valores tenham sido um pouco mais baixos que os normais. A nivel de lavoura comercial tem-se notado quedas acentuadas no teor de sacarose a partir do meio de safra com essa variedade.

Na próxima curva (Figura 7) já se compara as variedades SP70-1143, SP71-1406 e SP71-6163 com RB72454. Pelos dados da curva, constata-se que não houve incremento de riqueza e precocidade. A substituição deveu-se principalmente pela queda de produção das três variedades "SP" em função da ferrugem e também devido ao "amarelinho" na SP71-6163 (BRAGA JUNIOR \& SORDI, 1996). 
A seguir (Figura 8) tem-se a confrontação das variedades SP70-1143, SP71-1406 e SP71-6163 com a RB835089, variedade liberada em 17/09/92 (MATSUOKA et al., 1992). Especificamente quanto às curvas de maturação, não se observou incremento de sacarose e precocidade.

Na Figura 9 é feita a comparação entre as curvas de maturação das duas variedades de liberação mais recente, RB72454 e RB835089. As curvas mostraram valores bem próximos, com tendências de vantagem no início de safra para a RB835089 e, o inverso, no final.

Nas figuras de 10 a 17 estão apresentadas as curvas de todas as variedades estudadas em comparação com as variedades NA56-79 e RB835089. Nenhuma das variedades foi mais precoce que a NA56-79. Quanto ao teor de sacarose ao longo da safra, somente a SP70-1143 se equiparou à RB72454. Entre as variedades mais antigas, a Co419 foi a primeira a apresentar um incremento no teor de sacarose. A NA56-79 demonstrou um ganho de precocidade em relação a sua genitora, Co419 (MACHADO JUNIOR, 1994). Com o advento da NA56-79, passou-se a reconhecer a importância de variedades de maturação precoce. Coincidentemente foi à época de sua prevalência que se implantou no Brasil o sistema de pagamento de cana pelo teor de sacarose, quando a vantagem da precocidade ficou ainda mais patente (MATSUOKA, 1991 e 1993). 


\subsection{Considerações finais}

A ferrugem interferiu nos resultados de produção. Esta afirmação está baseada na comparação conjunta de TCH nos três locais (Tabelas 13, 14 e 15) e da média de sintomas de ferrugem por local (Tabela 10). Nos locais onde a incidência de ferrugem foi maior, FAB e CCA, as duas variedades mais resistentes e produtivas, RB835089 e RB72454, mostraram uma significativa diferença em relação às demais.

Os dados de falhas em planta e soca foram os mais úteis dentre as avaliações complementares realizadas. Eles permitiram melhor avaliação das variedades para a brotação de socas, que é uma das principais características na avaliação de variedades. Os resultados obtidos foram coerentes com o comportamento das variedades a nível de campo em lavouras comerciais; pode-se sugerir, portanto, tais avaliações para os Programas de Melhoramento na avaliação precoce das novas variedades para capacidade de brotação de socas.

Quando à questão principal que é o "estudo da evolução do potencial produtivo das variedades melhoradas de cana-de-açúcar", tem-se que considerar o seguinte: os dados devem ser analisados na ausência ou presença da ferrugem? Obter dados na ausência da ferrugem se torna difícil, por causa da disseminação da doença. No presente trabalho pode-se, como 
uma estimativa na ausência da ferrugem, utilizar os resultados da FSJ, onde os sintomas da doença foram inferiores aos outros locais (Tabela 10). Partindo dos dados em TCH (Tabela 15) e considerando a variedade mais antiga das estudadas, Co290, conclui-se que quando comparada às mais recentes, RB72454 e RB835089, o ganho em produção foi de 15\% em quarenta anos, uma vez que essa variedade, de acordo com MATSUOKA (1991), predominou como a mais plantada no Estado de São Paulo de 1941 a 1954. Em forma mais abrangente, considerando-se os dados dos três ensaios, onde a influência da ferrugem foi maior (Tabela 16), constata-se que a variedade Co290 se posicionou melhor que variedades mais recentes, sendo suplantada apenas por três variedades: RB835089, RB72454 e SP70-1143. A Co290 deixou de ser cultivada face à sua queda de produtividade, provocada pelo vírus do mosaico e possivelmente também a podridão vermelha, Glomerella tucumanensis Speg. (ARRUDA \& ARRUDA, 1949; MATSUOKA, 1991). Ocorre que na condução dos ensaios não se constatou infecção por mosaico e também por podridão vermelha; conclui-se, portanto, que o ambiente biótico das condições do experimento não foi o mesmo de quando esta variedade começou a apresentar quedas de produtividade.

Quanto às variedades que apresentaram maior incidência de ferrugem (Tabela 10), deve-se admitir que a pressão do inóculo foi intensa, prejudicando essas variedades, uma vez que ainda se cultiva um percentual 
elevado de variedades intermediárias e suscetíveis a doença (BRAGA \& SORDI, 1996; GHELLER, 1996). Visualiza-se, portanto, que há uma grande interferência das doenças, pela presença ou ausência da pressão de inóculo, que interfere na manifestação do potencial produtivo das variedades, quanto à produção de colmos.

Quanto à pol (Tabelas 17 a 20 e Figuras 2 a 17), notou-se um incremento nos teores de sacarose, partindo-se das variedades mais pobres, Co290 e CB41-76, e chegando às variedades mais ricas: NA56-79, RB72454, RB835089 e Co419. O ganho quanto à pol foi da ordem de 15\%, tomando-se por base a comparação entre as variedades CB41-76 e a NA56-79, a mais pobre e a mais rica, respectivamente. Há de se considerar também que a utilização de variedades mais precoces possibilitaram a antecipação do início das safras, 30 a 45 dias, propiciando o aumento do período de moagem, com a maximização da estrutura industrial, trazendo benefícios difíceis de serem mensurados.

Finalmente, chegando no aspecto mais importante, que é a produção de açúcar por área, expressa em TPH, a partir dos dados das Tabelas 21 a 24 verifica-se que ocorreu um incremento de $35,5 \%$, comparandose a mais produtiva e de liberação mais recente, RB835089, com a Co290, a primeira a ser cultivada, dentre as estudadas. 
Há, no entanto, um dado mais expressivo que é a comparação quanto à produção de açúcar por área (TPH) entre as variedades SP71-1406 e SP71-6163, que no início dos anos 90 representavam $40 \%$ da área cultivada no Estado de São Paulo (GHELLER. 1996), com as variedades RB72454 e RB835089. As "RB" apresentaram um incremento médio, considerando os dados da Tabela 21, de 91\%; esta diferença se deve, principalmente, ao efeito depressivo da ferrugem nas variedades "SP". Dados de TPH de colheitas até 1986, comparativos entre as variedades RB72454 e SP71-1406, evidenciam que entre essas duas variedades a diferença quanto a produtividade não era tão grande, embora a primeira fosse mais produtiva (MANEJO, 1986).

Com o conjunto de dados avaliados, para todas as variáveis, desenvolveu-se um dendrograma, que ilustra o agrupamento entre as variedades, apresentado na Figura 18. A variedade SP71-6163 se distanciou em relação às demais assim como as variedades RB835089 e RB72454. As demais estão mais próximas entre si, evidenciando que perante as condições ambientais atuais, variedades obtidas em épocas distintas se equivalem. Caso não fossem obtidas novas variedades a produtividade da cultura sofreria um retrocesso. 


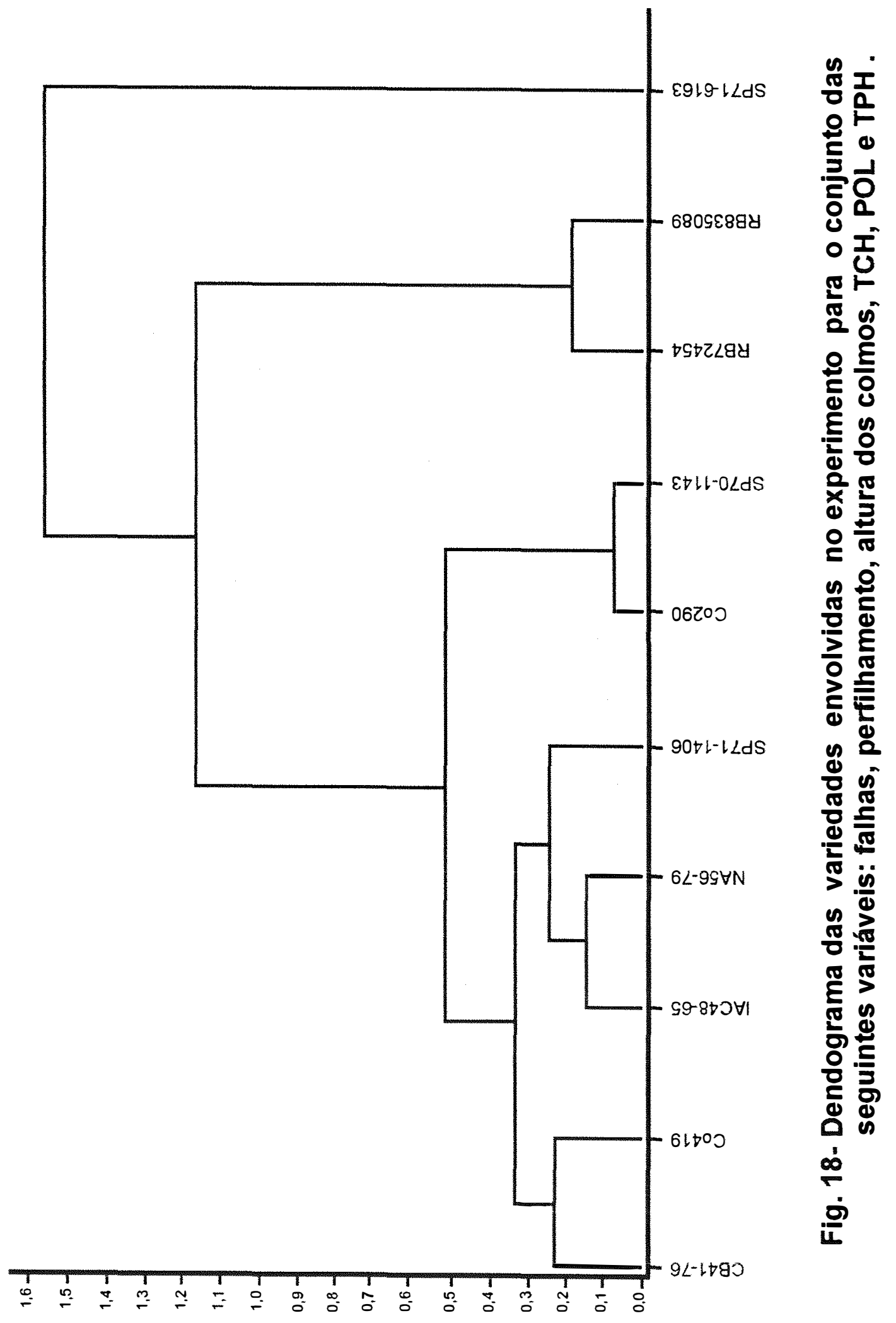




\section{CONCLUSÕES}

- Mesmo com as crescentes exigências tecnológicas e a alteração do ambiente com a introdução de doenças e o uso intensivo solo os programas de melhoramento no Estado de São Paulo tem obtido variedades melhoradas que asseguram ganhos crescentes de produtividade no setor sucroalcooleiro.

- A ferrugem deprime a produção agrícola das variedades suscetiveis, anulando ganhos de produtividade pelo melhoramento. Variedades antigas, desde que resistentes, são na atualidade mais produtivas que as recentes suscetiveis.

- O delineamento de falha em cana-planta permite caracterizar as variedades de cana-de-açúcar para capacidade de brotação inicial, enquanto que 0 diferencial entre soca e planta permite a caracterização da capacidade de brotação de soca. 


\section{REFERÊNCIAS BIBLIOGRÁFICAS}

AGUIRRE JR., J.M. Creação de novas variedades de canna no Estado de

S.Paulo.Campinas: Instituto Agronômico, 1936. 64p. (Boletim Técnico, n 34).

AMORIM, L. et al. Metodologia de avaliação da ferrugem da cana-de-açúcar (Puccinia melanocephala). Boletim Técnico Copersucar, São Paulo, v. 39, p. $13-16,1987$.

ARRUDA, S. C. \& ARRUDA. H. C. Comportamento e produção da muda sã da variedade Co290, no Estado de São Paulo. Arq. Inst. Biol., 19:175-201.

ARRUDA, S.C. A história das grandes epifitias da cana de açucar. O Biológico, São Paulo, v.7, p. 313-318, 1941.

AZZI, G.M. A situação das variedades de cana-de-açúcar cultivadas no Estado de São Paulo. Brasil Açucareiro, Rio de Janeiro, v.78, n.3, p.26-29, set. 1971.

BASSINELLO, A.I. Características agroindustriais de algumas variedades comerciais, II. Brasil Açucareiro, Rio de Janeiro, v.87, n.4, p.8-10, abr.1976. 
BASSINELLO, A.I., MATSUOKA, S., MENDES, A.C. Variedades de cana-deaçúcar para o Estado de São Paulo. Araras: IAA/Planaisucar/Cosul, 1976. 20p. (Boletim Técnico, n.3).

BAVER, L.D. Practical lessons from trends in Hawaiian sugar production. In: CONGRESS OF THE INTERNATIONAL SOCIETY OF SUGAR CANE TECHNOLOGISTS, 11., 1962. Proceedings.Amsterdan, Elsevier, 1963. p.68-77.

BINÔMIO tempo $x$ temperatura no controle do raquitismo da soqueira (RSD) da cana-de-açúcar, pelo processo de termoterapia de gemas isoladas. Cadernos COPERSUCAR. Série Melhoramento, 25, São Paulo, 1989. 5 p. BRAGA JUNIOR, R.L.C. \& SORDI, R.A. Evolução das áreas cultivadas com variedade SP de cana-de-açucar nos últimos cinco anos. In: CONGRESSO NACIONAL DA SOCIEDADE DOS TÉCNICOS AÇUCAREIROS E ALCOOLEIROS DO BRASIL, 6., 1996. Maceió. Anais... Maceió: STAB,1996. p.230-237.

BRIEGER, F. Situação do melhoramento da cana-de-açúcar no Estado de São Paulo. In: Instituto Agronômico: 50 anos anos Estação Experimental de Piracicaba. Piracicaba: Secretaria da Agricultura do Governo do Estado de São Paulo, 1978. p.13-18.

BRIEGER, F.O. O que plantar em cana-de-açúcar. Boletim Informativo Copereste,.Ribeirão Preto, v.7, n.2, p.4-6, fev.1968. 
BRIEGER, F.O. \& ZUNCKELLER, V.E. Recomendações para o plantio de 1965. Boletim Informativo Copereste, Ribeirão Preto, v.4, n.2, p. 1-4, jan. 1965.

BUSSAB, W. O.; MIAZAKI, S. E.; ANDRADE, D. F. Introdução a análise de agrupamentos. In: $9^{\circ}$ SIMPÓSIO BRASILEIRO DE PROBABILIDADE E ESTATÍSTICA. São Paulo, 1990. 105 p.

BULLIO, T.M. \& CAMPOS, R.de M. Avaliação econômica do programa de melhoramento da Copersucar. Boletim Técnico Copersucar, São Paulo,v. 42, p.3-5, 1988.

CANA-DE-AÇUCAR. O Agronômico, Campinas, v.32, p.77-86, 1980.

CARVALHO, F.C.de et al. Estudo da integração vertical na agroindústria sucroalcooleiro no Estado de São Paulo, 1970-92. Agricultura em São Paulo, São Paulo,v.40, n.1, p 157-182, 1993.

COPERSUCAR. Censo varietal quantitativo 1991. São Paulo: COPERSUCAR, 1992. 23p.

COPERSUCAR. Censo varietal quantitativo 1993. São Paulo: COPERSUCAR, 1994. 16p.

COPERSUCAR. Censo varietal quantitativo 1994. São Paulo: COPERSUCAR, 1995. $12 p$.

COPERSUCAR. Reação de variedades de cana-de-açucar à ferrugem e ao carvão no estado de São Paulo. São Paulo: COPERSUCAR, 1988. 4p. 
DANIELS, J. \& TEW, T.L. Hybridization procedures. In: HEINZ, D.J. (ed.) Sugarcane improvement through breeding. Amsterdam: Elsevier, 1987, p. 13-342.

FERNANDES, J. A curiosa história da variedade NA56-79. Álcool e Áçúcar, São Paulo, v.2, n.6, p.18-19, set./out. 1982.

FERRUGEM da cana-de-açúcar e sua constatação no município de Capivari. Boletim Técnico Copersucar, São Paulo, 9p., dez. 1986 (Edição Especial). GHELLER, A.C.A. Variedades de cana-de-açúcar cultivadas no Estado de São Paulo em 1995 - censo varietal. In: CONGRESSO NACIONAL DA SOCIEDADE DOS TÉCNICOS AÇÚCAREIROS E ALCOOLEIROS DO BRASIL, 6., 1996, Maceió. Anais... Maceió: STAB, 1996. p.173-180.

HEINZ, D.J. Introduction. In: HEINZ, D.J.(ed.) Sugarcane improvement through breeding. Amsterdam: Elsevier, 1987. p.1-5.

IAA/PLANALSUCAR. Variedades RB para o centro-sul do Brasil. Araras: IAA/PLANALSUCAR, 1982a. 13p.

IAA/PLANALSUCAR. Nova variedade RB72454. Piracicaba: IAA/PLANALSUCAR, 1982b. 15p.

IAA/PLANALSUCAR. Nova variedades RB para a região centro-sul do Brasil. Piracicaba: IAA/PLANALSUCAR, 1988. 31p.

IAA/PLANALSUCAR. Uma variedade de cana-de-açúcar para todo o Brasil. Piracicaba: IAA/PLANALSUCAR,1987. 29p. 
KOIKE, H. \& GILLAPSE JR, A. G. Mosaic. In: RICAUD, C. et al. (ed.) Diseases of sugarcane. Amsterdan: Elsevier, 1989. p. 301-322.

LIMA, G. C. P. Dissertação a cerca da canna de assucar. Rio de Janeiro. 1842. 43 p. Tese (Doutorado em Medicina) - Faculdade de Medicina do Rio de Janeiro. 1842.

LONGO, V.A. \& MATSUOKA, S. Morfologia de variedades de cana-deaçúcar; manual de caracterização. Piracicaba: Planalsucar, 1984. 16p.

LOOMIS, R.S. \& WILLIAMS, W.A. Maximum crop productivity: an estimate. Crop science, Madison, v.3, p.67-72, 1963.

MACHADO JÚNIOR, G.R. Sugarcane variety notes: an international directory. Piracicaba: Centro de Tecnologia Copersucar, 1994. 94p.

MACHADO, E. C. et al. Índices biométricos de duas variedades de cana-deaçúcar. Pesq. Agropec. Bras., Brasilia, v. 17, n. 9, p. 1321-1329, set. 1982.

MACHADO, G.R., SILVA, W.M. da, IRVINE, J.E. Sugarcane breeding in Brazil: the copersucar program. In: SEMINARIO DE TECNOLOGIA AGRONOMICA, 6., 1987, São Paulo: Copersucar, 1987. p. 217-232.

MANEJO varietal. In: Relatório anual de 1986. Piracicaba: PLANALSUCAR, 1986. 380p.

MARIOTTI, J. El éxito de las variedades argentinas mejoradas. Avance Agroindustrial, San Miguel de Tucumán, v.3, n.11, p.11-13, dez. 1982. 
MATSUOKA, S. O impacto causado pela NA56-79, na agroindústria canavieira nacional. Álcool e Açúcar, São Paulo, v.68, p.16-21, jun./jul. 1993.

MATUSOKA, S. Recuperação de produtividade de variedades de cana-deaçúcar pelo tratamento térmico de teletes. Brasil açucareiro, Rio de Janeiro, v.87, n5, p. 412-416. 1976.

MATSUOKA, S. Ter ou não ter doença, eis a questão. Summa Phytopathologica, Jaguariúna, v. 19, n.3/4, p.145-151, 1993.

MATSUOKA, S. The contribuition of man-made varieties to the sugar cane industry in São Paulo. Ciência e Cultura, São Paulo, v.43, n.4, p.282-289, jul./ago. 1991.

MATSUOKA, S. et al. A retrospective analyses of crop damage caused by sugarcane rust in Brazil. I. Losses in summer planted cane. In: RAO, G. P. et al. (eds.). Current trends in sugarcane pathology. Delhi: International Books \& Periodicals Suply Service, 1994. p. 11-25.

MATSUOKA, S. et al. Cinco novas variedades RB de cana-de-açúcar para São Paulo. Álccol e Açúcar, São Paulo, v.64, p. 8-15, set/out. 1992

MATSUOKA, S. et al. Variedades superprecoces da cana-de-açúcar. Álcool e Açúcar, São Paulo, v.78, p.22-30, fev./mar. 1995.

MATTOS, A. R. Açúcar e álcool no Brasil. São Paulo: Nacional, 1942. 221p. MELHORAMENTO. In: Relatório anual 1995/96. São Paulo: COPERSUCAR, 1996. p.34-44. 
MENEGHIN, S. et al. Amarelinho da cana-de-açúcar. Estudos relacionados ao sistema radicular. Summa Phytopathologica, Piracicaba, v. 20, n. 1, p. 53 , 1994.

MIOCQUE, J. Y. J. O vento e a cana-de-açúcar. STAB, Piracicaba, v.14, n.6, p.14-16, jul./ago. 1996

MIOCQUE, J.Y.J. \& MACHADO JR, .G.R. Review of sugarcane varieties and breeding in Brazil. Sugar Journal, New Orleans, v.40, n.7, p.9-13, dez. 1977.

MIOCQUE, J.Y.J. O melhoramento da cana-de-açúcar no Brasil. STAB, Piracicaba, v.11, n.4, p.24-28, mar./abr. 1993.

NAGUMO, M. Programa de Melhoramento PO Usina da Barra. Piracicaba: Usina da Barra, 1993. 11 p.

NOVAS variedades Copersucar. Boletim Técnico Copersucar, 1983. (Edição especial)

PADRONIZAÇÃO de métodos: seleção e experimentação, avaliação de características agronômicas, avaliação de doenças. Araras: UFSCar/CCA/DBV 1994. 11p.

PELIN, E.R. O aumento da produtividade agrícola e o custo social da produção do álcool. In: PELIN,E.R. Avaliação econômica do álcool hidratado carburante no curto e médio prazos. São Paulo: Instituto de Pesquisas Econômicas, USP, 1985. p.83-116. 
PINAZZA, A.H., GEMENTE, A.C., MATSUOKA, S. Retorno social dos recursos aplicados em pesquisa canavieira: o caso da variedade NA56-79 no Estado de São Paulo. Saccharum APC, São Paulo, v.7, n.30, p. 22-32, jan./fev. 1984.

SKINNER, J. C. et al. Selection methods, criteria, and indices. In: HEINZ, D. J. (ed.) Sugarcane improvement through breeding. Amsterdan: Elsevier, 1987, p. 409-453.

QUARTA geração de variedades de variedades de cana-de-açúcar Copersucar. Boletim Técnico Copersucar, São Paulo, 1993. 16p. (Edição especial)

QUINTA geração de variedades de variedades de cana-de-açúcar Copersucar. Boletim Técnico Copersucar, São Paulo, 1995. 27p. (Edição especial) RELATÓRIO anual 1980. Piracicaba: IAA/PLANALSUCAR, 1981, 116p. RELATÓRIO anual 1985. Piracicaba: IAA/PLANALSUCAR, 1986, 167p. ROCHA, A.M.C. Emergência, perfilhamento e produção de colmos da cana-de-açúcar ( Saccharuma spp) em função das épocas de plantio no Estado de São Paulo. Piracicaba:ESALQ, 1984. 154 p. Dissertação (Mestrado em Agronomia) - Escola Superior de Agricultura "Luiz de Queiroz", Universidade de São Paulo, 1984. 
RUAS, G. C. et al. Principais variedades de cana-de-açúcar cultivadas no Brasil em 1981 e 1982. Saccharum APC, São Paulo, v.6, n.29, p. 30-39, nov./dez. 1983.

SANGUINO, A. Moléstias da cana-de-açúcar. In: Instituto Agronomico Estação Experimental de Piracicaba, 50 anos. Piracicaba: IAA/Planalsucar, 1978.p. 43-49.

SEGALLA, A. L.; OLIVEIRA, H. de; OMETTO, J. C. Variedades de cana-deaçúcar VI - experiências de época de corte para o Estado de São Paulo (1959-1961). Bragantia, Campinas, v. 26, n. 4, p. 39-77, mar. 1967.

SEGALLA, A.L. Variedades de cana-de-açúcar, In: Instituto Agronomico Estação Experimental de Piracicaba, 50 anos. Piracicaba: IAA/Planalsucar, 1978.p.19-34.

SEGUNDA geração de variedades de cana Copersucar. Boletim Técnico Copersucar, São Paulo, 1989. 23p. (Edição especial)

SORDI, R.A. et al. A ferrugem da cana-de-açúcar no Brasil. Brasil Açucareiro, Rio de Janeiro, v.104, n.5/6, p.6-13, 1986.

STEEL, R. G. D. \& TORRIE, J. H. Principles and procedures of statistics. New York: MCGraw-Hill. 1980. 633 p.

STOLF, R., IAIA, A.M., LEE, T.S.G. Índice de falhas segundo o método Stolf: correlação com o rendimento agrícola em soqueiras de cana-de-açúcar. Álcool e Açúcar, São Paulo, v.11, n.58, p.12-16, mailjun. 1991. 
TERCEIRA geração de variedades de variedades de cana Copersucar. Boletim Técnico Copersucar, São Paulo, 1991. 23p. (Edição especial) UNIVERSIDADE FEDERAL DE SÃO CARLOS-DBV. PROGRAMA DE COOPERAÇÃO TÉCNICO-CIENTÍFICA NA ÁREA DE MELHORAMENTO DA CANA-DE-AÇÚCAR. Relatório Técnico, 1995. Araras, 1996. 94 p.

VEGA, J. Síndrome do amarelecimento das folhas da cana-de-açúcar: evidências de associação com vírus. Summa Phytopathologica. Piracicaba, v. 20, n. 1, p. 50, 1994.

WALKER, D.I.T. Breeding for disease resistance. In: HEINZ, D.J., ed. Sugarcane improvement through breeding. Amsterdam: Elsevier, 1987. p. 455-502. 
APEN NDICES 

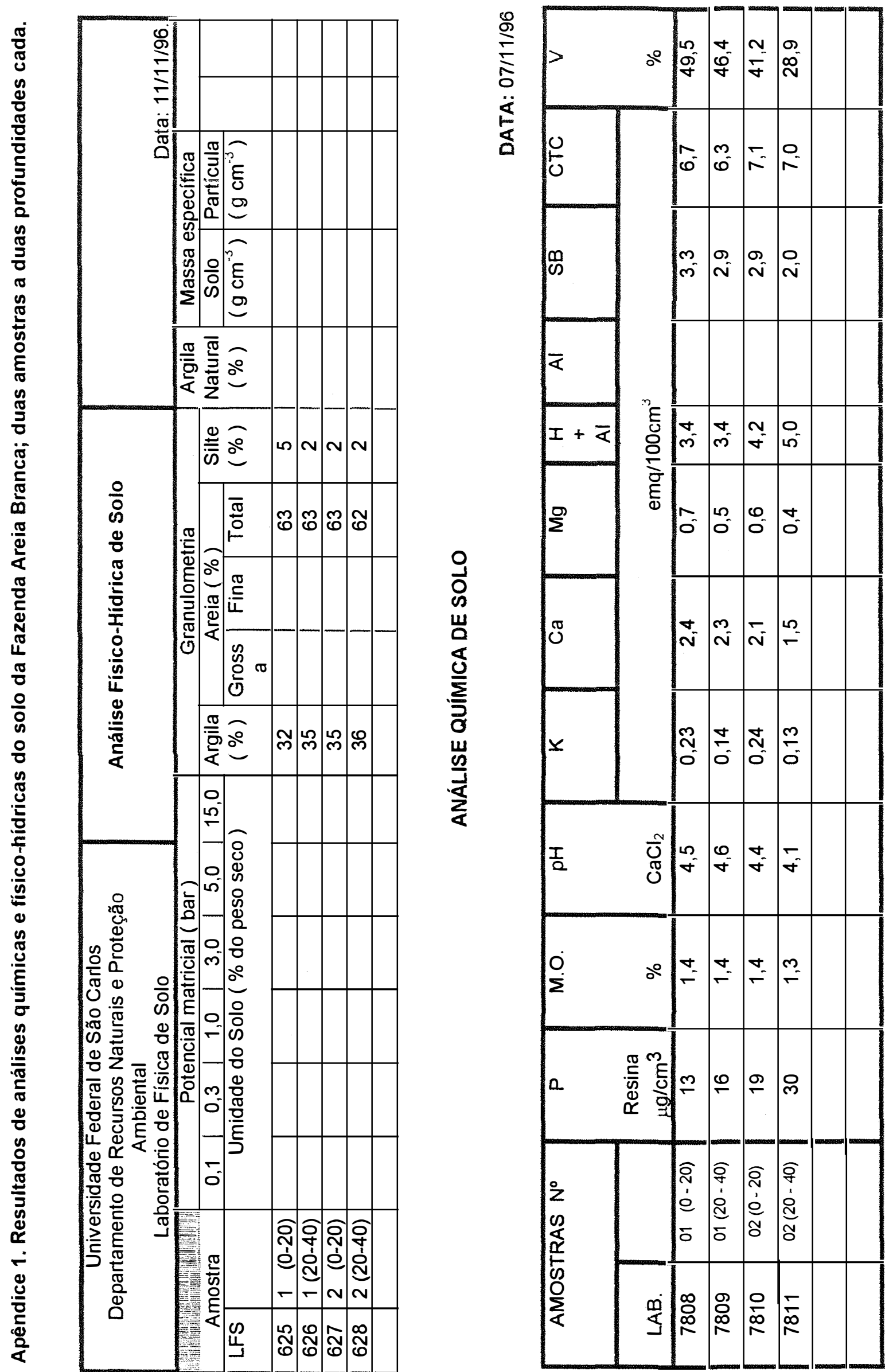

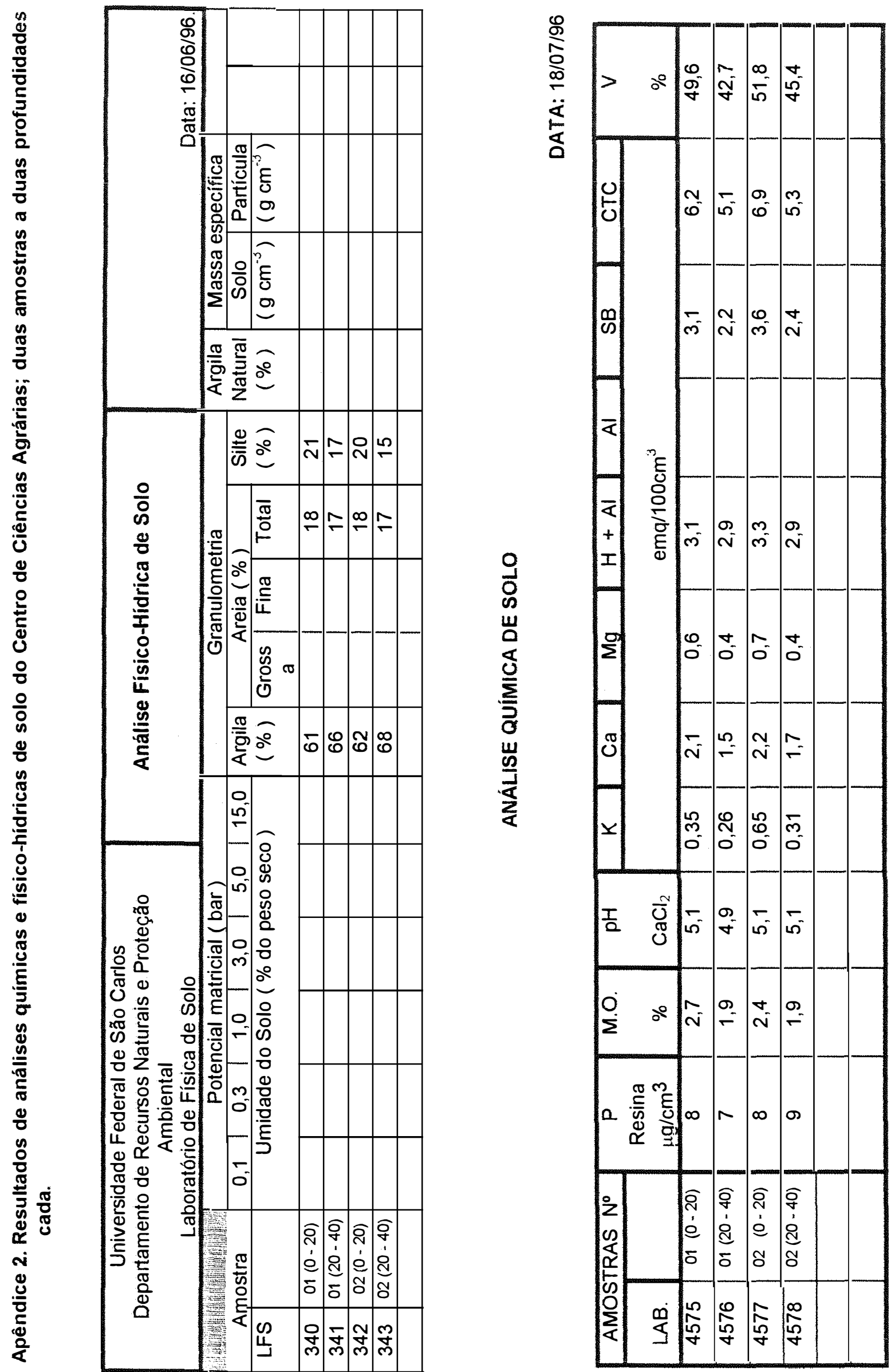

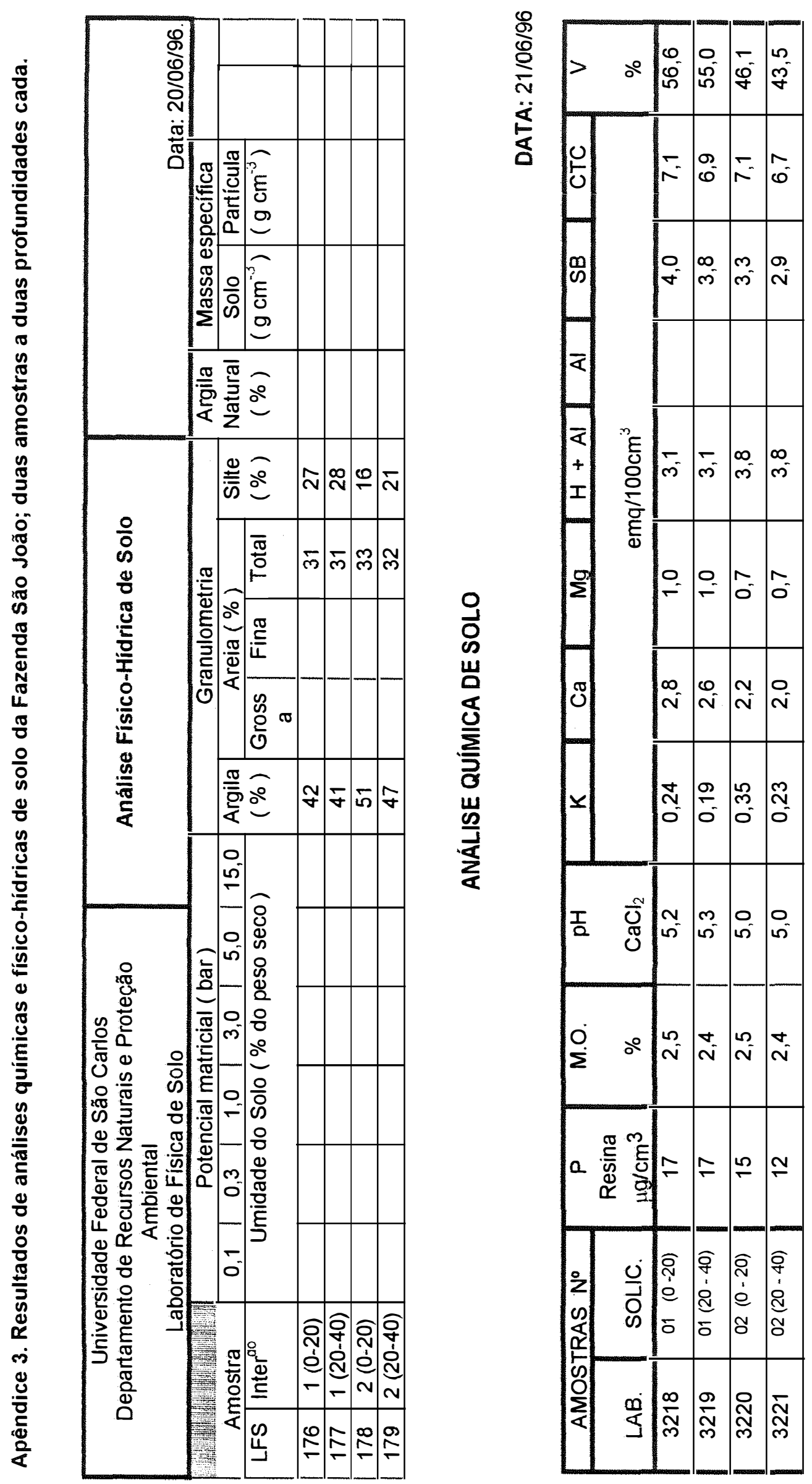
Apêndice 4- Numeração de folhas da cana-de-açúcar conforme Kuijper

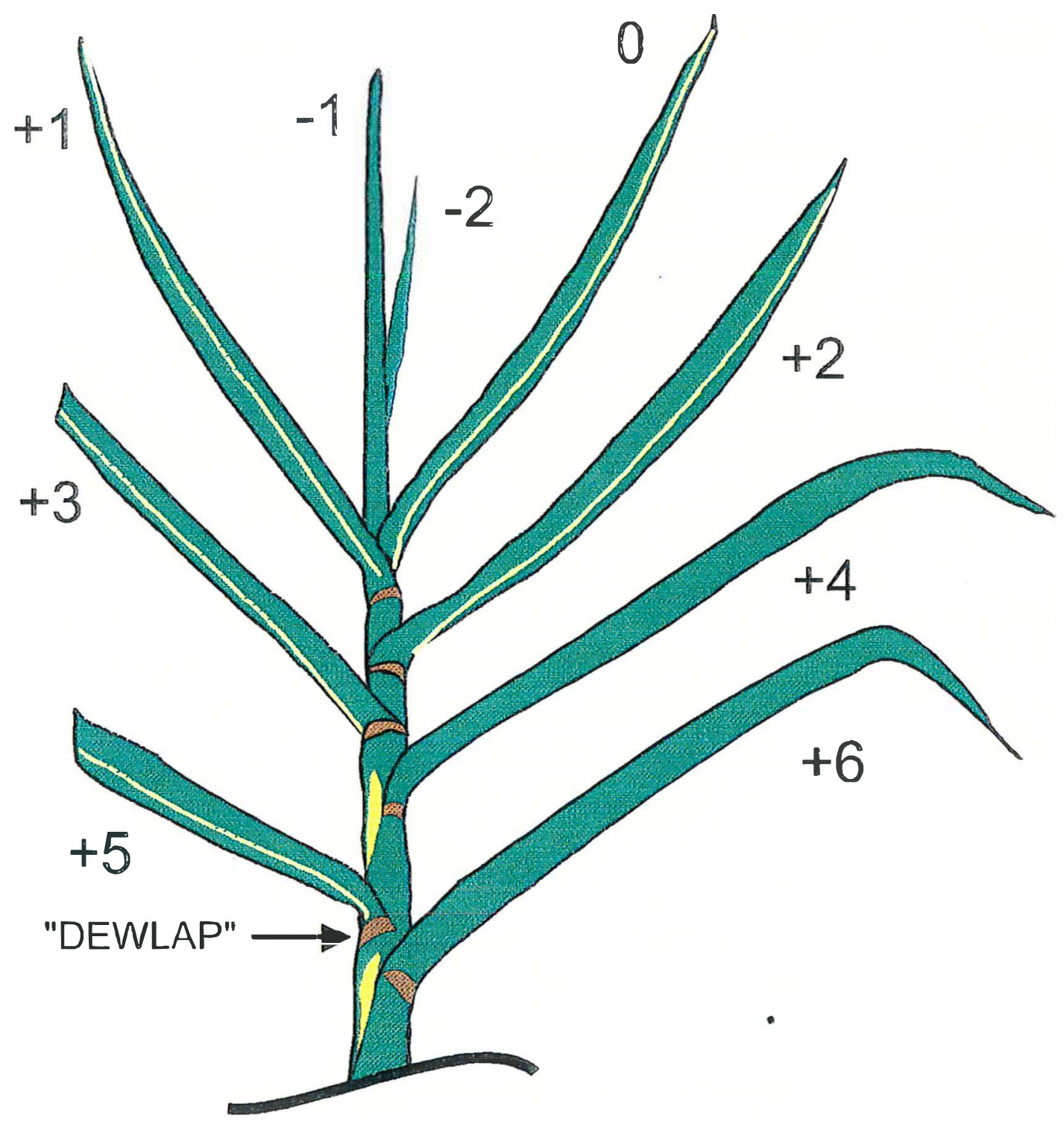


Apêndice 5. Escala diagramática para notas de sintomas de ferrugem (AMORIM et al., 1987).

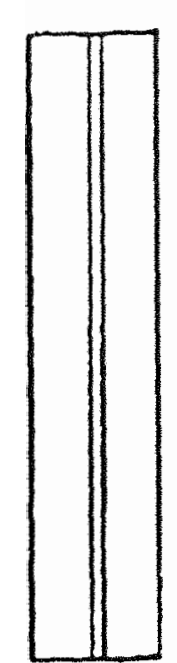

1

$0 \% \quad 0,5 \%$

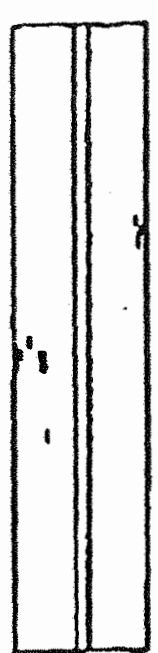

2

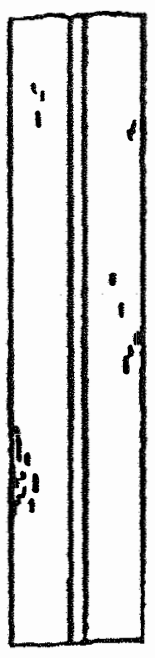

3

$1 \% \quad 5 \%$

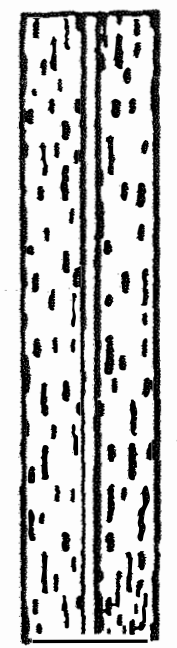

5

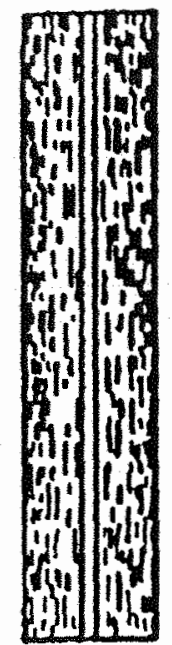

6

$10 \%$

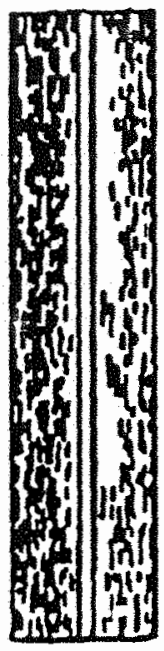

7

$35 \% \quad 50 \%>50 \%$

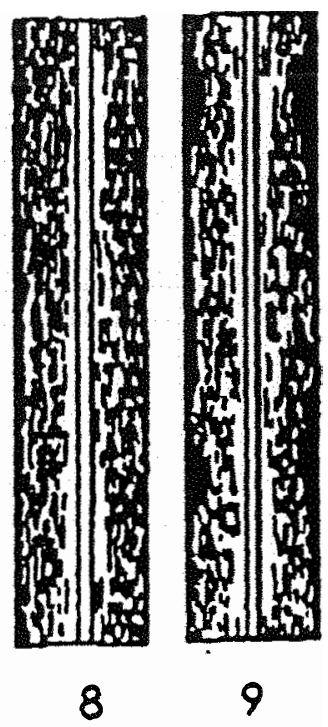

$25 \%$ 
Apêndice 6 - Esquema para graduação de florescimento (PADRONIZAÇÃO, 1994)

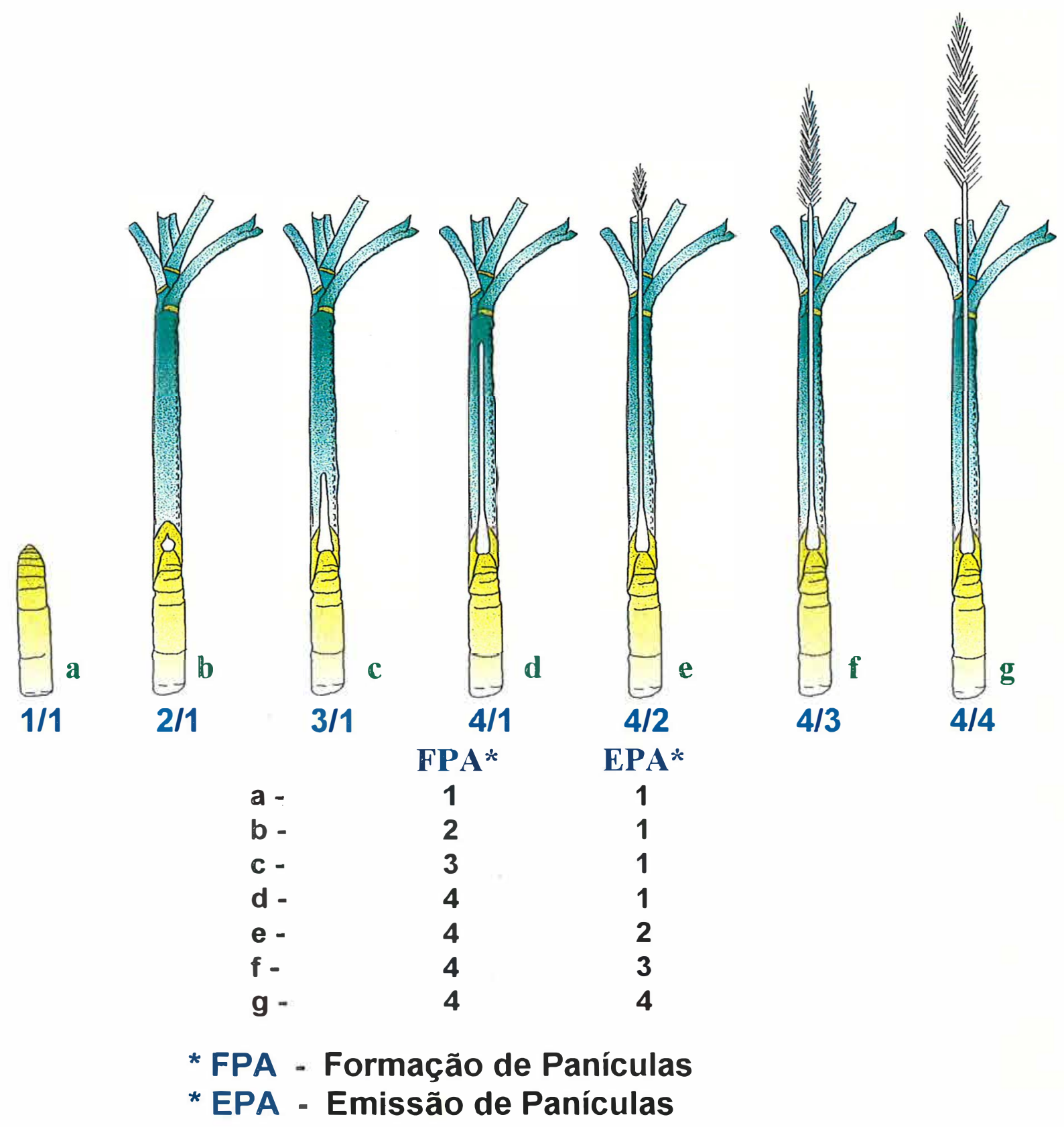

OBS: As notas referentes à Emissão de Panículas (EPA), quando diferentes de 1, variam de acordo com o estágio de desenvolvimento e a porcentagem de panículas na parcela observada.

$$
\begin{aligned}
& \text { e - entre } 01 \text { e } 25 \% \\
& \text { - entre } 26 \text { e } 70 \% \\
& \text { g - acima de } 70 \%
\end{aligned}
$$




\section{Avaliação de chochamento}

1. Cortar o colmo transversalmente, do ponteiro para baixo ou vice-versa; notar o chochamento a cada internódio, verificando seu diâmetro e sua extensão; em seguida dar as notas, baseando-se nos seguintes parâmetros:

Notas para diâmetro de chochamento Notas para extensão do chochamento

1 - Ausência

2 - Pouco (menos de $25 \%$ do círculo)

3 - Médio (até $50 \%$ do círculo)

4 - Intenso (mais de $50 \%$ do círculo)
1 - Ausência

2 - Pouco (até $1 / 3$ do colmo)

3 - Médio (até $1 / 2$ do colmo)

4 - Bastante (mais de 1/2 do colmo)

\section{EXEMPLOS:}

- Nota 2/2 (diâmetro/extensão) - pouco chochamento (2), e apenas em 1/3 da cana (2). Avaliar diâmetro na parte mediana da extensão chocha.

\section{(8)}

- Nota 3/2 - chochamento médio (3), e apenas em 1/3 da cana

(2).

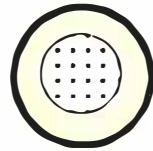

- Nota 4/3 - chochamento intenso (4), e até o meio da cana (3).

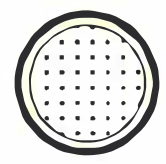




\section{5 $\quad$ \%}
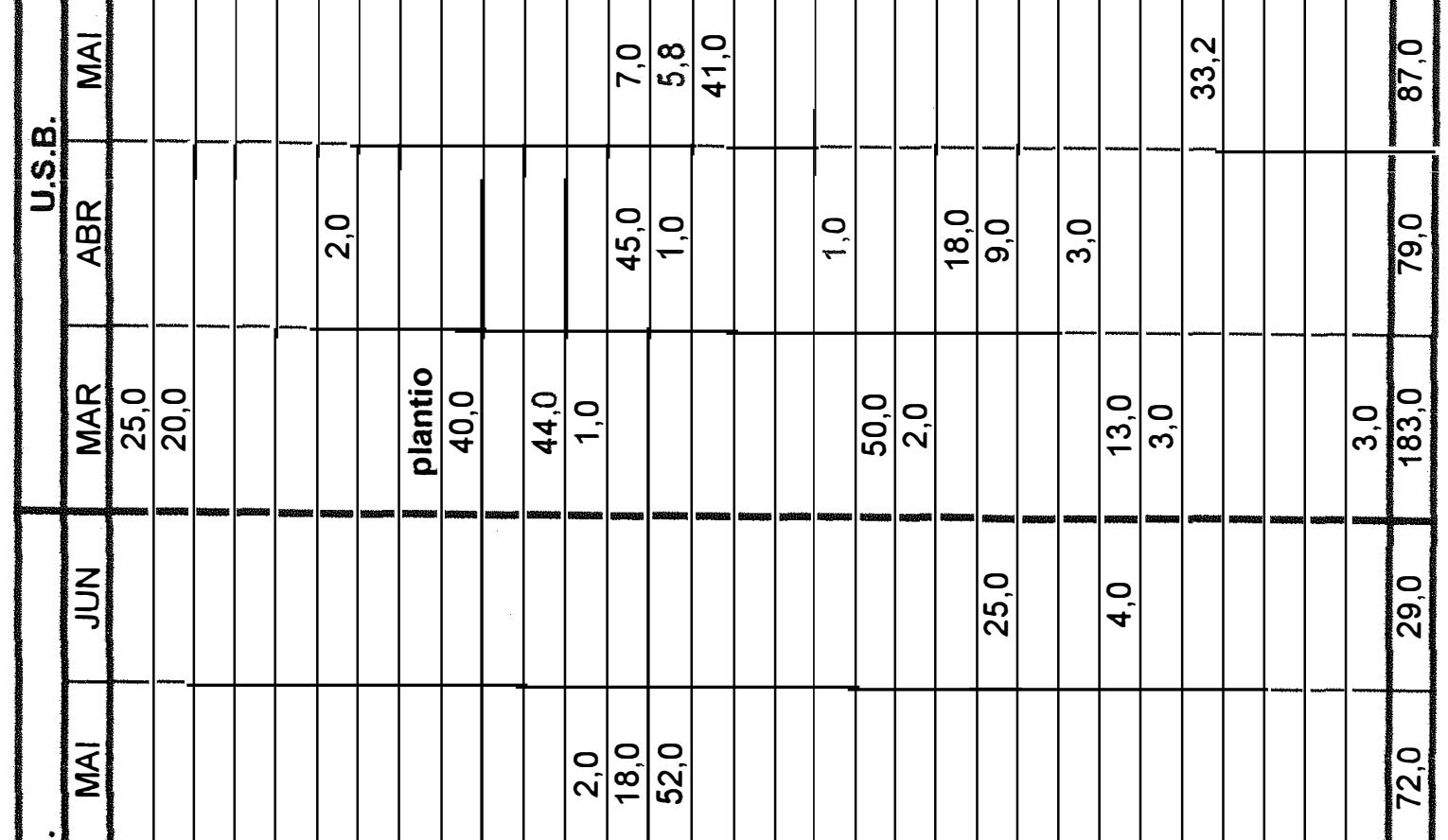

i)

ذ)

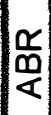

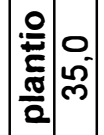

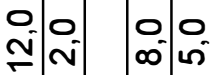

ชิ

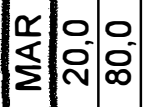

$\begin{array}{lllll}0 & 0 & 0 & 0 & 0 \\ 0 & 0 & 0 & 0 \\ 0 & 0 & 0 \\ 0 & 0 & 0\end{array}$

\begin{tabular}{l}
0 \\
0 \\
\multirow{y}{*}{}
\end{tabular}

$\begin{array}{ll}0 & \\ \sim & 0 \\ \sim & \infty\end{array}$

$\begin{array}{ll}0 & 0 \\ \infty & 0\end{array}$

염

3

西

앙.

文

에에에

옴

응

.

文全。

نํ.

온

응-

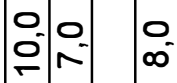

일

$\frac{0}{2}$
$\frac{0}{0}$
$\frac{0}{0}$
$\frac{0}{0}$
$\frac{0}{0}$
$\frac{0}{8}$
$\frac{0}{4}$
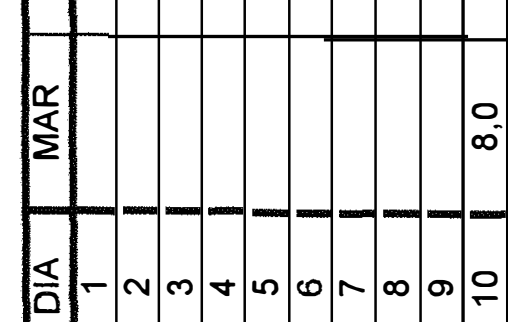

을

의웅응

영

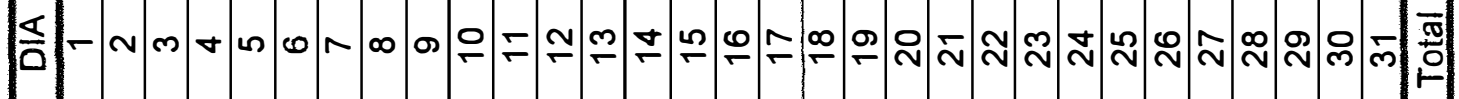


Apêndice 9. Precipitação pluviométrica anual nos três locais dos ensaios.

\begin{tabular}{lcccccccccc}
\hline & \multicolumn{3}{c}{1994} & \multicolumn{3}{c}{1995} & \multicolumn{3}{c}{1996} \\
\hline Meses & FAB & CCA & FSJ & FAB & CCA & FSJ & FAB & CCA & FSJ \\
\hline Janeiro & 267 & 352 & 504 & 233 & 345 & 198 & 254 & 320 & 175 \\
\hline Fevereiro & 229 & 237 & 192 & 629 & 735 & 540 & 243 & 388 & 281 \\
Março & 183 & 70 & 284 & 241 & 209 & 194 & 234 & 244 & 272 \\
Abril & 79 & 39 & 62 & 88 & 133 & 139 & 36 & 35 & 78 \\
Maio & 87 & 89 & 72 & 46 & 23 & 70 & 37 & 91 & 89 \\
Junho & 35 & 53 & 29 & 38 & 26 & 10 & 20 & 7 & 50 \\
Julho & 37 & 0 & 10 & 53 & 59 & 28 & 0 & 0 & 0 \\
Agosto & 0 & 0 & 0 & 0 & 0 & 0 & 30 & 25 & 15 \\
Setembro & 0 & 0 & 0 & 109 & 47 & 68 & 192 & 185 & 140 \\
Outubro & 39 & 181 & 195 & 208 & 174 & 225 & - & - & - \\
Novembro & 273 & 235 & 283 & 194 & 148 & 84 & - & - & - \\
Dezembro & 370 & 278 & 274 & 182 & 273 & 313 & - & - & - \\
\hline TOTAL & 1599 & 1534 & 1905 & 2021 & 2172 & 1869 & 1046 & 1295 & 1100 \\
\hline
\end{tabular}


Apêndice 10. Dados brutos do número e metros das falhas em cana-planta e cana-soca na Fazenda Area Branca.

\begin{tabular}{|c|c|c|c|c|c|}
\hline \multirow[b]{2}{*}{ Variedade } & \multirow[b]{2}{*}{ Rep. } & \multicolumn{2}{|c|}{ Cana-planta } & \multicolumn{2}{|c|}{ Cana-soca } \\
\hline & & $\mathrm{N}^{0}$ & Metragem & $\mathrm{N}^{0}$ & Metragem \\
\hline \multirow[t]{3}{*}{ CB41-76 } & 1 & 1 & 0,50 & 3 & 2,23 \\
\hline & II & 1 & 0,55 & 3 & 2,36 \\
\hline & III & 1 & 0,85 & 2 & 1,61 \\
\hline \multirow[t]{3}{*}{ Co290 } & 1 & 0 & 0,00 & 8 & 6,20 \\
\hline & II & 1 & 0,65 & 4 & 3,61 \\
\hline & III & 0 & 0,00 & 9 & 6,50 \\
\hline \multirow[t]{3}{*}{ Co419 } & 1 & 1 & 0,60 & 6 & 4,11 \\
\hline & II & 0 & 0,00 & 5 & 3,39 \\
\hline & III. & 1 & 0,65 & 10 & 9,90 \\
\hline \multirow[t]{3}{*}{ IAC48-65 } & 1 & 2 & 1,00 & 4 & 2,60 \\
\hline & II & 0 & 0,00 & 2 & 1,50 \\
\hline & III & 2 & 1,00 & 3 & 2,11 \\
\hline \multirow[t]{3}{*}{ NA56-79 } & 1 & 1 & 0,65 & 3 & 2,29 \\
\hline & II & 1 & 0,60 & 5 & 2,73 \\
\hline & III & 0 & 0,00 & 3 & 2,14 \\
\hline \multirow[t]{3}{*}{ RB72454 } & 1 & 2 & 1,10 & 5 & 4,62 \\
\hline & II & 0 & 0,00 & 5 & 2,94 \\
\hline & III & 0 & 0,00 & 4 & 3,05 \\
\hline \multirow[t]{3}{*}{ RB835089 } & 1 & 1 & 0,55 & 3 & 2,31 \\
\hline & II & 3 & 1,85 & 3 & 2,00 \\
\hline & III & 1 & 0,70 & 2 & 1,45 \\
\hline \multirow[t]{3}{*}{ SP70-1143 } & 1 & 3 & 1,60 & 2 & 1,19 \\
\hline & II & 0 & 0,00 & 1 & 0,60 \\
\hline & III & 0 & 0,00 & 0 & 0,00 \\
\hline \multirow[t]{3}{*}{ SP71-1406 } & 1 & 0 & 0,00 & 12 & 10,60 \\
\hline & II & 0 & 0,00 & 5 & 3,12 \\
\hline & III & 0 & 0,00 & 2 & 1,50 \\
\hline \multirow[t]{3}{*}{ SP71- 6163} & 1 & 3 & 1,50 & 16 & 13,32 \\
\hline & II & 1 & 0,55 & 15 & 11,52 \\
\hline & III & 0 & 0,00 & 10 & 9,85 \\
\hline
\end{tabular}


Apêndice 11. Dados brutos do número e metros das falhas em cana-planta e cana-soca no Centro de Ciências Agrárias.

\begin{tabular}{|c|c|c|c|c|c|}
\hline \multirow[b]{2}{*}{ Variedade } & \multirow[b]{2}{*}{ Rep. } & \multicolumn{2}{|c|}{ Cana-planta } & \multicolumn{2}{|c|}{ Cana-soca } \\
\hline & & $N^{0}$ & Metragem & $N^{\circ}$ & Metragem \\
\hline \multirow[t]{3}{*}{ CB41-76 } & 1 & 7 & 4,50 & 6 & 5,05 \\
\hline & II & 4 & 2,20 & 2 & 2,25 \\
\hline & III & 6 & 4,22 & 6 & 6,20 \\
\hline \multirow[t]{3}{*}{ Co290 } & 1 & 8 & 5,50 & 8 & 8,00 \\
\hline & II & 9 & 8,40 & 7 & 7,90 \\
\hline & III & 4 & 2,35 & 5 & 2,90 \\
\hline \multirow[t]{3}{*}{ Co419 } & 1 & 10 & 8,50 & 12 & 13,80 \\
\hline & II & 7 & 6,30 & 14 & 11,20 \\
\hline & III & 12 & 8,85 & 14 & 13,00 \\
\hline \multirow[t]{3}{*}{ IAC48-65 } & 1 & 1 & 0,55 & 2 & 1,07 \\
\hline & II & 4 & 2,15 & 4 & 3,40 \\
\hline & III & 1 & 0,55 & 4 & 4,30 \\
\hline \multirow[t]{3}{*}{ NA56-79 } & 1 & 3 & 2,20 & 1 & 0,65 \\
\hline & II & 4 & 2,60 & 6 & 4,90 \\
\hline & III & 3 & 1,53 & 5 & 5,10 \\
\hline \multirow[t]{3}{*}{ RB72454 } & 1 & 5 & 4,00 & 5 & 4,90 \\
\hline & II & 12 & 7,80 & 6 & 5,50 \\
\hline & III & 10 & 5,75 & 7 & 5,70 \\
\hline \multirow[t]{3}{*}{ RB835089 } & 1 & 6 & 3,80 & 6 & 4,60 \\
\hline & 11 & 6 & 4,40 & 6 & 4,60 \\
\hline & III & 5 & 2,60 & 6 & 4,80 \\
\hline \multirow[t]{3}{*}{ SP70-1143 } & 1 & 1 & 0,70 & 0 & 0,00 \\
\hline & 11 & 2 & 1,10 & 3 & 1,90 \\
\hline & III & 2 & 1,20 & 1 & 0,70 \\
\hline \multirow[t]{3}{*}{ SP71-1406 } & 1 & 3 & 2,00 & 7 & 4,42 \\
\hline & 11 & 1 & 0,60 & 8 & 7,10 \\
\hline & III & 3 & 1,65 & 6 & 5,50 \\
\hline \multirow[t]{3}{*}{ SP71- 6163} & 1 & 4 & 2,90 & 13 & 13,70 \\
\hline & II & 7 & 4,20 & 9 & 10,20 \\
\hline & III & 4 & 2,70 & 13 & 16,90 \\
\hline
\end{tabular}


Apêndice 12. Dados brutos do número e metros das falhas em cana-planta e cana-soca na Fazenda São João.

\begin{tabular}{|c|c|c|c|c|c|}
\hline \multirow[b]{2}{*}{ Variedade } & \multirow[b]{2}{*}{ Rep. } & \multicolumn{2}{|c|}{ Cana-planta } & \multicolumn{2}{|c|}{ Cana-soca } \\
\hline & & $\mathrm{N}^{\circ}$ & Metragem & $\mathrm{N}^{\circ}$ & Metragem \\
\hline \multirow[t]{3}{*}{ CB41-76 } & 1 & 4 & 2,70 & 4 & 3,50 \\
\hline & II & 4 & 2,68 & 9 & 8,49 \\
\hline & III & 0 & 0,00 & 4 & 2,70 \\
\hline \multirow[t]{3}{*}{ Co290 } & 1 & 6 & 4,20 & 10 & 8,20 \\
\hline & II & 1 & 0,55 & 3 & 2,40 \\
\hline & III & 3 & 1,90 & 6 & 5,10 \\
\hline \multirow[t]{3}{*}{ Co419 } & 1 & 4 & 2,50 & 17 & 16,60 \\
\hline & II & 6 & 3,70 & 13 & 12,20 \\
\hline & III & 9 & 6,00 & 10 & 9,50 \\
\hline \multirow[t]{3}{*}{ IAC48-65 } & 1 & 4 & 3,40 & 5 & 4,20 \\
\hline & II & 3 & 1,85 & 4 & 2,70 \\
\hline & III & 3 & 2,05 & 2 & 1,90 \\
\hline \multirow[t]{3}{*}{ NA56-79 } & 1 & 7 & 4,65 & 6 & 6,00 \\
\hline & II & 0 & 0,00 & 0 & 0,00 \\
\hline & III & 5 & 3,30 & 4 & 2,60 \\
\hline \multirow[t]{3}{*}{ RB72454 } & 1 & 2 & 1,35 & 6 & 3,90 \\
\hline & II & 3 & 2,80 & 10 & 9,00 \\
\hline & III & 4 & 2,80 & 11 & 10,10 \\
\hline \multirow[t]{3}{*}{ RB835089 } & 1 & 1 & 0,80 & 8 & 7,80 \\
\hline & II & 7 & 5,10 & 8 & 6,20 \\
\hline & III & 10 & 8,00 & 8 & 7,20 \\
\hline \multirow[t]{3}{*}{ SP70-1143 } & 1 & 6 & 6,00 & 6 & 7,30 \\
\hline & II & 7 & 6,20 & 4 & 4,50 \\
\hline & III & 9 & 8,90 & 6 & 5,30 \\
\hline \multirow[t]{3}{*}{ SP71-1406 } & 1 & 3 & 1,80 & 9 & 10,40 \\
\hline & II & 3 & 2,45 & 11 & $8,30$. \\
\hline & III & 8 & 4,90 & 4 & 3,90 \\
\hline \multirow[t]{3}{*}{ SP71- 6163} & 1 & 7 & 5,05 & 16 & 11,50 \\
\hline & II & 4 & 3,20 & 8 & 8,30 \\
\hline & III & 4 & 4,30 & 4 & 4,50 \\
\hline
\end{tabular}


Apêndice 13. Dados originais do perfilhamento em cana-planta, leitura nos $8,0 \mathrm{~m}$ da linha central da parcela nos $90,150,180,240$ e 300 dias, na Fazenda Areia Branca.

\begin{tabular}{|c|c|c|c|c|c|c|}
\hline \multirow[b]{2}{*}{ Variedade } & \multirow[b]{2}{*}{ Rep. } & \multicolumn{5}{|c|}{ Número de dias na leitura } \\
\hline & & 90 & 150 & 180 & 240 & 300 \\
\hline \multirow[t]{3}{*}{ CB41-76 } & 1 & 74 & 146 & 159 & 124 & 100 \\
\hline & II & 119 & 185 & 193 & 138 & 107 \\
\hline & III & 127 & 178 & 167 & 143 & 105 \\
\hline \multirow[t]{3}{*}{ Co290 } & 1 & 117 & 183 & 166 & 138 & 93 \\
\hline & 11 & 174 & 206 & 204 & 145 & 129 \\
\hline & III & 135 & 206 & 169 & 152 & 121 \\
\hline \multirow[t]{3}{*}{ Co419 } & 1 & 95 & 132 & 158 & 115 & 109 \\
\hline & II & 116 & 155 & 152 & 135 & 120 \\
\hline & III & 85 & 118 & 168 & 116 & 101 \\
\hline \multirow[t]{3}{*}{ IAC 48-65 } & 1 & 58 & 98 & 105 & 105 & 99 \\
\hline & II & 85 & 126 & 140 & 122 & 98 \\
\hline & III & 104 & 163 & 162 & 136 & 123 \\
\hline \multirow[t]{3}{*}{ NA56-79 } & 1 & 139 & 146 & 171 & 136 & 120 \\
\hline & II & 117 & 148 & 153 & 126 & 113 \\
\hline & III & 157 & 169 & 156 & 145 & 116 \\
\hline \multirow[t]{3}{*}{ RB72454 } & 1 & 106 & 169 & 238 & 171 & 136 \\
\hline & II & 156 & 252 & 279 & 189 & 150 \\
\hline & III & 142 & 228 & 216 & 170 & 138 \\
\hline \multirow[t]{3}{*}{ RB835089 } & 1 & 110 & 155 & 170 & 129 & 112 \\
\hline & II & 88 & 172 & 200 & 146 & 119 \\
\hline & III & 133 & 177 & 218 & 161 & 125 \\
\hline \multirow[t]{3}{*}{ SP70-1143 } & 1 & 108 & 175 & 187 & 132 & 117 \\
\hline & II & 166 & 195 & 213 & 146 & 123 \\
\hline & III & 97 & 173 & 171 & 137 & 123 \\
\hline \multirow[t]{3}{*}{ SP71-1406 } & 1 & 105 & 157 & 155 & 138 & 126 \\
\hline & II & 100 & 121 & 135 & 124 & 109 \\
\hline & III & 150 & 181 & 179 & 151 & 128 \\
\hline \multirow[t]{3}{*}{ SP71- 6163} & 1 & 84 & 134 & 182 & 158 & 130 \\
\hline & II & 99 & 163 & 126 & 114 & 98 \\
\hline & III & 103 & 154 & 189 & 151 & 129 \\
\hline
\end{tabular}


Apêndice 14. Dados originais do perfilhamento em cana-planta, leitura nos $8,0 \mathrm{~m}$ da linha central da parcela nos $90,150,180,240$ e 300 dias, no Centro de Ciências Agrárias.

\begin{tabular}{|c|c|c|c|c|c|c|}
\hline \multirow[b]{2}{*}{ Variedade } & \multirow[b]{2}{*}{ Rep. } & \multicolumn{5}{|c|}{ Número de dias na leitura } \\
\hline & & 90 & 150 & 180 & 240 & 300 \\
\hline \multirow[t]{3}{*}{ CB41-76 } & 1 & 90 & 116 & 130 & 111 & 97 \\
\hline & II & 123 & 137 & 177 & 108 & 88 \\
\hline & III & 64 & 90 & 113 & 93 & 81 \\
\hline \multirow[t]{3}{*}{ Co290 } & 1 & 83 & 114 & 135 & 97 & 93 \\
\hline & II & 90 & 130 & 123 & 96 & 94 \\
\hline & III & 75 & 126 & 135 & 111 & 96 \\
\hline \multirow[t]{3}{*}{ Co419 } & 1 & 59 & 94 & 110 & 100 & 90 \\
\hline & II & 67 & 85 & 84 & 98 & 82 \\
\hline & III & 79 & 129 & 130 & 101 & 90 \\
\hline \multirow[t]{3}{*}{ IAC48-65 } & 1 & 74 & 95 & 121 & 107 & 100 \\
\hline & II & 70 & 111 & 112 & 109 & 103 \\
\hline & III & 86 & 120 & 128 & 119 & 94 \\
\hline \multirow[t]{3}{*}{ NA56-79 } & 1 & 89 & 132 & 130 & 97 & 85 \\
\hline & II & 112 & 136 & 111 & 119 & 104 \\
\hline & III & 94 & 133 & 129 & 106 & 102 \\
\hline \multirow[t]{3}{*}{ RB72454 } & 1 & 86 & 120 & 156 & 119 & 98 \\
\hline & II & 66 & 133 & 155 & 110 & 92 \\
\hline & III & 74 & 129 & 157 & 110 & 100 \\
\hline \multirow[t]{3}{*}{ RB835089 } & 1 & 90 & 142 & 137 & 113 & 96 \\
\hline & II & 86 & 136 & 122 & 113 & 88 \\
\hline & III & 100 & 172 & 171 & 120 & 107 \\
\hline \multirow[t]{3}{*}{ SP70-1143 } & 1 & 101 & 146 & 167 & 114 & 94 \\
\hline & II & 122 & 180 & 149 & 159 & 140 \\
\hline & III & 100 & 161 & 179 & 138 & 117 \\
\hline \multirow[t]{3}{*}{ SP71-1406 } & 1 & 86 & 110 & 114 & 87 & 79 \\
\hline & II & 73 & 85 & 116 & 96 & 80 \\
\hline & III & 60 & 87 & 95 & 83 & 78 \\
\hline \multirow[t]{3}{*}{ SP71- 6163} & 1 & 74 & 96 & 135 & 90 & 73 \\
\hline & II & 60 & 121 & 148 & 142 & 109 \\
\hline & III & 62 & 129 & 159 & 136 & 106 \\
\hline
\end{tabular}


Apêndice 15. Dados originais do perfilhamento em cana-planta, leitura nos $8,0 \mathrm{~m}$ da linha central da parcela nos $90,150,180,240$ e 300 dias, na Fazenda São João.

\begin{tabular}{|c|c|c|c|c|c|c|}
\hline \multirow[b]{2}{*}{ Variedade } & \multirow[b]{2}{*}{ Rep. } & \multicolumn{5}{|c|}{ Número de dias na leitura } \\
\hline & & 90 & 150 & 180 & 240 & 300 \\
\hline \multirow[t]{3}{*}{ CB41-76 } & 1 & 114 & 132 & 113 & 127 & 102 \\
\hline & II & 145 & 158 & 138 & 130 & 113 \\
\hline & III & 133 & 153 & 137 & 91 & 89 \\
\hline \multirow[t]{3}{*}{ Co290 } & 1 & 100 & 139 & 120 & 143 & 102 \\
\hline & II & 87 & 133 & 119 & 123 & 105 \\
\hline & III & 121 & 162 & 153 & 122 & 133 \\
\hline \multirow[t]{3}{*}{ Co419 } & 1 & 97 & 108 & 99 & 99 & 97 \\
\hline & II & 104 & 149 & 144 & 106 & 106 \\
\hline & III & 86 & 115 & 70 & 92 & 83 \\
\hline \multirow[t]{3}{*}{ IAC48-65 } & 1 & 94 & 105 & 109 & 155 & 135 \\
\hline & II & 84 & 110 & 91 & 121 & 115 \\
\hline & III & 77 & 98 & 91 & 102 & 112 \\
\hline \multirow[t]{3}{*}{ NA56-79 } & 1 & 85 & 103 & 104 & 112 & 87 \\
\hline & II & 150 & 168 & 161 & 135 & 133 \\
\hline & III & 135 & 149 & 169 & 141 & 138 \\
\hline \multirow[t]{3}{*}{ RB72454 } & 1 & 113 & 109 & 124 & 108 & 94 \\
\hline & II & 121 & 130 & 139 & 135 & 108 \\
\hline & III & 118 & 128 & 139 & 129 & 108 \\
\hline \multirow[t]{3}{*}{ RB835089 } & 1 & 139 & 147 & 151 & 134 & 105 \\
\hline & II & 153 & 163 & 135 & 118 & 118 \\
\hline & III & 120 & 142 & 150 & 126 & 102 \\
\hline \multirow[t]{3}{*}{ SP70-1143 } & 1 & 88 & 121 & 140 & 138 & 124 \\
\hline & II & 109 & 109 & 131 & 96 & 118 \\
\hline & III & 80 & 98 & 111 & 121 & 105 \\
\hline \multirow[t]{3}{*}{ SP71-1406 } & 1 & 114 & 104 & 103 & 113 & 94 \\
\hline & II & 99 & 105 & 101 & 106 & 103 \\
\hline & III & 96 & 103 & 101 & 113 & 87 \\
\hline \multirow[t]{3}{*}{ SP71- 6163} & 1 & 79 & 89 & 88 & 94 & 89 \\
\hline & II & 121 & 113 & 114 & 115 & 119 \\
\hline & III & 81 & 88 & 95 & 97 & 98 \\
\hline
\end{tabular}


Apêndice 16. Dados originais das leituras dos sintomas de ferrugem em canaplanta, na Fazenda Areia Branca.

\begin{tabular}{|c|c|c|c|c|c|c|c|c|c|c|c|c|c|c|c|c|}
\hline \multirow[b]{2}{*}{ Variedade } & \multirow[b]{2}{*}{ Rep. } & \multicolumn{5}{|c|}{$08 / 09 / 94$} & \multicolumn{5}{|c|}{$12 / 12 / 94$} & \multicolumn{5}{|c|}{$22 / 02 / 95$} \\
\hline & & 1 & 2 & 3 & 4 & 5 & 1 & 2 & 3 & 4 & 5 & 1 & 2 & 3 & 4 & 5 \\
\hline \multirow[t]{3}{*}{ CB41-76 } & 1 & 3 & 3 & 3 & 3 & 4 & 2 & 3 & 2 & 3 & 2 & 2 & 3 & 2 & 3 & 3 \\
\hline & II & 4 & 3 & 4 & 4 & 4 & 3 & 2 & 2 & 1 & 2 & 2 & 3 & 2 & 2 & 2 \\
\hline & III & 3 & 3 & 2 & 3 & 3 & 2 & 2 & 2 & 2 & 2 & 2 & 2 & 2 & 2 & 2 \\
\hline \multirow[t]{3}{*}{ Co290 } & 1 & 4 & 3 & 4 & 3 & 4 & 2 & 2 & 2 & 2 & 1 & 1 & 1 & 2 & 2 & 1 \\
\hline & II & 3 & 4 & 3 & 4 & 4 & 3 & 2 & 2 & 2 & 2 & 2 & 2 & 2 & 2 & 2 \\
\hline & III & 3 & 4 & 4 & 4 & 3 & 2 & 2 & 2 & 1 & 1 & 2 & 2 & 2 & 2 & 2 \\
\hline \multirow[t]{3}{*}{ Co419 } & 1 & 1 & 1 & 1 & 1 & 1 & 2 & 2 & 1 & 1 & 1 & 1 & 1 & 2 & 2 & 1 \\
\hline & II & 1 & 1 & 1 & 1 & 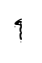 & 1 & 2 & 1 & 1 & 1 & 2 & 2 & 2 & 1 & 2 \\
\hline & III & 1 & 1 & 1 & 1 & 1 & 2 & 2 & 2 & 2 & 1 & 2 & 2 & 2 & 2 & 2 \\
\hline \multirow[t]{3}{*}{ IAC48-65 } & 1 & 3 & 3 & 4 & 3 & 3 & 2 & 2 & 1 & 1 & 1 & 3 & 3 & 3 & 3 & 4 \\
\hline & II & 5 & 4 & 4 & 4 & 4 & 1 & 2 & 2 & 2 & 2 & 3 & 4 & 3 & 3 & 3 \\
\hline & |II & 5 & 4 & 5 & 4 & 5 & 2 & 3 & 3 & 2 & 2 & 3 & 3 & 3 & 3 & 3 \\
\hline \multirow[t]{3}{*}{ NA56-79 } & 1 & 5 & 5 & 4 & 6 & 5 & 3 & 3 & 3 & 4 & 4 & 4 & 4 & 4 & 4 & 4 \\
\hline & II & 6 & 4 & 5 & 5 & 6 & 3 & 4 & 4 & 5 & 5 & 4 & 4 & 4 & 5 & 4 \\
\hline & III & 4 & 4 & 5 & 5 & 5 & 4 & 4 & 5 & 5 & 5 & 5 & 5 & 4 & 5 & 5 \\
\hline \multirow[t]{3}{*}{ RB72454 } & 1 & 1 & 1 & 1 & 1 & 1 & 1 & 1 & 2 & 2 & 1 & 1 & 1 & 1 & 1 & 1 \\
\hline & II & 1 & 1 & 1 & 1 & 1 & 2 & 1 & 2 & 1 & 1 & 1 & 1 & 1 & 1 & 1 \\
\hline & III & 1 & 1 & 1 & 1 & 1 & 1 & 2 & 1 & 2 & 1 & 1 & 1 & 1 & 1 & 1 \\
\hline \multirow[t]{3}{*}{ RB835089 } & 1 & 1 & 1 & 1 & 1 & 1 & 1 & 1 & 1 & 1 & 1 & 2 & 2 & 2 & 2 & 2 \\
\hline & II & 1 & 1 & 1 & 1 & 1 & 1 & 1 & 1 & 1 & 1 & 2 & 2 & 2 & 2 & 2 \\
\hline & III & 1 & 1 & 1 & 1 & 1 & 1 & 1 & 1 & 1 & 1 & 2 & 2 & 2 & 2 & 2 \\
\hline \multirow[t]{3}{*}{ SP70-1143 } & 1 & 4 & 6 & 5 & 6 & 5 & 3 & 3 & 3 & 3 & 3 & 5 & 5 & 4 & 4 & 5 \\
\hline & II & 6 & 6 & 5 & 6 & 6 & 3 & 4 & 3 & 4 & 3 & 5 & 4 & 5 & 4 & 4 \\
\hline & III & 4 & 6 & 5 & 6 & 6 & 3 & 2 & 3 & 4 & 3 & 4 & 4 & 4 & 4 & 4 \\
\hline \multirow[t]{3}{*}{ SP71-1406 } & 1 & 5 & 6 & 6 & 5 & 5 & 2 & 2 & 2 & 3 & 3 & 5 & 4 & 5 & 5 & 5 \\
\hline & II & 4 & 5 & 4 & 5 & 5 & 3 & 4 & 3 & 3 & 4 & 5 & 4 & 5 & 4 & 4 \\
\hline & III & 6 & 6 & 7 & 5 & 5 & 4 & 4 & 4 & 3 & 3 & 4 & 4 & 4 & 5 & 5 \\
\hline \multirow[t]{3}{*}{ SP71- 6163} & 1 & 6 & 6 & 6 & 5 & 5 & 2 & 2 & 2 & 2 & 2 & 4 & 4 & 4 & 3 & 4 \\
\hline & II & 4 & 3 & 5 & 5 & 5 & 2 & 1 & 2 & 2 & 3 & 4 & 4 & 4 & 4 & 4 \\
\hline & III & 5 & 5 & 5 & 5 & 5 & 2 & 2 & 2 & 2 & 2 & 4 & 4 & 4 & 4 & 4 \\
\hline
\end{tabular}


Apêndice 17. Dados originais das leituras dos sintomas de ferrugem em cana-planta no Centro de Ciências Agrárias.

\begin{tabular}{lcccccccccccccccc}
\hline \multirow{2}{*}{ Variedade } & Rep. & 1 & 2 & 3 & 4 & 5 & 1 & 2 & 3 & 4 & 5 & 1 & 2 & 3 & 4 & 5 \\
\hline CB41-76 & I & 2 & 1 & 1 & 2 & 2 & 1 & 1 & 1 & 1 & 1 & 1 & 1 & 1 & 1 & 1 \\
& II & 2 & 1 & 2 & 2 & 2 & 1 & 1 & 1 & 1 & 1 & 1 & 1 & 1 & 1 & 1 \\
C0290 & III & 1 & 2 & 2 & 2 & 3 & 1 & 1 & 1 & 1 & 1 & 1 & 1 & 1 & 1 & 1 \\
& I & 3 & 2 & 2 & 3 & 2 & 1 & 1 & 1 & 1 & 1 & 2 & 2 & 2 & 2 & 2 \\
& II & 2 & 1 & 1 & 2 & 2 & 1 & 1 & 1 & 1 & 1 & 2 & 2 & 2 & 2 & 1 \\
C0419 & III & 3 & 3 & 2 & 3 & 3 & 1 & 1 & 1 & 1 & 1 & 2 & 2 & 2 & 1 & 1 \\
& I & 1 & 1 & 1 & 1 & 1 & 1 & 1 & 1 & 1 & 1 & 1 & 1 & 1 & 1 & 1 \\
& II & 1 & 1 & 1 & 1 & 1 & 1 & 1 & 1 & 1 & 1 & 1 & 1 & 1 & 1 & 1 \\
IAC48-65 & III & 1 & 1 & 1 & 1 & 1 & 1 & 1 & 1 & 1 & 1 & 1 & 1 & 1 & 1 & 1 \\
& I & 2 & 2 & 3 & 3 & 3 & 1 & 1 & 1 & 1 & 1 & 2 & 1 & 1 & 2 & 1 \\
NA56-79 & II & 2 & 3 & 3 & 3 & 2 & 1 & 1 & 1 & 1 & 1 & 2 & 2 & 1 & 2 & 1 \\
& III & 2 & 2 & 3 & 3 & 2 & 1 & 1 & 1 & 1 & 1 & 2 & 1 & 2 & 2 & 2 \\
RB72454 & I & 3 & 3 & 3 & 3 & 3 & 2 & 2 & 2 & 2 & 2 & 2 & 2 & 2 & 1 & 2 \\
& II & 3 & 3 & 4 & 4 & 4 & 1 & 2 & 1 & 2 & 2 & 2 & 1 & 2 & 2 & 2 \\
& III & 3 & 5 & 3 & 4 & 4 & 3 & 2 & 3 & 3 & 3 & 3 & 3 & 3 & 3 & 3 \\
RB835089 & I & 1 & 1 & 1 & 1 & 1 & 1 & 1 & 1 & 1 & 1 & 1 & 1 & 1 & 1 & 1 \\
& II & 1 & 1 & 1 & 1 & 1 & 1 & 1 & 1 & 1 & 1 & 1 & 1 & 1 & 1 & 1 \\
& III & 1 & 1 & 1 & 1 & 1 & 1 & 1 & 1 & 1 & 1 & 1 & 1 & 1 & 1 & 1 \\
SP70-1143 & I & 1 & 1 & 1 & 1 & 1 & 1 & 1 & 1 & 1 & 1 & 1 & 1 & 1 & 1 & 1 \\
& II & 1 & 1 & 1 & 1 & 1 & 1 & 1 & 1 & 1 & 1 & 1 & 1 & 1 & 1 & 1 \\
& III & 1 & 1 & 1 & 1 & 1 & 1 & 1 & 1 & 1 & 1 & 1 & 1 & 1 & 1 & 1 \\
& I I & 3 & 3 & 3 & 4 & 3 & 1 & 1 & 2 & 2 & 1 & 2 & 2 & 1 & 2 & 2 \\
SP71-1406 & II & 3 & 3 & 4 & 4 & 3 & 2 & 2 & 2 & 2 & 2 & 2 & 3 & 3 & 2 & 2 \\
& III & 3 & 3 & 3 & 3 & 3 & 3 & 2 & 3 & 2 & 3 & 3 & 3 & 2 & 3 & 3 \\
& I & 4 & 3 & 4 & 4 & 3 & 1 & 1 & 1 & 2 & 2 & 2 & 2 & 2 & 2 & 2 \\
SP71-6163 & II & 3 & 3 & 4 & 3 & 3 & 2 & 1 & 1 & 2 & 1 & 1 & 2 & 1 & 1 & 1 \\
& III & 3 & 3 & 4 & 3 & 3 & 1 & 2 & 2 & 2 & 1 & 2 & 2 & 2 & 2 & 2 \\
& I & 3 & 3 & 4 & 4 & 3 & 1 & 1 & 1 & 1 & 1 & 4 & 3 & 3 & 3 & 2 \\
& II & 3 & 2 & 3 & 2 & 2 & 2 & 2 & 2 & 2 & 2 & 3 & 2 & 2 & 2 & 2 \\
& III & 4 & 4 & 4 & 4 & 3 & 2 & 1 & 2 & 1 & 2 & 2 & 1 & 2 & 2 & 2 \\
\hline
\end{tabular}


Apêndice 18. Dados originais das leituras dos sintomas de ferrugem em canaplanta na Fazenda São João.

\begin{tabular}{|c|c|c|c|c|c|c|c|c|c|c|c|c|c|c|c|c|}
\hline \multirow[b]{2}{*}{ Variedade } & \multirow[b]{2}{*}{ Rep } & \multicolumn{5}{|c|}{$18 / 10 / 94$} & \multicolumn{5}{|c|}{$14 / 12 / 94$} & \multicolumn{5}{|c|}{$23 / 02 / 95$} \\
\hline & & 1 & 2 & 3 & 4 & 5 & 1 & 2 & 3 & 4 & 5 & 1 & 2 & 3 & 4 & 5 \\
\hline \multirow[t]{3}{*}{ CB41-76 } & 1 & 1 & 1 & 1 & 1 & 1 & 1 & 1 & 1 & 1 & 1 & 2 & 2 & 2 & 1 & 2 \\
\hline & $\|$ & 1 & 1 & 1 & 1 & 1 & 1 & 1 & 1 & 1 & 1 & 2 & 2 & 2 & 2 & 2 \\
\hline & III & 1 & 1 & 1 & 1 & 1 & 1 & 1 & 1 & 1 & 1 & 2 & 2 & 2 & 2 & 2 \\
\hline \multirow[t]{3}{*}{ Co290 } & 1 & 1 & 1 & 1 & 1 & 1 & 1 & 1 & 1 & 1 & 1 & 2 & 2 & 2 & 2 & 2 \\
\hline & II & 1 & 1 & 1 & 1 & 1 & 1 & 1 & 1 & 1 & 1 & 2 & 2 & 2 & 2 & 2 \\
\hline & III & 1 & 1 & 1 & 1 & 1 & 1 & 1 & 1 & 1 & 1 & 2 & 2 & 2 & 2 & 2 \\
\hline \multirow[t]{3}{*}{ Co419 } & 1 & 1 & 1 & 1 & 1 & 1 & 1 & 1 & 1 & 1 & 1 & 1 & 1 & 1 & 1 & 1 \\
\hline & $\|$ & 1 & 1 & 1 & 1 & 1 & 1 & 1 & 1 & 1 & 1 & 1 & 1 & 1 & 1 & 1 \\
\hline & III & 1 & 1 & 1 & 1 & 1 & 1 & 1 & 1 & 1 & 1 & 1 & 1 & 1 & 1 & 1 \\
\hline \multirow[t]{3}{*}{ IAC48-65 } & 1 & 1 & 1 & 1 & 1 & 1 & 1 & 1 & 1 & 2 & 1 & 3 & 3 & 3 & 3 & 3 \\
\hline & II & 1 & 1 & 1 & 1 & 1 & 1 & 1 & 1 & 2 & 1 & 3 & 3 & 3 & 3 & 3 \\
\hline & III & 1 & 1 & 1 & 1 & 1 & 2 & 1 & 1 & 1 & 1 & 3 & 3 & 3 & 3 & 3 \\
\hline \multirow[t]{3}{*}{ NA56-79 } & 1 & 1 & 1 & 1 & 1 & 1 & 1 & 2 & 1 & 1 & 1 & 5 & 5 & 5 & 5 & 5 \\
\hline & II & 1 & 1 & 1 & 1 & 1 & 1 & 2 & 1 & 1 & 1 & 4 & 4 & 4 & 4 & 4 \\
\hline & III & 1 & 1 & 1 & 1 & 1 & 1 & 1 & 1 & 2 & 1 & 4 & 4 & 4 & 4 & 4 \\
\hline \multirow[t]{3}{*}{ RB72454 } & 1 & 1 & 1 & 1 & 1 & 1 & 1 & 1 & 1 & 1 & 1 & 1 & 1 & 1 & 1 & 1 \\
\hline & II & 1 & 1 & 1 & 1 & 1 & 1 & 1 & 1 & 1 & 1 & 1 & 1 & 1 & 1 & 1 \\
\hline & III & 1 & 1 & 1 & 1 & 1 & 1 & 1 & 1 & 1 & 1 & 1 & 1 & 1 & 1 & 1 \\
\hline \multirow[t]{3}{*}{ RB835089 } & 1 & 1 & 1 & 1 & 1 & 1 & 1 & 1 & 1 & 1 & 1 & 1 & 1 & 1 & 1 & 1 \\
\hline & II & 1 & 1 & 1 & 1 & 1 & 1 & 1 & 1 & 1 & 1 & 1 & 1 & 1 & 1 & 1 \\
\hline & III & 1 & 1 & 1 & 1 & 1 & 1 & 1 & 1 & 1 & 1 & 1 & 1 & 1 & 1 & 1 \\
\hline \multirow[t]{3}{*}{ SP70-1143 } & 1 & 1 & 1 & 1 & 1 & 1 & 2 & 2 & 1 & 1 & 1 & 3 & 3 & 3 & 3 & 3 \\
\hline & II & 1 & 1 & 1 & 1 & 1 & 2 & 2 & 1 & 1 & 1 & 3 & 3 & 3 & 3 & 3 \\
\hline & III & 1 & 1 & 1 & 1 & 1 & 1 & 1 & 1 & 2 & 1 & 4 & 4 & 4 & 4 & 4 \\
\hline \multirow[t]{3}{*}{ SP71-1406 } & 1 & 1 & 1 & 1 & 1 & 1 & 1 & 1 & 1 & 1 & 1 & 4 & 4 & 4 & 4 & 4 \\
\hline & II & 1 & 1 & 1 & 1 & 1 & 1 & 1 & 1 & 1 & 1 & 3 & 3 & 3 & 3 & 3 \\
\hline & III & 1 & 1 & 1 & 1 & 1 & 1 & 1 & 1 & 1 & 1 & 4 & 4 & 4 & 4 & 4 \\
\hline \multirow[t]{3}{*}{ SP71- 6163} & 1 & 1 & 1 & 1 & 1 & 1 & 1 & 1 & 1 & 1 & 1 & 3 & 3 & 3 & 3 & 3 \\
\hline & II & 1 & 1 & 1 & 1 & 1 & 1 & 1 & 1 & 1 & 1 & 4 & 4 & 4 & 4 & 4 \\
\hline & III & 1 & 1 & 1 & 1 & 1 & 1 & 1 & 1 & 1 & 1 & 3 & 3 & 3 & 3 & 3 \\
\hline
\end{tabular}




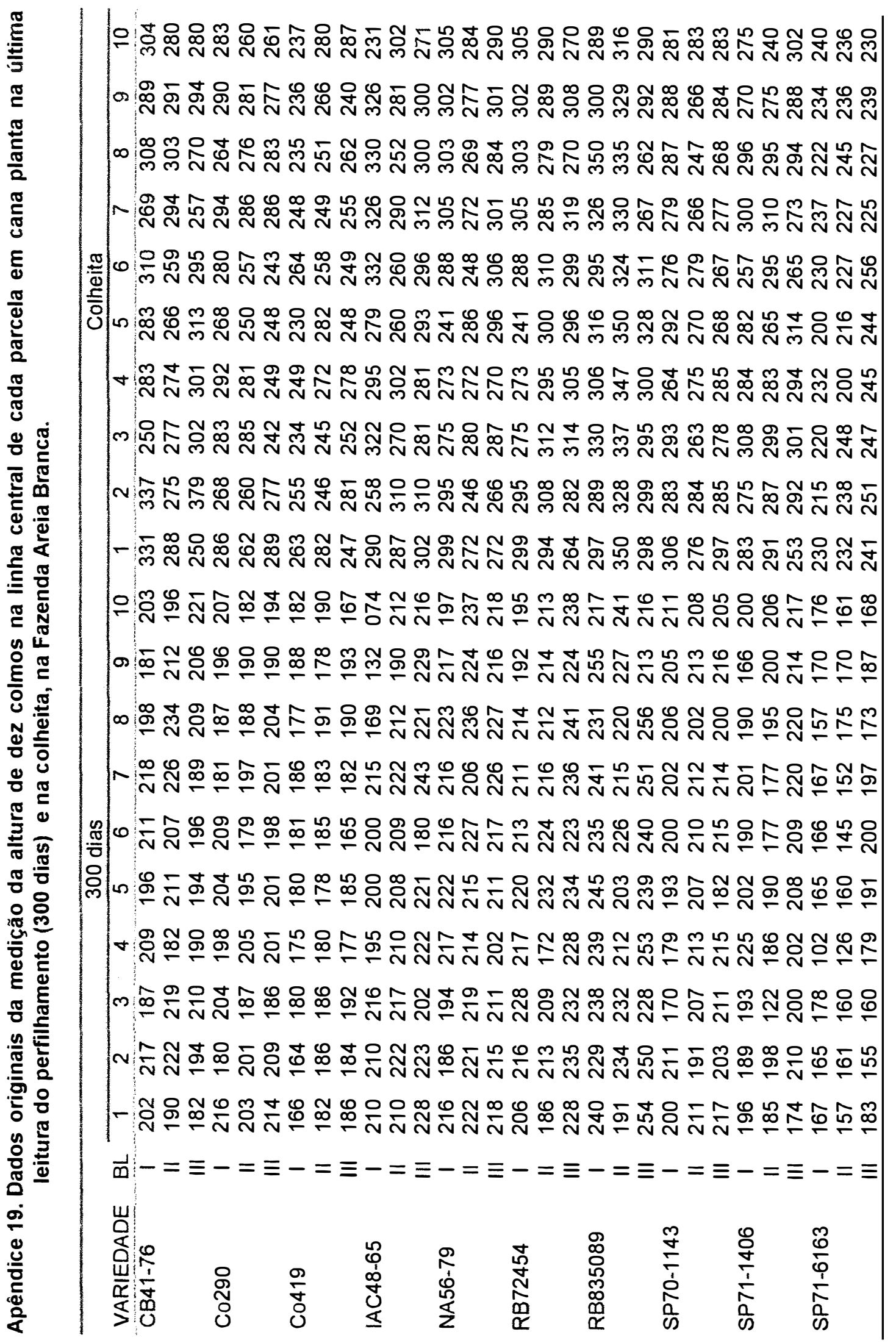




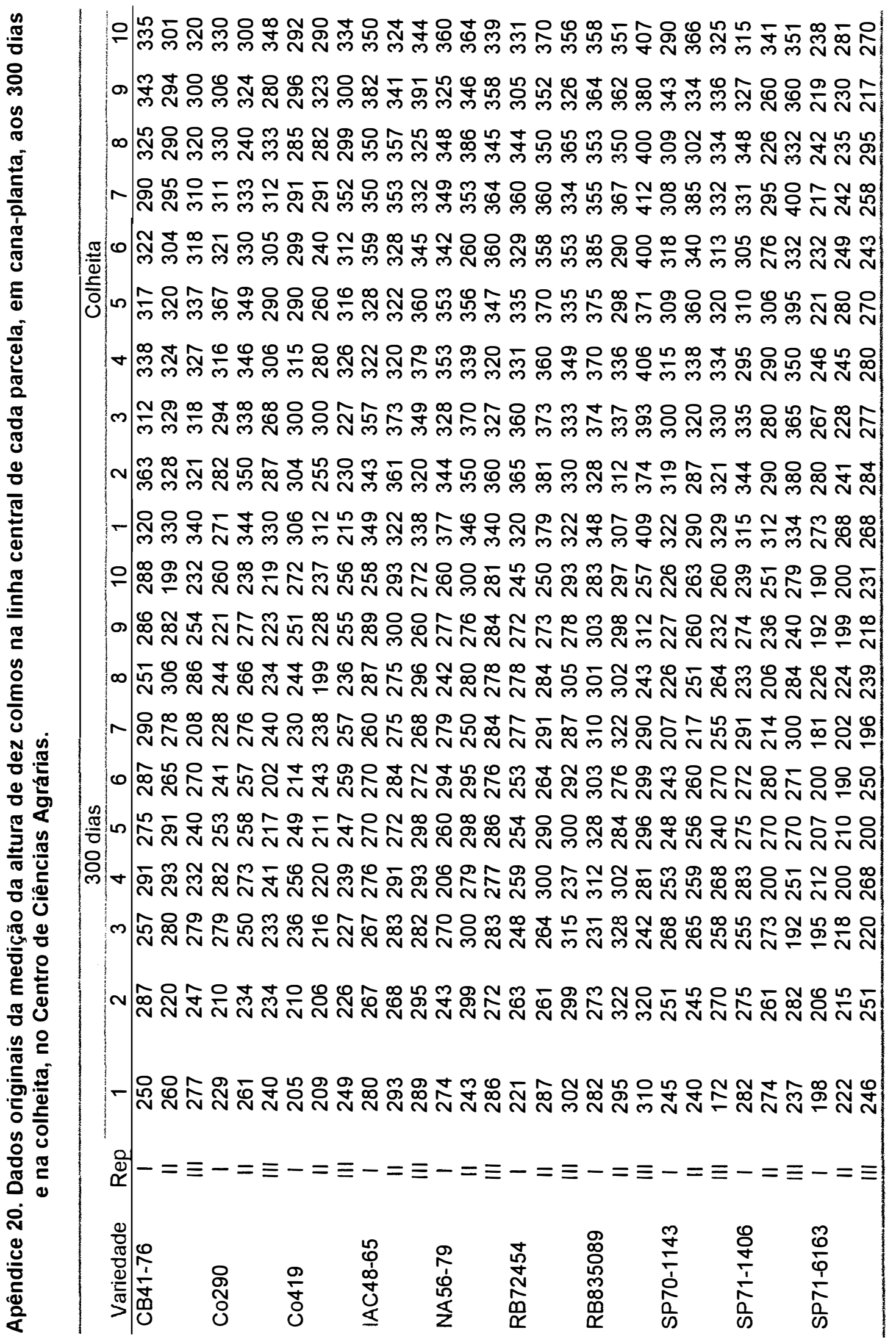




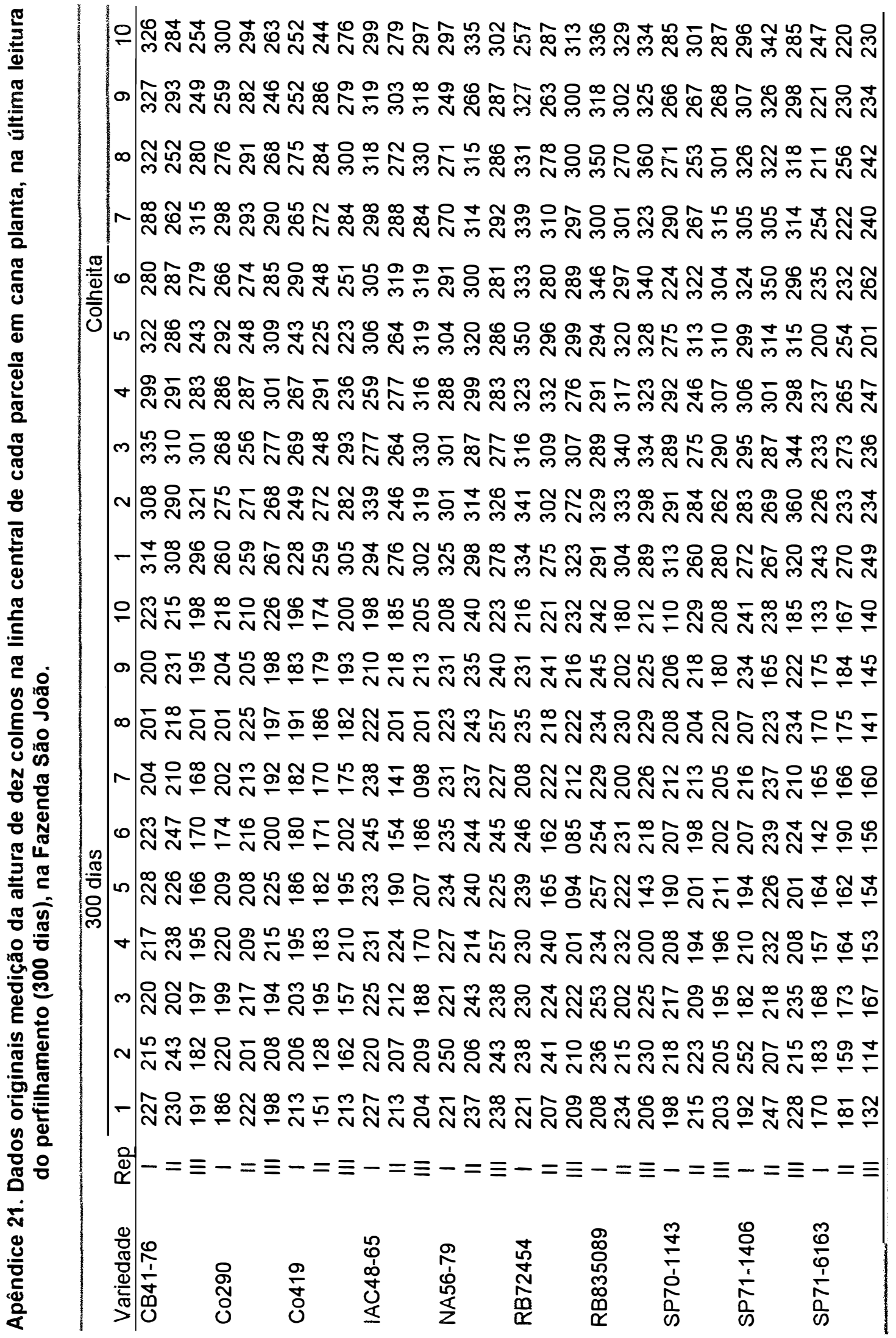


Apêndice 22. Florescimento e chochamento cana-planta e cana-soca na Fazenda Areia Branca.

\begin{tabular}{lcccc}
\hline & \multicolumn{2}{c}{ Cana-planta } & \multicolumn{2}{c}{ Cana-soca } \\
\cline { 2 - 5 } VARIEDADE & FLO & CHO & FLO & CHO \\
\hline CB41-76 & $1-1$ & $1-1$ & $1-1$ & $1-1$ \\
C0290 & $1-1$ & $1-1$ & $4-1$ & $3-2$ \\
C0419 & $1-1$ & $1-1$ & $4-1$ & $2-2$ \\
IAC48-65 & $4-3$ & $3-2$ & $4-4$ & $4-3$ \\
NA56-79 & $1-1$ & $2-2$ & $4-2$ & $4-2$ \\
RB72454 & $1-1$ & $1-1$ & $1-1$ & $1-1$ \\
RB835089 & $1-1$ & $1-1$ & $3-1$ & $2-2$ \\
SP70-1143 & $1-1$ & $3-2$ & $4-3$ & $3-3$ \\
SP71-1406 & $1-1$ & $1-1$ & $1-1$ & $1-1$ \\
SP71-6163 & $1-1$ & $1-1$ & $1-1$ & $1-1$ \\
\hline
\end{tabular}


Apêndice 23. Florescimento e chochamento cana-planta e planta-soca no Centro de Ciências Agrárias.

\begin{tabular}{lcccc}
\hline & \multicolumn{2}{c}{ Cana-planta } & \multicolumn{2}{c}{ Cana-soca } \\
\cline { 2 - 5 } VARIEDADE & FLO & CHO & FLO & CHO \\
CB41-76 & $1-1$ & $1-1$ & $1-1$ & $1-1$ \\
C0290 & $1-1$ & $1-1$ & $4-1$ & $3-2$ \\
C0419 & $1-1$ & $1-1$ & $1-1$ & $1-1$ \\
IAC48-65 & $4-3$ & $3-3$ & $4-4$ & $3-3$ \\
NA56-79 & $1-1$ & $1-1$ & $4-3$ & $3-2$ \\
RB72454 & $1-1$ & $1-1$ & $2-1$ & $1-1$ \\
RB835089 & $1-1$ & $1-1$ & $4-3$ & $2-2$ \\
SP70-1143 & $1-1$ & $3-2$ & $4-4$ & $3-4$ \\
SP71-1406 & $1-1$ & $1-1$ & $1-1$ & $1-1$ \\
SP71-6163 & $1-1$ & $1-1$ & $1-1$ & $1-1$ \\
\hline
\end{tabular}


Apêndice 24. Florescimento e chochamento cana-planta e cana-soca na Fazenda São João.

\begin{tabular}{lcccc}
\hline & \multicolumn{2}{c}{ Cana-planta } & \multicolumn{2}{c}{ Cana-soca } \\
\cline { 2 - 5 } VARIEDADE & FLO & CHO & FLO & CHO \\
\hline CB41-76 & $1-1$ & $1-1$ & $1-1$ & $1-1$ \\
C0290 & $1-1$ & $1-1$ & $2-1$ & $3-2$ \\
C0419 & $1-1$ & $1-1$ & $1-1$ & $1-1$ \\
IAC48-65 & $4-3$ & $3-3$ & $4-2$ & $3-3$ \\
NA56-79 & $1-1$ & $1-1$ & $1-1$ & $1-1$ \\
RB72454 & $1-1$ & $1-1$ & $1-1$ & $1-1$ \\
RB835089 & $1-1$ & $2-2$ & $1-1$ & $2-2$ \\
SP70-1143 & $1-1$ & $3-2$ & $2-1$ & $3-2$ \\
SP71-1406 & $1-1$ & $1-1$ & $1-1$ & $1-1$ \\
SP71-6163 & $1-1$ & $1-1$ & $1-1$ & $1-1$ \\
\hline
\end{tabular}


Apêndice 25. Dados originais das análises para a curva de maturação no Centro de Ciências Agrárias.

\begin{tabular}{|c|c|c|c|c|c|c|c|c|}
\hline \multirow[b]{2}{*}{ Variedade } & \multirow[b]{2}{*}{ Rep. } & \multicolumn{7}{|c|}{ Datas } \\
\hline & & $24 / 04$ & $01 / 06$ & $26 / 06$ & $19 / 07$ & $22 / 08$ & $20 / 09$ & $31 / 10$ \\
\hline \multirow[t]{3}{*}{ CB41-76 } & 1 & 9,17 & 12,32 & 13,17 & 13,30 & 16,30 & 15,76 & 15,04 \\
\hline & II & 10,24 & 13,21 & 13,53 & 14,46 & 16,76 & 16,67 & 15,61 \\
\hline & III & 10,41 & 13,02 & 13,40 & 14,55 & 13,37 & 15,18 & 16,12 \\
\hline \multirow[t]{3}{*}{ Co290 } & 1 & 10,05 & 11,16 & 13,03 & 13,95 & 15,38 & 14,10 & 14,14 \\
\hline & II & 10,21 & 11,17 & 12,32 & 14,79 & 14,76 & 16,11 & 11,47 \\
\hline & III & 11,53 & 11,53 & 11,32 & 13,51 & 14,86 & 16,22 & 13,01 \\
\hline \multirow[t]{3}{*}{ Co419 } & 1 & 10,43 & 13,71 & 14,06 & 15,42 & 16,48 & 17,09 & 14,98 \\
\hline & II & 10,63 & 11,38 & 14,84 & 15,78 & 17,23 & 17,50 & 15,92 \\
\hline & III & 10,74 & 12,48 & 15,52 & 15,17 & 15,84 & 16,73 & 13,96 \\
\hline \multirow[t]{3}{*}{ IAC48-65 } & 1 & 11,85 & 14,19 & 13,45 & 15,15 & 15,89 & 16,50 & 16,08 \\
\hline & II & 10,63 & 13,54 & 14,28 & 15,56 & 16,67 & 16,56 & 16,15 \\
\hline & III & 11,06 & 13,73 & 13,73 & 16,50 & 15,12 & 16,16 & 15,60 \\
\hline \multirow[t]{3}{*}{ NA56-79 } & I & 14,32 & 15,18 & 14,97 & 15,73 & 16,84 & 16,94 & 15,90 \\
\hline & II & 13,39 & 14,67 & 14,30 & 15,47 & 16,43 & 16,81 & 15,79 \\
\hline & III & 13,90 & 14,69 & 14,91 & 15,95 & 15,68 & 15,99 & 16,54 \\
\hline \multirow[t]{3}{*}{ RB72454 } & I & 11,28 & 14,41 & 15,55 & 15,34 & 17,44 & 18,51 & 17,79 \\
\hline & II & 11,91 & 14,17 & 14,36 & 15,79 & 17,00 & 17,92 & 17,21 \\
\hline & III & 11,17 & 14,45 & 14,01 & 15,08 & 16,25 & 18,48 & 17,68 \\
\hline \multirow[t]{3}{*}{ RB835089 } & I & 12,24 & 15,71 & 15,15 & 15,44 & 16,83 & 17,94 & 17,00 \\
\hline & II & 13,53 & 14,57 & 14,94 & 15,97 & 16,87 & 17,83 & 15,88 \\
\hline & III & 13,02 & 14,03 & 14,67 & 15,62 & 16,16 & 17,56 & 16,39 \\
\hline \multirow[t]{3}{*}{ SP70-1143 } & I & 11,91 & 13,49 & 14,68 & 15,13 & 17,52 & 18,10 & 17,52 \\
\hline & II & 11,91 & 14,45 & 14,55 & 16,23 & 16,37 & 16,35 & 17,63 \\
\hline & III & 11,24 & 13,53 & 14,13 & 15,09 & 16,84 & 18,25 & 17,58 \\
\hline \multirow[t]{3}{*}{ SP71-1406 } & 1 & 12,95 & 13,53 & 15,63 & 15,11 & 17,06 & 17,00 & 15,65 \\
\hline & II & 13,19 & 13,61 & 14,38 & 15,62 & 16,04 & 15,90 & 14,17 \\
\hline & III & 11,74 & 14,29 & 14,96 & 15,24 & 17,51 & 17,27 & 16,64 \\
\hline \multirow[t]{3}{*}{ SP71- 6163} & I & 12,74 & 13,27 & 15,15 & 16,42 & 16,76 & 14,86 & 11,19 \\
\hline & II & 12,56 & 13,95 & 14,28 & 14,45 & 13,19 & 11,09 & 9,18 \\
\hline & III & 12,24 & 14,03 & 13,59 & 14,67 & 11,89 & 10,20 & 9,34 \\
\hline
\end{tabular}


Apêndice 26. Dados originais de peso e pol em cana-planta e cana-soca, na Fazenda Areia Branca.

\begin{tabular}{lcccc}
\hline & \multicolumn{2}{c}{ Colheita } & \multicolumn{2}{c}{ Colheita } \\
\cline { 2 - 5 } VARIEDADE & \multicolumn{2}{c}{ Cana-planta: $21 / 07 / 96$} & \multicolumn{2}{c}{ Cana-soca: $16 / 09 / 96$} \\
\cline { 2 - 5 } CB41-76 & PESO & POL \% C & PESO & POL $\%$ C \\
& 552 & 13,40 & 460 & 14,89 \\
C0290 & 600 & 13,72 & 565 & 13,82 \\
& 590 & 14,11 & 625 & 14,83 \\
C0419 & 624 & 12,99 & 605 & 14,29 \\
& 638 & 14,08 & 625 & 15,21 \\
& 687 & 14,15 & 740 & 14,53 \\
IAC48-65 & 702 & 16,13 & 613 & 15,67 \\
& 705 & 15,81 & 560 & 16,12 \\
NA56-79 & 699 & 16,05 & 660 & 15,94 \\
& 501 & 14,78 & 485 & 13,83 \\
& 597 & 14,05 & 455 & 14,82 \\
RB72454 & 635 & 14,85 & 570 & 14,81 \\
& 480 & 15,77 & 440 & 15,44 \\
RB835089 & 531 & 15,11 & 530 & 14,71 \\
& 524 & 15,03 & 485 & 14,73 \\
& 832 & 15,40 & 720 & 16,40 \\
SP70-1143 & 897 & 14,80 & 860 & 15,31 \\
& 777 & 15,22 & 615 & 15,39 \\
& 777 & 15,80 & 915 & 15,46 \\
SP71-1406 & 811 & 15,14 & 900 & 15,46 \\
& 812 & 14,45 & 810 & 15,34 \\
SP71-6163 & 614 & 14,23 & 650 & 15,85 \\
& 624 & 13,84 & 595 & 15,43 \\
& 636 & 15,42 & 720 & 16,00 \\
& 564 & 15,33 & 325 & 13,10 \\
& 503 & 14,90 & 415 & 15,50 \\
& 554 & 14,19 & 495 & 13,63 \\
& 511 & 14,25 & 230 & 12,97 \\
& 427 & 14,38 & 175 & 13,64 \\
& 526 & 14,93 & 295 & 13,87 \\
\hline
\end{tabular}


Apêndice 27. Dados originais de peso e pol em cana-planta e cana-soca das parcelas no Centro de Ciencias Agrárias.

\begin{tabular}{|c|c|c|c|c|}
\hline \multirow[b]{3}{*}{ VARIEDADE } & \multicolumn{2}{|c|}{ Colheita } & \multicolumn{2}{|c|}{ Colheita } \\
\hline & \multicolumn{2}{|c|}{ Cana-planta: 19/09/95 } & \multicolumn{2}{|c|}{ Cana-soca: 07/08/96 } \\
\hline & PESO & POL \% C & PESO & POL \% C \\
\hline \multirow[t]{3}{*}{ CB41-76 } & 617 & 13,30 & 490 & 14,07 \\
\hline & 658 & 14,46 & 415 & 13,94 \\
\hline & 782 & 14,55 & 455 & 14,08 \\
\hline \multirow[t]{3}{*}{ Co290 } & 615 & 13,95 & 625 & 14,53 \\
\hline & 746 & 14,79 & 560 & 14,83 \\
\hline & 607 & 13,51 & 610 & 15,29 \\
\hline \multirow[t]{3}{*}{ Co419 } & 676 & 15,42 & 305 & 15,35 \\
\hline & 527 & 15,78 & 280 & 16,80 \\
\hline & 804 & 15,17 & 435 & 16,59 \\
\hline \multirow[t]{3}{*}{ IAC48-65 } & 585 & 15,15 & 455 & 14,90 \\
\hline & 586 & 15,56 & 425 & 16,05 \\
\hline & 615 & 16,50 & 405 & 15,77 \\
\hline \multirow[t]{3}{*}{ NA56-79 } & 577 & 15,73 & 455 & 16,85 \\
\hline & 657 & 15,47 & 495 & 16,15 \\
\hline & 649 & 15,95 & 430 & 15,86 \\
\hline \multirow[t]{3}{*}{ RB72454 } & 700 & 15,34 & 570 & 16,47 \\
\hline & 827 & 15,79 & 710 & 16,36 \\
\hline & 976 & 15,08 & 750 & 16,11 \\
\hline \multirow[t]{3}{*}{ RB835089 } & 714 & 15,44 & 755 & 17,06 \\
\hline & 728 & 15,97 & 735 & 15,52 \\
\hline & 884 & 15,62 & 810 & 15,83 \\
\hline \multirow[t]{3}{*}{ SP70-1143 } & 696 & 15,13 & 640 & 16,75 \\
\hline & 690 & 16,23 & 665 & 15,95 \\
\hline & 607 & 15,09 & 645 & 16,34 \\
\hline \multirow[t]{3}{*}{ SP71-1406 } & 707 & 15,11 & 250 & 15,90 \\
\hline & 781 & 15,62 & 275 & 15,93 \\
\hline & 735 & 15,24 & 365 & 15,82 \\
\hline \multirow[t]{3}{*}{ SP71- 6163} & 430 & 16,42 & 90 & 16,38 \\
\hline & 584 & 14,45 & 200 & 15,60 \\
\hline & 575 & 14,67 & 150 & 16,23 \\
\hline
\end{tabular}


Apêndice 28. Dados originais de peso e pol em cana-planta e cana-soca das parcelas na Fazenda São João.

\begin{tabular}{|c|c|c|c|c|}
\hline \multirow[b]{3}{*}{ VARIEDADE } & \multicolumn{2}{|c|}{ Colheita } & \multicolumn{2}{|c|}{ Colheita } \\
\hline & \multicolumn{2}{|c|}{ Cana-planta: 17/07/95 } & \multicolumn{2}{|c|}{ Cana-soca: 13/06/96 } \\
\hline & PESO & POL \% C & PESO & POL \% C \\
\hline \multirow[t]{3}{*}{ CB41-76 } & 675 & 14,16 & 507 & 9,96 \\
\hline & 669 & 13,22 & 370 & 9,70 \\
\hline & 593 & 14,18 & 501 & 10,03 \\
\hline \multirow[t]{3}{*}{ Co290 } & 566 & 13,72 & 407 & 10,84 \\
\hline & 642 & 14,15 & 562 & 10,56 \\
\hline & 538 & 14,55 & 440 & 10,03 \\
\hline \multirow[t]{3}{*}{ Co419 } & 640 & 16.12 & 308 & 10,19 \\
\hline & 586 & 15,36 & 290 & 11,24 \\
\hline & 564 & 14,61 & 505 & 10,72 \\
\hline \multirow[t]{3}{*}{ IAC48-65 } & 544 & 16,91 & 505 & 12,07 \\
\hline & 562 & 15,60 & 450 & 13,34 \\
\hline & 539 & 15,38 & 502 & 11,90 \\
\hline \multirow[t]{3}{*}{ NA56-79 } & 645 & 16,28 & 400 & 13,74 \\
\hline & 670 & 15,85 & 470 & 13,12 \\
\hline & 685 & 16,37 & 417 & 13,67 \\
\hline \multirow[t]{3}{*}{ RB72454 } & 703 & 17,59 & 615 & 14,01 \\
\hline & 664 & 13,77 & 650 & 12,06 \\
\hline & 650 & 15,82 & 428 & 13,40 \\
\hline \multirow[t]{3}{*}{ RB835089 } & 777 & 16,19 & 605 & 12,04 \\
\hline & 697 & 14,22 & 520 & 12,80 \\
\hline & 638 & 15,39 & 500 & 12,60 \\
\hline \multirow[t]{3}{*}{ SP70-1143 } & 594 & 15,19 & 470 & 10,62 \\
\hline & 542 & 14,62 & 496 & 10,45 \\
\hline & 568 & 14,73 & 505 & 11,18 \\
\hline \multirow[t]{3}{*}{ SP71-1406 } & 607 & 15,82 & 399 & 11,99 \\
\hline & 580 & 15,55 & 300 & 12,38 \\
\hline & 591 & 16,45 & 415 & 12,89 \\
\hline \multirow[t]{3}{*}{ SP71-6163 } & 444 & 14,89 & 260 & 13,82 \\
\hline & 458 & 16,09 & 510 & 13,15 \\
\hline & 384 & 15,78 & 300 & 12,02 \\
\hline
\end{tabular}

